\title{
ESTUDO DE FATORES AMBIENTAIS ASSOCIADOS À TRANSMISSÃO DA LEISHMANIOSE TEGUMENTAR AMERICANA ATRAVÉS DE SENSORIAMENTO REMOTO ORBITAL E SISTEMA DE INFORMAÇÃO GEOGRÁFICA
}

Antonio Ismael Paulino da Costa

Tese de Doutorado apresentada ao Departamento de Epidemiologia da Faculdade de Saúde Pública, Universidade de São Paulo Área de concentração: Epidemiologia

Orientador: Prof. Dr. Delsio Natal

São Paulo

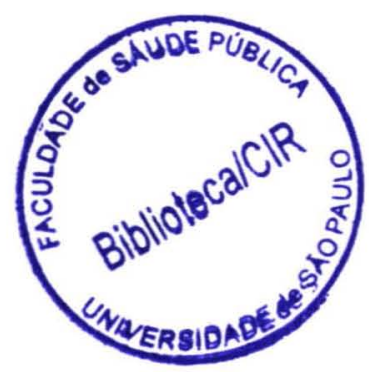


Autorizo, exclusivamente para fins acadêmicos e cientificos, a reprodução total ou parcial desta tese, por processos fotocopiadores.

Assinado:

Data:

$41599 / 2001$ dor 
Aos meus pais (em memória).

A Ciģa, ao Daniel e ao Henrique. 


\section{AGRADECIMENTOS}

Ao Prof. Dr. Delsio Natal pela orientação e pelo incentivo constante que permitiram a realização deste trabalho.

À Profa. Dra. Marisa Dantas Bitencourt pela orientação metodológica e pela cessão do uso dos equipamentos do Laboratório de Ecologia da Paisagem onde parte deste trabalho foi desenvolvido.

À minha mulher Ciça e aos meus filhos Daniel e Henrique, pela compreensão, apoio e incentivo.

À Superintendência de Controle de Endemias, pelo apoio.

Ao CNPq (Conselho Nacional de Pesquisa) pela bolsa de estudos concedida.

Ao Luís Filipe Mucci pelas discussões metodológicas e incentivo.

Ao Cláudio Casanova, pelas discussões e pelo incentivo.

À Cláudia Renata Siqueira, pela colaboração nos trabalhos de campo e digitalização do texto.

À Cristina Aparício pela colaboração na digitalização da carta topográfica e cessão do modelo de terreno de Espírito Santo do Pinhal.

Aos colaboradores da SUCEN, Delvo Baitelo, Clemison Norme Mattos e Wanda de Carvalho, pelo auxilio.

Ao Marcelo Matsumoto, Técnico do Lepac e agora colega Biólogo, pelo auxílio com os "softwares" e máquinas "infernais" que às vezes só funcionam se ele está presente.

Aos colegas da SUCEN, do curso de pós graduação e do Lepac pela amizade, incentivo e pela convivência nestes anos de luta. 


\section{RESUMO}

\section{Costa AIP. Estudo de fatores ambientais associados à transmissão da leishmaniose}

tegumentar americana através de sensoriamento remoto orbital e sistema de informação geográfica. São Paulo, 2001 (Tese de Doutorado - Faculdade de Saúde Pública da USP).

Objetivo. Este trabalho teve o objetivo de identificar fatores ambientais associados à ocorrência de leishmaniose tegumentar americana (LTA) no município de Itapira, SP e através de sua análise à luz dos conhecimentos difundidos sobre a epidemiologia desta doença, estabelecer parâmetros ambientais para os estudos ecológicos dos ciclos de transmissão desta doença. Métodos. Este estudo foi realizado no município de Itapira, SP, tendo como base casos autóctones de leishmaniose tegumentar americana, notificados a Secretaria da Saúde do Estado de São Paulo, entre 1992 e 1998. Foram utilizadas técnicas de classificação digital das imagens de sensoriamento remoto TM/Landsat-7, GPS (Global Positioning System) e cartografia ambiental para compor a base de dados referente à vegetação arbórea, localização das residências nos locais de provável transmissão de casos humanos, hidrografia e relevo. Dados de presença de espécies de flebotomíneos em alguns locais de provável transmissão (LPT) foram obtidos de coletas realizadas pela SUCEN para verificação de autoctonia dos casos e de coletas adicionais. Os diferentes planos de informação foram integrados e analisados através do programa Idrisi32. Resultados. Fragmentos de matas residuais estavam presentes em 19 dos 20 LPTs considerados. Em 9 destes locais, as matas situavam-se a menos de $200 \mathrm{~m}$ das residências dos LPT e nos 11 restantes esta distância era no máximo de $430 \mathrm{~m}$, aproximadamente. A área mínima total de matas associadas a um LPT era de aproximadamente 1ha e a máxima de cerca de $440 \mathrm{ha}$. $\mathrm{Na}$ grande maioria dos casos, $20 \%$ ou mais das áreas dos LPTs eram recobertos por vegetação 
arbórea. As maiores concentrações de matas associadas aos LPT (44\%) localizavam-se nas altitudes acima de $801 \mathrm{~m}$ e declividade superior a 10 graus. As residências nos LPT situavam-se, em sua maioria (80\%), em áreas de até $700 \mathrm{~m}$ de altitude e de pouca declividade mas, na maioria das vezes, a área peridomiciliar que constitui o LPT atingia declividades mais acentuadas, onde em geral estão localizadas as matas. Conclusões. A presença de fragmentos de matas medindo pelo menos 1 ha, situadas a uma distância de até $430 \mathrm{~m}$ das residências, assim como a existência de vegetação arbórea menos densa nas áreas peridomiciliares, parecem encerrar condições de transmissão domiciliar ao homem, indicando a dependência deste modo de transmissão em relação ao ciclo silvestre. Estas condições ambientais não favorecem a hipótese da existência de um ciclo domiciliar propriamente dito. A metodologia utilizada mostrou ser uma importante ferramenta na identificação e mensuração de fatores ambientais associados a LTA e deverão ser fundamentais para novas pesquisas ecológicas sobre seus ciclos de transmissão. 


\section{SUMMARY}

\section{Costa AIP. Estudo de fatores ambientais associados à transmissão da leishmaniose}

tegumentar americana através de sensoriamento remoto orbital e sistema de informação geográfica [Environmental factors related to the transmission of American Cutaneous Leishmaniasis using remote sensing and geographical information system]. São Paulo, 2001 (Tese de Doutorado - Faculdade de Saúde Pública da USP).

Objective. The aim of this research was to identify environmental factors related to the occurrence of American Cutaneous Leishmaniasis in the town of Itapira, SP and based on the epidemiology of the disease, establish environmental parameters for the ecological studies of its transmission cycle. Methods. This research was carried out in the town of Itapira, SP, based on autochthonous cases of American Cutaneous Leishmaniasis, notified to the Health Department of the State of São Paulo, between 1992 and 1998. Digital classification of TM/ Landsat images, GPS (Global Positioning System), and environmental cartography were used, in order to compose a data base on arboreous vegetation; localization of the cases in the probable transmission areas; hydrography; and relief. Presence of the sandfly species in some probable transmission areas, were obtained from samples carried out by SUCEN to check the autochthony of the cases and of additional data collection. The different information layers were integrated and analyzed by the Idrisi32 programme. Results. Fragments of residual woodlands were present in 19 of the 20 probable transmission areas considered. The minimum and maximum woodland area associated to a probable transmission area was approximately 1 hectare and 440 hectares respectively. In most cases, $20 \%$ or more of the probable transmission areas were covered with arboreous vegetation. The biggest woodland concentration, associated to the probable transmission area (44\%), was found in altitudes higher than $801 \mathrm{~m}$ and declivity greater than 10 degrees. The probable transmission areas were 
found, in the majority of cases $(80 \%)$, in areas of up to $700 \mathrm{~m}$ altitude and little declivity, but the probable transmission peridomiciliary areas, usually reaches higher altitudes, where woodlands are usually found. Conclusion. The presence of fragments of woodlands measuring at least 1 hectare, situated at a distance of up to $430 \mathrm{~m}$ from the residences, as well as the presence of less dense arboreous vegetation in the peridomiciliary areas, seems to present conditions for transmission to man, indicating the dependence of this means of transmission on the sylvatic cycle. These environmental conditions do not favor the hypothesis of the existence of a domestic cycle in itself. The methodology used has proven to be an important tool in the identification and analysis of environmental factors associated to probable transmission areas and should be fundamental for new ecological research on transmission cycles 


\section{ÍNDICE}

1. Introdução 1

$\begin{array}{lc}\text { 1.1 Fundamentação Teórica } & 8\end{array}$

1.1.1 Epidemiologia da LTA no nordeste do Estado de São Paulo 8

1.1.2 Vetores e reservatórios da L. (V.) braziliensis 10

1.1.3 Conceitos sobre os métodos e técnicas e técnicas utilizadas 22

2 Objetivos 26

21 Objetivo Geral 26

22 Objetivos específicos 26

3 Materialis e Métodos 27

3.1 Área de estudo $\quad 27$

3.2 Levantamento dos casos de leishmaniose tegumentar americana 28

3.3 Estimativa da distribuição da população rural 30

3.4 Distribuição das espécies vetoras 30

3.5 Levantamento da vegetação 30

3.6 Altitude e declividade 35

3.7 Classificação das matas segundo sua relação com a hidrografia 36

4 Resultados 37

5 Discussão $\quad 54$

6 Conclusões $\quad 66$

7 Referências Bibliográficas $\quad 68$

ANEXOS

Anexo 1 - Relação dos casos autóctones de LTA notificados no município

de Itapira, SP, entre 1992 e 1998

Anexo 2 - Figuras de matas residuais situadas no município de Itapira, SP, $2000 \quad 81$ 


\section{INTRODUÇÃO}

A Leishmaniose Tegumentar Americana (LTA) é uma designação genérica dada a um conjunto de zoonoses que formam um complexo de manifestações clínicas, cutâneas e mucocutâneas, que tem como agentes uma grande variedade de espécies de flagelados pertencentes ao gênero Leishmania. Seus agentes parasitam uma série de mamíferos, desde roedores, marsupiais, primatas, carnívoros e edentados até animais domésticos, como cães e cavalos, sendo transmitidos por uma variedade de flebotomíneos, responsáveis tanto pela manutenção dos ciclos zoonóticos, como pela sua transmissão ao homem (GRIMALDI et al. 1989, DEDET 1993).

Devido à grande variedade e especificidade das relações possíveis de ocorrer entre os diferentes elementos da cadeia, é grande a complexidade dos vários ciclos de transmissão que podem se estabelecer. Portanto, a diversidade de ecossistemas capazes de dar suporte à ocorrência da doença varia desde ambientes florestais primitivos, como os que ocorrem na região Amazônica, até aqueles extremamente alterados pela ação do homem, como é o caso da região Sudeste do Brasil, havendo mesmo um contraponto entre as duas regiões na atualidade (GOMES 1992).

As espécies de Leishmania com maior distribuição geográfica (Estados de Minas Gerais, São Paulo, Rio de Janeiro, Espírito Santo, Pará, Ceará, Bahia, Amazonas e Amapá) pertencem ao complexo Leishmania (Viannia) braziliensis, segundo as mais recentes revisões (GRIMALDI et al. 1989: DEDET 1993, LAINSON e SHAW 1987 e LAINSON et al. 1994).

Estes últimos afirmam ser tarefa muito difícil, até o momento, definir a eco-epidemiologia de $L(V$.$) braziliensis, pois parasitas classificados como tal parecem ter uma distribuição por áreas$ ecológicas muito distintas e com faunas muito diversificadas, seja de mamíferos seja de 
flebotomíneos. Uma saída para este impasse é o estudo em áreas ecológicas bem delimitadas, pois mesmo na hipótese de tratar-se de uma única espécie, cada área poderá exibir especificidades quanto aos outros elementos da cadeia de transmissão. Em termos da paisagem ambiental que propicia a transmissão, DEDET (1993) apresenta um esquema da evolução dos focos de LTA para a América do Sul, que vai de ecossistemas naturais selvagens e focos onde o homem estabelece seu domicílio dentro de tais matas - como no Estado do Pará - até ambientes semi-selvagens - como em áreas rurais da região leste do Brasil, e mesmo ambientes periurbanos, como no Rio de Janeiro e Belo Horizonte. Quanto ao vetor, LAINSON et al. (1994) afirmam que o único comprovado é Lutzomyia wellcomei, encontrado infectado na Serra dos Carajás, no Estado do Pará. Também segundo os mesmos, houve isolamento de parasitas que se supõe ser $L\left(V\right.$.) braziliensis dos seguintes flebotomíneos: Lutzomyia intermedia s. ${ }^{*}$, no Rio de Janeiro e em São Paulo e de Lutzomyia migonei, Lutzonyia wbitmani e Lutzomyiapessoai, em São Paulo.

É impossível estimar o número de casos clínicos de LTA associados a cada espécie de Leishmania em particular. Entretanto, para se ter uma idéia da magnitude do problema, somente em 1990 foram notificados cerca de 23.000 casos no Brasil (LACERDA 1994), dados que não incluem a maior parte dos casos ocorridos no Estado de São Paulo. Neste Estado a notificação de casos da doença vem crescendo de forma intensa a partir do final dos anos 70 . Segundo TOLEZANO (1994), foram notificados 124 casos no ano de 1978; 1099 casos de 1979 a 1985; e 2290 casos de 1986 a 1992. Dados mais atuais mostram que entre 1986 e 1995 registraram-se 3746 casos autóctones no Estado, com evidente tendência do aumento do coeficiente de incidência a partir de 1992 (KATZ 1997). A região nordeste de São Paulo abrange o Vale do Paraíba, e os Vales do Rio Mogi Guaçu e Pardo, regiões de colonização agrícola bastante antiga. Foi a região do Estado que registrou maior crescimento em número de casos autóctones nos últimos anos. Apresentou cerca de $6 \%$ dos casos de leishmaniose tegumentar ocorridos em São Paulo entre 1913 e 1939, percentual que evoluiu para cerca de 19\% entre 1986 e 1988 e para cerca de $25 \%$ entre 1989 e 1992 (TOLEZANO 1994). 
A característica da transmissão da leishmaniose tegumentar neste Estado sofreu transformações acentuadas ao longo deste século. Até os anos 50, caracterizava-se pela alta incidência de casos de transmissão, dependente do contato direto com as matas primitivas, e pela maior ocorrência em população adulta masculina (PESSOA e BARRETO 1948). A partir dos anos 70, as características predominantes nas áreas de planalto, passaram a ser a baixa incidência (com casos em focos isolados), transmissão peridomiciliar ou domiciliar e áreas endêmicas caracterizadas por uso agrícola intensivo e apresentando pequenos resíduos de matas secundárias (GOMES 1992, TOLEZANO 1994).

Muito do que se conhece da eco-epidemiologia da leishmaniose no Estado de São Paulo, origina-se de pesquisas sobre a ecologia dos vetores (FORATTINI et al. 1976, GOMES et al. 1980, ROCHA e SILVA et al. 1980, GOMES et al. 1983, GOMES et al. 1986, GOMES e GALATI 1987, GOMES et al. 1989, TANIGUCHI et al. 1991) e também, de algumas tentativas de isolamento do parasita para identificação de reservatórios e vetores e caracterização da espécie do parasita (TOLEZANO 1994). Os estudos epidemiológicos abrangem aspectos como idade, sexo, ocupação, tempo de moradia no local e sorologia e revelam, em sua maioria, pouca diferenciação da incidência por faixa etária, sexo ou atividade (TOLEZANO 1980; GOMES et al. 1992; LEOPOLDO e SILVA et al. 1984; MASCARINI et al. 1994).

A maioria dos estudos aponta $L$ intermedia como a principal espécie vetora, pois esta parece ter se adaptado muito bem a regiões de ecótono e áreas peridomiciliares, apresentando alto grau de antropofilia e estando amplamente distribuída nas áreas endêmicas da região sudeste do Brasil (FORATTINI 1972; GOMES et al. 1982, 1989; RANGEL et al. 1990). Entretanto, pouco se sabe a respeito da localização dos seus criadouros, sendo difícil afirmar seu grau de independência das matas. L whitmani, que foi a espécie predominante na transmissão em áreas de grande ocorrência de LTA no oeste do Estado de São Paulo na primeira metade do século XX (PESSOA E BARRETO 1948), parece ter papel secundário na atualidade, podendo ser mais freqüente em algumas áreas de remanescentes matas primitivas.

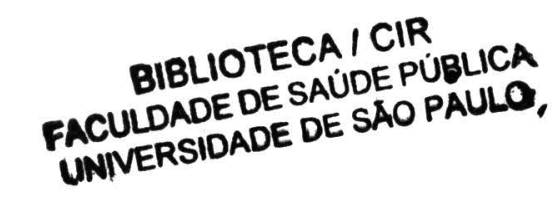


Ressalta-se que outras espécies também podem desempenhar papel secundário como vetoras: L migonei, L fischeri e L pessoai, apresentando graus variados de dependência das matas residuais. Em relação aos reservatórios naturais, falta comprovar a participação efetiva nos ciclos de transmissão daqueles mamíferos encontrados naturalmente infectados, dentre os quais destacam-se marsupiais (representados principalmente por Didelphis sp.) e roedores. Vários autores destacam também que as alterações provocadas na vegetação natural modificaram a fauna flebotomínea nas áreas de planalto: a dominância de L whitmani nas matas primitivas foi substituída pela dominância de $L$ intermedia, nas áreas transformadas pela ocupação humana.

Extenso levantamento realizado por ZUIDEMA et al. 1996 sobre o tema fragmentação florestal e biodiversidade, conclui que a fragmentação leva a uma diminuição da biodiversidade, correlação esta que varia conforme as dimensões dos fragmentos e dos taxa específicos. Por outro lado, estes fragmentos são responsáveis pela manutenção de uma parte da biodiversidade original, de populações que sobreviveram e se adaptaram às novas condições.

No caso da LTA, como a transmissão ao homem persiste - apesar da grande devastação das matas originais - nota-se hoje uma nova feição epidemiológica. A transmissão não é dependente apenas do contato do homem com as matas primárias. Qual é a estrutura deste novo ambiente em termos de cobertura de vegetação? Qual o papel que os fragmentos de matas desempenham na manutenção da comunidade envolvida em seu ciclo de transmissão? A partir desses elementos, surgem outras questões: se este ciclo foi capaz de manter-se em um ambiente de menor biodiversidade, que ambiente é este? Existe um ciclo domiciliado de transmissão? Qual o grau de dependência ou independência das matas na transmissão desta endemia hoje? Além disso apresenta-se outra importante questão: que metodologia e que ferramentas seriam capazes de realizar uma descrição adequada destas feições paisagísticas e possibilitariam processar a grande quantidade de dados necessários para a realização de tal análise? 
A epidemiologia paisagística e a ecologia da paisagem proporcionam a ferramenta conceitual básica para o estudo da ecologia dos vetores e dos reservatórios das doenças transmitidas por vetores (KITRON et al. 1998). As feições da paisagem têm sido há muito reconhecidas como importantes determinantes destas doenças, pois influenciam a ecologia dos vetores, dos reservatórios e por conseqüência dos agentes etiológicos. Historicamente a ecologia da paisagem estava ligada ao estudo de grandes áreas, mas pode ser utilizada em escalas espaciais menores. O mais importante é a aplicabilidade destas teorias à epidemiologia das doenças transmitidas por artrópodes. Dada a complexidade e a quantidade de dados envolvidos nestas análises, somente o desenvolvimento dos Sistemas de Informação Geográfica (SIG), Global Positioning System (GPS) e o sensoriamento remoto orbital, além da geoestatística, forneceu à ecologia paisagística o instrumental necessário para a implementação de uma abordagem analítica.

Estas novas ferramentas permitem identificar com maior precisão onde estão aparecendo novas doenças; quais os fatores determinantes na distribuição de uma doença e como podemos determinar riscos local e regional da transmissão de doenças. Ainda segundo os autores a ecologia da paisagem considera parâmetros como tamanho, forma e limite das áreas e corredores, isto é, rotas de conexão entre habitats favoráveis a uma população.

A utilização destas tecnologias pode ocorrer basicamente em dois sentidos: quando as relações ecológicas entre os elementos da cadeia de transmissão são suficientemente conhecidas, propiciam uma modelagem ambiental preditiva do risco de transmissão; quando estas relações ainda não estão suficientemente esclarecidas, permitem levantar e analisar informações temporais e espaciais na busca de correlações entre os elementos da cadeia e as feições ambientais. Esses instrumentos permitem estabelecer hipóteses, que uma vez testadas, podem subsidiar o esclarecimento das relações ecológicas e epidemiológicas das doenças.

A partir de finais da década de 1980 e principalmente depois de 1990, houve uma crescente utilização do geoprocessamento e também do sensoriamento remoto orbital não só para cartografia ambiental como também para estudos de epidemiologia e controle das 
doenças habitat dependentes, além de tópicos relacionados como doenças parasitárias, doenças transmitidas por vetores, poluição ambiental e qualidade da água (HUGH-JONES 1991). Segundo GOETZ, PRINCE e SMALL (2000), boa parte da literatura sobre sensoriamento remoto é focada na classificação da vegetação. Em epidemiologia, o tipo de vegetação pode ser muito relevante. Freqüentemente é encontrada forte correlação das doenças e da abundância de vetores com a quantidade e densidade da vegetação em virtude da co-variação da cobertura vegetal com variáveis ambientais como temperatura, diversidade de habitats e energia do ambiente. CURRAN et al. (2000) chamam atenção para o fato de que o mapeamento quantitativo da vegetação está melhor desenvolvido para estudos epidemiológicos em escala regional e que, para entender os processos que sustentam o padrão de distribuição das doenças e seus vetores (seria necessário acrescentar os reservatórios naturais), deve-se conhecer e mapear o tipo de cobertura de solo.

Os estudos sobre ecologia e epidemiologia paisagística das doenças, quer as transmitidas por vetores, quer as difundidas através de hospedeiros intermediários, abrangem doenças transmitidas por mosquitos, como arboviroses (LINTHICUM et al. 1987, WOOD et al. 1992) e malária (BECK et al. 1994); por carrapatos, como a doença de Lyme e riquetisioses (DISTER et al. 1997, GLASS et al. 1992, NICHOLSON e MATHER 1996); por moscas, como tripanossomose africana (HENDRICKX et al. 1999); e a partir de hospedeiros intermediários, como na esquistossomose mansônica (KLOOS, GAZZINELLI e ZUYLE 1998). Estes estudos envolvem uma diversidade de ambientes, tipos de vegetação, variáveis não biológicas e escalas de trabalho desde o nível regional até o local, o que denota a grande utilidade destas ferramentas para o estudo da epidemiologia paisagística.

Em relação às leishmanioses, a bibliografia é mais reduzida, possivelmente, em parte, devido ao menor conhecimento que se tem a respeito da ecologia dos vetores e ou reservatórios - especialmente no que diz respeito às leishmanioses tegumentares do Novo Mundo. Este fato tem dificultado os estudos de avaliação e previsão de áreas de risco através de modelos ecológicos baseados em SIG. 
ELNAIEM et al. (1998), no Sudão, realizaram um estudo sobre a distribuição de Phlebotomus orientalis em que buscavam determinar a associação deste flebotomíneo com variáveis ambientais (NDVI - medida indireta da densidade de vegetação verde, temperatura, umidade relativa, espécies arbóreas e tipo de solo) através do uso de SIG e interpretação de imagens de satélite, em uma escala regional. Os resultados apontaram associação da presença do flebotomineo com determinadas espécies arbóreas e também com solo argiloso. Segundo os autores este solo encharca-se rapidamente no início das chuvas, porém também seca com facilidade, sendo um dos determinantes da vegetação e clima locais. Nos locais positivos para P. orientalis, tanto o NDVI máximo como o mínimo foram menores que para sítios negativos, portanto apresentando uma relação inversa com a quantidade de vegetação.

Em estudo conduzido na Tunísia por MBARKI et al. (1996), baseado na incidência de casos humanos da doença, o enfoque foi a identificação de áreas cobertas por diferentes tipos de vegetação que serviam de habitat para os roedores reconhecidos como os principais reservatórios da Leishmania major na região. Os autores relatam que a distribuição da doença era muito sensivel a fatores ambientais sendo maior em biótopos mais favoráveis aos reservatórios do parasita. Estimaram que a partir do local de início da epidemia os casos se expandiram a uma distância de até $1000 \mathrm{~m}$ do foco inicial, num primeiro momento e que em anos posteriores atingiu cerca de $2500 \mathrm{~m}$. Ressaltam ainda que este método de ávaliação da dispersão da doença foi mais efetivo do que um outro baseado no raio de vôo do vetor. No sudoeste asiático, CROSS, NEWCOMB e TUKER (1996) estudaram a distribuição de Phlebotomus papatasi e a partir de dados sobre a presença dessa espécie, temperatura ambiente, umidade relativa do ar, ponto de orvalho e NDVI, desenvolveram um modelo preditivo da ocorrência deste flebotomíneo. Para eles a faixa de NDVI favorável à presença do vetor situava-se entre 0 e 0,06 - reflexo de um ambiente extremamente árido. Destacam ainda que a capacidade preditiva desse modelo estava de acordo com informações da literatura sobre a distribuição sazonal e geográfica de $P$. papatasi na região e que permitia, por sua vez, indicar locais favoráveis a transmissão de doenças pelo vetor em questão, embora não fosse possível indicar áreas 
específicas em virtude do caráter focal do vetor e dos patógenos.

No Brasil são escassos os estudos utilizando sensoriamento remoto e SIG aplicados a LTA. Duas destas publicações são complementares e referem-se ao município de Lagoinha localizado no Vale do Rio Paraíba, SP, o qual registrou vários casos de leishmaniose tegumentar (MIRANDA et al. 1996, 1998). Em todas as localidades onde ocorreram casos da doença, os autores identificaram remanescentes de vegetação arbórea nos limites dos locais de transmissão (estabelecidos em $900 \mathrm{~m}$ a partir das residências dos casos humanos).Verificaram também a presença de córregos permanentes dentro desse limite em todas as localidades estudadas. Através da comparação de imagens obtidas em vários anos não constataram alterações significativas na vegetação que pudessem explicar a ocorrência dos casos. CAMPBELL-LENDRUM et al. (1999) apresentaram resultados preliminares de um estudo paisagístico realizado no Nordeste do Brasil, em área de ocorrência de casos de leishmaniose tegumentar (suspeitando que foram devidos a $L(V$.) braziliensis e transmitida por $L$ whitmani). Identificaram a vegetação situada no entorno de casas localizadas em vilas rurais, através da classificação de imagens de radar, baseado em satélite, de alta resolução espacial (18m). Esta classificação foi utilizada como uma variável preditiva da presença de $L$ whitmani. A partir desses dados destacam que a abundância da espécie está associada aos remanescentes florestais e plantações de banana e que mapas de vegetação baseados em imagens de satélite são ferramentas com alto potencial para testar o efeito de mudanças de uso da terra na abundância de flebotomíneos e na epidemiologia da doença e também, para localizar espacialmente o risco de transmissão da leishmaniose.

\section{1 Fundamentação teórica}

\subsubsection{Epidemiologia da LTA no nordeste do Estado de São Paulo}

As principais características da transmissão da LTA no Estado de São Paulo, constatadas a partir de 1986, são a ocorrência de casos em todas as faixas etárias, em ambos os sexos, mas ainda com certa predominância no sexo masculino nas faixas etárias acima dos 20 
anos (KATZ 1997). O fator ocupacional não parece ser determinante na transmissão do parasito, mas os maiores percentuais de ocorrência da doença em trabalhadores do setor agropecuário pode indicar a ocorrência de transmissão em focos naturais, em áreas de matas. A ocorrência de casos na faixa etária de menores de 10 anos e em pessoas do sexo feminino, estas exercendo apenas atividades domésticas em grande porcentagem, apontam para a hipótese de ocorrência de transmissão domiciliar ou peridomiciliar, uma vez que esses indivíduos não estariam expostos ao contato com os vetores em áreas de matas (KATZ 1997). O padrão de ocorrência, por faixa etária e sexo, não foi uniforme quando se considerou as diferentes regiões do Estado, apresentando também variações anuais em uma mesma região. O tempo de moradia parece ser fator importante na determinação da transmissão da LTA, pois este autor encontrou um alto percentual de indivíduos afetados que moravam no municipio a mais de 10 anos.

As regiões administrativas de São João da Boa Vista e Piracicaba, onde situa-se o Vale do Rio Mogi Guaçu, apresentaram o maior incremento da transmissão a partir dos anos 90 . Nestas regiões existia um alto porcentual de municípios com transmissão, sendo que alguns apresentaram surtos com maior número de casos, enquanto outros apresentam casos esporádicos.

Em estudo epidemiológico, abrangendo casos notificados entre 1986 e 1993, constatou-se que o Vale do Rio Mogi Guaçu era a principal área de transmissão na região nordeste do Estado de São Paulo, verificando-se distribuição de casos por todas a faixas etárias, predominância de aproximadamente $62 \%$ de casos no sexo masculino e $47 \%$ em indivíduos que "exerciam atividades relacionadas a freqüência a matas residuais" (MASCARINI et al. 1994). Provavelmente esta última constatação refere-se a indivíduos que exerciam atividades no setor agropecuário, de acordo com a classificação utilizada por KATZ (1997), pois ambos os estudos utilizam como fonte as fichas epidemiológicas de notificação utilizadas pela Secretaria da Saúde. Fundamentalmente, tais 
aspectos da transmissão no Vale do Rio Mogi Guaçu, não diferem do padrão geral constatado para as regiões administrativas em que se insere e daquele observado para o Estado de São Paulo como um todo.

\subsubsection{Vetores e reservatórios da L. (V.) braziliensis}

\subsubsection{Vetores}

Para fazer uma análise das condições ambientais associadas à transmissão do agente da Leishmaniose Tegumentar Americana ao homem e produzir um modelo preditivo de áreas de risco, deve-se considerar uma série de variáveis a respeito das espécies vetoras, tais como distância de vôo e raio de dispersão; localização dos criadouros e locais de repouso; influência da topografia de terreno e altitude, entre outros. Entretanto, a partir do levantamento que se segue, verifica-se uma série de lacunas no conhecimento destas variáveis, o que confirma a necessidade de realizar estudos para identificar esses fatores de risco.

A primeira questão ainda não esclarecida surge em relação à comprovação das espécies vetoras de $L(V$.) braziliensis. Até hoje somente Lutzomyia wellcomei, no sul do Estado do Pará, foi incriminada como vetora desta espécie do parasito (LAINSON et al. 1994), segundo os critérios essenciais sugeridos por KILLICK-KENDRICK (1990), ou seja: a demonstração de que o flebotomíneo em questão é antropofilico; e de isolamentos repetidos e identificação da mesma espécie de Leishmania no flebotomíneo que aquela isolada a partir de casos humanos na mesma área. Segundo estes autores, observações complementares seriam a demonstração de que aquela espécie que se alimenta nos reservatórios específicos é capaz de infectar-se e transmitir o parasito. A abundância relativa de uma espécie em uma área de transmissão é apenas um fator auxiliar, não sendo suficiente para incriminar uma espécie como vetora de determinada espécie de Leishmania. A suspeição sobre outras espécies de flebotomíneos no Brasil serem vetoras da $L(V$.) braziliensis, obedece critérios epidemiológicos complementares como antropofilia, antropofagia, abundância relativa em locais endêmicos e isolamentos ocasionais do parasito. 
Em relação aos flebotomíneos neotropicais, foram realizados poucos trabalhos para estimar seu comportamento de dispersão e distância de vôo. Pesquisa realizada em uma área de mata primitiva no Panamá por CHANIOTIS (1974) e em área de plantação de café na Colômbia por ALEXANDER (1987), chegaram a resultados que mostram a tendência de várias espécies neotropicais permanecerem relativamente próximo ao local em que são soltas, evidenciando um comportamento de dispersão restrito. CHANIOTIS (1974) afirma que suas pesquisas não evidenciam comportamento de "homing tendency" destes flebotomíneos, ou seja, estas espécies não mostraram uma tendência de retornarem aos locais de repouso onde foram coletados. Em ambos trabalhos os autores desenvolveram esforços de recaptura num raio limitado a $200 \mathrm{~m}$ dos locais de soltura dos flebotomíneos, aproximadamente. Mesmo assim, ALEXANDER (1987) baseado em seus resultados, não acredita que estas espécies alcancem distâncias de vôo maiores que $200 \mathrm{~m}$ em uma única noite. Comentando as diferenças de comportamento entre os flebotomíneos neotropicais e os do Velho Continente, este autor diz não acreditar que o fato daqueles experimentos no Velho Mundo demonstrarem distâncias de vôo muito superiores para suas espécies esteja relacionado a diferenças fisiológicas. Para ele a principal justificativa é a disponibilidade de alimento nos ambientes florestais tropicais próximo dos locais de vida dos flebotomíneos, não sendo necessário desenvolver vôos mais longos à procura de repasto sangüíneo ou dieta rica em açúcares.

Entretanto, MORRISON et al. (1993), trabalhando na Colômbia com Lutzomyia longipalpis em área agrícola entremeada de remanescentes de matas secundárias, encontraram resultados bastante diferentes dos citados anteriormente. A maior distância percorrida por um exemplar desta espécie foi de $960 \mathrm{~m}$ e apesar de somente $2 \%$ dos flebotomíneos terem sido coletado a mais de $470 \mathrm{~m}$ do ponto de soltura, dois deles percorreram aquela distância em apenas um dia. Cerca de $48 \%$ dos espécimes foram recapturados a distâncias de 100 a $300 \mathrm{~m}$ e $50 \%$ foram recoletados a distâncias inferiores a $60 \mathrm{~m}$. Esses autores afirmam que o comportamento diferenciado em relação às espécies neotropicais, referidas nos trabalhos anteriores, pode estar relacionado ao fato de L longipalpis ter-se adaptado ao habitat mais árido 
representado pelas áreas agricolas e também ao seu comportamento de corte estar associado aos animais domésticos. Ou seja a procura pelos abrigos destes animais domésticos, que normalmente não estão muito próximo uns dos outros, levaria a espécie a percorrer distâncias maiores.

Nenhum trabalho experimental foi realizado, até hoje, com as espécies consideradas prováveis transmissoras da LTA no Estado de São Paulo, ou mesmo em outras áreas endêmicas do Brasil. Entretanto, a literatura especializada relata algumas observações indicativas do raio de dispersão destas espécies. Assim, BARRETO (1943) afirma ter coletado exemplares de $L$ whitmani e $L$ pessoai em uma casa situada a cerca de $150 \mathrm{~m}$ da mata (onde estas espécies foram coletadas de forma abundante), sem que houvesse entre os dois locais nenhuma vegetação que pudesse servir de criadouro ou mesmo abrigo para os flebotomíneos. FORATTINI (1973) destaca que observações realizadas tanto no Brasil como no Peru, sugerem que o raio máximo de vôo dos flebotomineos estaria em torno de $200 \mathrm{~m}$, ressaltando contudo, que a procura para instalação de criadouros pode estimular os flebotomíneos a percorrer maiores distâncias, chegando a cerca de $500 \mathrm{~m}$.

Considerando-se as afirmações de MORRINSON et al. (1993), sobre a adaptação e $L$ longipalpis a ambientes agrícolas; as de ALEXANDER (1987) e de FORATTINI (1973), sobre o comportamento de dispersão ligado à procura de alimento, e associando-se estas considerações ao tipo de ambiente antrópico a que as nossas espécies parecem ter se adaptado, poderíamos esperar que estas espécies tenham um comportamento de vôo intermediário entre L Longipalpis e as espécies exclusivas de áreas florestadas.

A partir desses elementos, o presente estudo baseou-se na seguinte hipótese de trabalho: a maioria da população de flebotomíneos estaria concentrada em um raio de $200 \mathrm{~m}$ de seus criadouros ou sítios de repouso, mas com capacidade máxima de vôo de $600 \mathrm{~m}$.

Um importante parâmetro biológico sobre a transmissão de LTA é o horário de atividade das espécies transmissoras, principalmente pelo que este parâmetro representa em termos de possibilidade de contato homem-vetor. As espécies consideradas como vetoras da 
LTA no Estado de São Paulo possuem atividades preferencialmente noturnas (GOMES 1994), sendo que o horário de maior atividade pode variar de espécie para espécie, assim como entre ecótopos diferentes para uma mesma espécie. Por exemplo, na região do Vale do Rio Ribeira, SP, FORATTINI et al. (1976) obtiveram resultados que pareciam indicar que a atividade da população de $L$ intermedia capturada no peridomicílio, aumentava progressivamente a partir das primeiras horas da noite, atingindo o máximo entre 1 e 2 horas, enquanto as capturas na mata indicavam que a atividade desta população era maior nas primeiras horas da noite, decrescendo a partir das 24 horas. Já GOMES et al. (1983) observou que o máximo de atividade em galinheiro experimental localizado fora da mata, ocorria entre 20 e 22 horas, enquanto dentro da mata, o pico de atividade ocorria às 2 horas com subpicos entre as 23 e 24 horas. TEODORO et al. (1991), no Norte do Paraná, em capturas de flebotomíneos na margem de uma mata residual entre as 18 horas e 1 hora, verificaram que a atividade de $L$ intermedia, $L$ whitmani, $L$ migonei e $L$ fischeri era maior a partir de 22 horas e atingia o máximo à 1 hora, com exceção de $L$ migonei cujo pico se dava às $22 / 23$ horas. Em foco recente de transmissão de LTA, próximo a Campinas, SP em área próxima ao rio Jundiaí (bacia do Tietê) situada próximo a mata residual e residências rurais, verificou-se que $L$ intermedia, $L$ migonei, $L$ whitmani e L fischeri apresentavam maior atividade entre a segunda e a quinta hora após o crepúsculo vespertino e que a partir da sexta hora, a atividade destas espécies era muito reduzida MAYO et al. (1998).

O horário de maior atividade das espécies de flebotomíneos vetoras da LTA em nossa região, restringe a transmissão da Leishmania ao homem ao periodo noturno. Desse modo a transmissão pode ocorrer na própria mata, quando o homem aí exerce alguma atividade neste horário. Caso contrário, a transmissão pode acontecer nas áreas domiciliares (incluindo o domicílio e o peridomicílio), desde que existam condições ambientais para o estabelecimento de populações dos vetores e seu contato com reservatórios da Leishmania.

Em relação ao ambiente em que os principais vetores ocorrem, as pesquisas realizadas apontam que todas as espécies, em maior ou menor grau, são capazes de ocupar os ambientes 
alterados pelo homem, incluindo desde vegetações naturais degradadas, até áreas peridomiciliares cobertas por diversos tipos de vegetação plantada. No Estado de São Paulo, ao menos nas áreas de planalto, a ênfase é dada à associação entre transmissão domiciliar ou peridomiciliar e L intermedia. Mesmo L wbitmani, apontada por GOMES (1994) como sendo preferencialmente de áreas de matas em São Paulo, já teve criadouros identificados em ambiente peridomiciliar, (FORATTINI 1953, 1954, 1960; CASANOVA 2001) em área de transmissão de LTA localizada no noroeste de São Paulo. Flebotomíneos adultos desta espécie também já foram encontrados em maior freqüência neste tipo de ambiente, do que em área de mata (MAYO et al. 1998; PIGNATI et al 1995). No norte do Estado do Paraná, em duas localidades, $L$ whitmani foi encontrada em abundância tanto na margem de matas residuais como em áreas peridomiciliares, se bem que em uma delas as casas estavam localizadas a cerca de $10 \mathrm{~m}$ da mata (AGUIAR et al. 1989, TEODORO et al. 1991). No nordeste, $L$ whitmani tem sido incriminada como uma das principais espécies vetoras da LTA em ambientes peridomiciliares (VEXENAT et al. 1986; AZEVEDO e RANGEL 1991; BRANDÃO-FILHO 1994). Ainda, no Estado de São Paulo, a espécie mais estudada e incriminada como a principal transmissora da Leishmania, é $L$ intermedia. Não há controvérsia quanto à sua adaptação aos ambientes antrópicos (FORATTINI et al. 1976, GOMES et al. 1980, 1982), embora não se possa descartar a participação das matas residuais como ambientes propícios ao desenvolvimento de populações desta espécie, como mostram as pesquisas no litoral e no planalto em São Paulo (FORATTINI et al. 1976, CASANOVA 2001), assim como em outras áreas no Paraná (TEODORO E KÜHL 1997).

Em relação ao ambiente onde ocorre a maioria dos focos de transmissão de LTA, tanto no Nordeste, quanto no Sudeste e Sul do Brasil, os autores são unânimes em descrever um ambiente com vegetação natural praticamente extinta, apenas com remanescentes de matas secundárias e mais raramente de mata primitiva (FALQUETO et al. 1982, 1986; BARRETO et al. 1984; TEODORO et al. 1991; RANGEL et al. 1986; FORATTINI et al. 1972; GOMES et al. 1989). A grande unidade paisagistica onde se situa a área endêmica nestas regiões é a Mata 
Atlântica - que no litoral do Estado de São Paulo ainda está razoavelmente preservada, sendo representada pela mata úmida sempre verde e na região do planalto assume a forma de mata semidescídua (GOMES 1994). As pesquisas realizadas em São Paulo e em outros estados, geralmente fazem descrições sucintas do tipo de vegetação presente nas áreas endêmicas, chamando a atenção para a degradação da cobertura florestal original e sua substituição por áreas de cultivo. Raras vezes foram descritas, em um mesmo trabalho, coletas abrangendo tipos diferentes de matas, condições de localização em relação à topografia e hidrografia. Entretanto, as pesquisas que abrangeram alguns destes aspectos chegaram a conclusões interessantes quanto à composição da fauna flebotomínea. GALATI et al. 1996, em área de transmissão de LTA no Mato Grosso do Sul, realizaram coletas de flebotomíneos em vegetação de cerradão (localizado no alto dos espigões), cerrado, mata de galeria (localizada na base dos espigões margeando os rios) e mata de encosta (localizada na encosta do morro onde ocorre afloramento de rochas), além de observarem também o ambiente peridomiciliar. Os autores constataram que a maior diversidade de espécies e quantidade de espécimes ocorria no cerradão e na floresta de encosta: uma espécie importante como vetor da leishmaniose visceral, L Longipalpis, foi encontrada apenas na mata de encosta. Já L whitmani foi mais abundante no cerradão e na floresta de galeria, mostrando-se menos abundante no cerrado e peridomicílio. Chamam a atenção ainda, para a baixa densidade desta espécie no peridomicílio, contrastando com seu comportamento em áreas do Nordeste, Sudeste e Sul do Brasil, reforçando a tese de tratar-se de um complexo de espécies crípticas. Relatam que a altitude no município varia de 200 a 700m, mas não fazem referência a esse aspecto nos pontos de coleta, embora citem a localização das diversas vegetações em relação à topografia.

\subsubsection{Reservatónios silvestres}

Em relação ao reservatório silvestre da $L(V$.) braziliensis não há até o momento conhecimento suficiente para incriminar nenhum mamifero, apesar das várias tentativas de isolamento e do registro de parasitas infectando principalmente roedores. Parasitas 
supostamente pertencentes a essa espécie foram isolados em vários Estados brasileiros como Pará, Ceará, Minas Gerais e São Paulo, a partir de espécies de roedores como Proechimys sp., Rhipidomys leucodactylus, Rattus rattus, Oryzomys nigripes, Oryzomys capito e Akodon arviculoides, do marsupial Didelphis marsupialis, e do bicho-preguiça Choloepus didactylus (GRIMALDI et al. 1989; LAINSON e SHAW 1987; LAINSON et al.1994; DEDET 1993).

No Estado de São Paulo, em matas residuais localizadas próximo ao rio Mogi Guaçu, na região nordeste do Estado de São Paulo, foram encontrados naturalmente infectados com Leishmania $(V$.) braziliensis (senso lato) os roedores $A$. arviculoides, $O$. capito e $O$. nigripes FORATTINI et al. $(1972,1973)$.

Consideramos importante destacar alguns dados ecológicos, encontrados na literatura, sobre estes roedores. $O$. capito é um roedor amplamente distribuído pela América do Sul e ocorre em uma grande variedade de habitats, que vão desde campos até matas tropicais (FONSECA e KIERULFF 1989; STALLINGS 1989). Em matas de galeria localizadas em área de cerrados na região central do Brasil, este roedor foi capturado em grande número atingindo densidade máxima de 7,5 animais/ha (MARES E ERNEST 1995). Entretanto, estes autores chamam a atenção para o fato de que a densidade desta espécie apresentou grande variabilidade em outras pesquisas realizadas mesmo em áreas próximas, o que pode ser decorrente de variações microclimáticas, composição da vegetação e disponibilidade de alimento. ALHO, PEREIRA e PAULA (1986), trabalhando em ambiente semelhante, capturaram esta espécie exclusivamente em mata de galeria, onde estimaram sua área de vida em cerca de 0,22ha. Afirmam tratar-se de espécie arborícola de hábito noturno, com capacidade para explorar o ambiente terrestre. Em área de Mata Atlântica no Vale do Rio Doce, MG, verificou-se que seu habitat era de matas úmidas em diferentes níveis de conservação, variando desde um grau de perturbação médio até áreas íntegras (STALLINGS 1989). 
O. nigripes é um roedor que pode freqüentar vários tipos de habitats em áreas de cerrado, desde matas de galeria até cerradão. Entretanto, é mais comum no cerrado propriamente dito, sendo que sua área de vida foi estimada em 0,4ha (ALHO, PEREIRA e PAULA 1986). Em região de Mata Atlântica no Vale do Rio Doce, MG, este roedor foi capturado por STALLINGS (1989) exclusivamente em áreas úmidas abertas, com vegetação predominantemente de gramíneas e foi raramente encontrado em área de matas por FONSECA e KIERULFF (1989). Estes autores citam pesquisas mostrando que esta espécie faz uso exclusivamente de arbustos para construção de seus ninhos, tanto em região de cerrado como de Mata Atlântica. Na região do Vale do Ribeira (Sudeste do Estado de São Paulo) foi capturada em número expressivo tanto em mata, quanto em áreas peridomiciliares, em comunidade rural com ocorrência de casos humanos e caninos de LTA (GOMES et al. 1990).

A. cursor é uma espécie de roedor muito comum na região de cerrados. Em estudo realizado na região central do Brasil, foi capturado freqüentemente em mata de galeria (80\%), embora também tenha sido capturado em áreas de cerrado e cerradão, segundo ALHO, PEREIRA e PAULA (1986). Nesta pesquisa verificou-se valor máximo de densidade populacional de até 5 indivíduos/ha e sua área de vida foi estimada em 0,4 ha aproximadamente. Em área de mata atlântica em Minas Gerais, FONSECA e KIERULFF (1989) relatam que esta espécie foi capturada mais freqüenteménte em mata secundária, porém STALLINGS (1989) encontrou-a em maior densidade em ambiente úmido aberto, dominado por gramineas, embora freqüentasse vários habitats, desde floresta secundária até bosque de eucalipto.

\subsubsection{Reservatórios "domésticas"}

Parte da discussão que se trava a respeito da domiciliação do ciclo da leishmaniose tegumentar americana no Brasil, em especial nas áreas de colonização mais antiga em que a vegetação natural foi mais alterada, tem como base a participação de animais domésticos como reservatório da $L(V$.) braziliensis. 
Aqueles que defendem a hipótese de que esse ciclo está domiciliado, o fazem em função de indicações indiretas de que o cão efetivamente participa deste ciclo no ambiente peridomiciliar e também devido ao fracasso quase generalizado de encontrar espécies silvestres naturalmente infectadas pela $L(V$.) braziliensis. Apesar disto, nem todos que defendem a participação dos animais domésticos, em especial do cão, defendem claramente a hipótese de domiciliação da transmissão.

As indicações de participação do cão no ciclo "domiciliado", nas áreas com transmissão, vão desde o encontro e identificação da mesma espécie do parasita tanto no homem como no cão; da prevalência de infeção canina medida através de testes sorológicos; até a associação entre infecção humana e canina nas mesmas residências.

Assim, OLIVEIRA-NETO et al. (1988), estudando um foco de transmissão em Nova Iguaçu, R. J., isolaram e identificaram $L(V$.) braziliensis de 26 casos humanos, de dois cães e de uma mula; além disso encontraram uma prevalência de $32 \%$ de cães com lesões cutâneas e cerca de $30 \%$ dos eqüinos com parasitas nas lesões. Para os autores, estas coincidências, além daquelas estudadas por outros autores que trabalharam em áreas com características semelhantes, sugerem a participação destes animais domésticos ao menos como amplificadores para a manutenção da doença. A partir do número de mulheres e crianças com LTA assim como do registro de três crianças com úlceras nas pálpebras, sugerindo que foram picadas durante o sono, os autores concluem pela transmissão domiciliar do parasita.

Estudos realizados em duas áreas endêmicas do Espírito Santo, Brasil, compararam dados de incidência de casos humanos com a presença de cães infectados no domicílio ou em domicílios próximos, chegando-se à conclusão da existência de alta correlação entre a doença humana e canina (FALQUETO et al. 1986, 1991). Com base nestes dados, no isolamento e caracterização de $L(V$.) braz̧iliensis de casos humanos e caninos, além da não localização de animais silvestres infectados com o parasita, os autores discutem a possibilidade da doença, na atualidade, apresentar um ciclo domiciliado em que o cão seria o reservatório, e por outro lado destacam importância secundária dos animais silvestres, na manutenção da endemia. 
Estudos realizados por BARRETO et al. (1984) em área endêmica da Bahia, identificaram seis amostras de parasitas isolados de cães como sendo $L(V$.) braziliensis, semelhante ao parasito isolado de lesões cutâneas do homem da região. Citam também que, apesar de terem sido examinados cerca de 600 animais silvestres, não foram identificados reservatórios silvestres. Os mesmos apontam importância do cão como reservatório secundário de Leishmania $(V$.) braziliensis na área de estudo, devido a: a) semelhança de comportamento entre o parasita circulando no homem e no cão; b) ocorrência de crianças que não freqüentam mata, provavelmente adquirindo a doença em suas residências; c) animais silvestres que freqüentam o domicílio não tem sido encontrados infectados; d) o vetor $L$ wbitmani é antropofilico e também é atraído pelo cão, sendo predominante no domicílio e arredores; e) este flebotomíneo infecta-se experimentalmente em cães parasitados com $L(V$.$) .$ braziliensis canina da região.

Um contraponto aos estudos citados anteriormente é o que foi realizado por PIRMEZ et al. (1988) em pesquisa realizada em foco de transmissão de LTA humana em Jacarepaguá. Apesar dos autores terem demonstrado a presença de parasitas em vários cães suspeitos de ser portadores de LTA, concluem ser dificil identificar se os cães contraíram a doença no peridomicílio ou nas matas próximas, uma vez que $31 \%$ dos cães examinados acompanhavam seus donos em caçadas nas matas secundárias da região.

No Estado de São Paulo, em anos recentes, a participação do cão no ciclo de transmissão da LTA tem sido investigada em áreas endêmicas, sem contudo ficar claro qual sua participação neste ciclo. GOMES et al. (1990), em pesquisa realizada no Vale do Ribeira encontraram apenas $2,4 \%$ de cães comprovadamente parasitados em uma área rural endêmica e não verificaram atividade enzoótica na área, quer através de cães sentinelas, quer em roedores silvestres. Sugerem a fragilidade do ciclo extraflorestal da enzootia, pelo menos em áreas consideradas "novas" em termos de ocorrência de casos. Já TOLEZANO et al. (1998) realizaram inquérito canino através de imunofluorescência indireta (RIFI) e teste de intradermo-reação em dois municípios localizados em áreas de transmissão de características 
diversas: um município localizado em uma área com focos naturais de transmissão registrados desde meados do século (município de Eldorado, no Vale do Rio Ribeira) e outra, de recente identificação de focos naturais, representada pelo município de Itupeva, localizada na região de Jundiaí. Os autores acreditam que o cão possa ter alguma participação na manutenção de $L$ (V.) braziliensis nas regiões de colonização mais antiga e de identificação mais recente de focos naturais (Itupeva) e que, em princípio, não entendem ser seu papel o de verdadeiros reservatórios naturais. Pela impossibilidade de demonstração de taxas significativas de infecção canina em outras regiões, os autores crêem na possibilidade da existência de um verdadeiro reservatório silvestre que mantém o ciclo deste parasita na natureza.

RODRIGUES (1999) estudando um foco de transmissão no município de Ilha Bela, litoral de São Paulo, observou associação estatisticamente significante entre a presença de infecção humana e infecção ativa em cães, embora não tenha observado associação entre infecção humana e positividade de cães medida através de intradermo-reação.

REITHINGER e DAVIES (1999) através de revisão bibliográfica extensa, chamam a atenção para o fato de estar crescendo a corrente dos que defendem a tese de que o cão é também o reservatório da LTA, assim como é da leishmaniose visceral americana, a partir de evidências crescentes da transmissão da LTA no ambiente doméstico e pelo fato de vários estudos, como alguns dos já citados, terem encontrado altas taxas de infeção em cães. Os autores chamam a atenção para a importância da definição do papel do cão neste ciclo. Como reservatório primário (isto é, aquele hospedeiro capaz de manter a circulação endêmica do parasita na ausência de qualquer outro hospedeiro); como reservatório secundário (ou seja aquela espécie cuja presença amplificaria as taxas de transmissão, mas não seria capaz de manter a endemia sem a presença do reservatório primário); e finalmente, como hospedeiro acidental (cuja presença não teria impacto na taxa de transmissão da doença).

Os autores estabelecem três parâmetros que juntos definiriam a probabilidade do cão ter papel significante na epidemiologia da LTA. São eles: prevalência da infecção nos cães; taxa de picada dos flebotomíneos transmissores nos cães; e infectividade dos cães para os 
flebotomíneos transmissores. Após a análise da bibliografia, concluem que as evidências apresentadas até o momento para o papel dos cães como reservatórios da LTA são circunstanciais, sustentando-se no isolamento e identificação de um grande número de parasitas e na detecção de uma prevalência relativamente alta de LTA em cães, em locais endêmicos. Estas evidências portanto, seriam insuficientes para determinar o papel de reservatório da doença. Os autores chamam a atenção para o fato de que uma incriminação do cão como reservatório primário da LTA determinaria a possibilidade de adoção de medidas de controle da doença, dirigidas à população canina, como no caso da leishmaniose visceral americana. $\mathrm{O}$ exposto parece indicar que os autores realmente buscaram definir evidências de que o cão tem um papel de reservatório primário na epidemiologia da LTA, fato que, em sua opinião não chegou a ser comprovado.

Estes três parâmetros seriam indicativos suficientes para demonstrar o papel do cão apenas como reservatório secundário da LTA. KILLICK-KENDRICK e WARD (1981) dizem que para a incriminação de um animal como reservatório primário deve ser demonstrado que o parasita, isolado do suspeito reservatório e do homem sejam indistinguíveis; que a infeção não seja rara na população do animal; que o vetor se alimenta freqüentemente no animal; e, que a infeção no animal seja tal, que o vetor se infecte facilmente ao sugá-lo. Uma evidência mais direta de que o cão tem um papel como reservatório primário desta endemia, além do preenchimento dos requisitos apresentados por REITHINGER e DAVIES (1999) seria a demonstração de que o ciclo peridomiciliar, com a participação do cão, está isolado do ciclo silvestre. Uma das formas de verificar isto seria examinar mais detalhadamente a cobertura vegetal natural remanescente ou não, nos locais de transmissão. Através da verificação de parâmetros dos remanescentes florestais como: localização em relação aos focos endêmicos; características de capacidade de suporte às populações de flebotomíneos transmissores e de reservatónios silvestres (uma vez identificados através de pesquisas sistemáticas de infeção natural) e impossibilidade de serem freqüentadas por cães domésticos; e impossibilidade das populações vetoras e/ou de reservatónios silvestres freqüentarem os peridomicilios ou domicilios, 
poderia ser estimada a probabilidade de existir um ciclo domiciliado de transmissão, com a participação do cão como reservatório. No entanto, na maioria dos trabalhos citados aqui sobre participação do cão no ciclo da LTA, há referências à existência de remanescentes de matas, muitas vezes secundárias, nas proximidades dos casos, parecendo não existir um isolamento entre as áreas peridomiciliares e áreas de mata, onde o ciclo silvestre poderia estar ocorrendo, e que deporia contra a existência de um ciclo domiciliado.

\subsubsection{Conceitos sobre os métodos e técnicas utilizadas}

\subsubsection{Sensoriamento remoto orbital aplicado à epidemiologia paisagística}

O uso de sensoriamento remoto orbital como ferramenta para a epidemiologia baseiase na possibilidade que este representa para a identificação de feições paisagísticas através de medidas das radiações eletromagnéticas refletidas pelos alvos terrestres. Uma vez identificadas as feições paisagisticas podem ser associadas aos habitats de vetores e reservatórios das doenças (CURRAN et al. 2000).

Através de um sensor a bordo de um satélite parte da energia recebida do sol e refletida pelos alvos terrestres é captada e registrada na forma de número digital, que na imagem é representado em tons de cinza (em geral 256 proporcionais a este número). Uma imagem digital é composta por um arranjo bidimensional de linhas e colunas que formam elementos pictóricos (picture elements ou pixels). Cada pixel representa a média observação realizada em uma área de solo (LILLESAND e KIEFER, 1994). O tamanho do pixel representa a resolução espacial da imagem e depende do sistema imageador, podendo variar de poucos metros até alguns quilômetros (em geral a resolução é informada em medida linear). Vários dos sistemas em órbita na atualidade realizam o imageamento em vários comprimentos de onda do espectro eletromagnético, geralmente indo do visível ao termal. Cada imagem da mesma cena correspondente a um determinado comprimento de onda recebe o nome de banda.

Para ser utilizada de forma integrada com as bases de dados existente em um SIG é necessário estabelecer uma relação entre as coordenadas da imagem e o sistema de 
coordenadas geográficas utilizado. Este processo recebe o nome de georreferenciamento da imagem. O georreferenciamento usa transformações geométricas simples (usualmente transformações polinomiais de primeiro e segundo graus) calculadas a partir de pares de pontos correspondentes na imagem e no sistema de referência (INPE 1998). Estes pontos de referência podem ser obtidos através de cartas geográficas ou de pontos no solo obtidos através de GPS. Utiliza-se normalmente como referência feições que podem ser facilmente identificáveis na imagem tais como cruzamentos de estradas, pontes sobre rios e foz de rios.

A interpretação e classificação de imagens digitais para o uso em epidemiologia paisagística aplicada a doenças transmitidas por vetores está baseada na possibilidade de distinção entre três elementos básicos da paisagem: água, solo e vegetação, para posteriormente separar os diferentes tipos de vegetação. Portanto usa-se a banda do infravermelho próximo, pela alta reflectância apresentada pela vegetação sadia nesta faixa do espectro eletromagnético, associada a uma banda em que água tenha uma boa refletância (no caso a banda 3) e a uma banda em que o solo apresente uma alta refletância. Além disso a vegetação, o solo e água comportam-se de modo diferente nestas três bandas, permitindo uma melhor separação das outras classes de cobertura. A distinção destes elementos baseia-se no fato de que podem apresentar respostas diferentes uns dos outros e também respostas específicas em função da banda analisada. As técnicas convencionais de interpretação e de classificação de imagens incluem a interpretação visual, baseada na capacidade humana de distinguir informações de tons, textura e contexto e relaciona-las com as feições paisagisticas. Já as técnicas digitais levam em conta o número digital associado aos níveis de cinza das imagens para realizar agrupamentos de pixels associados a classes de cobertura do solo. Estes métodos foram aplicados em estudos epidemiológicos e apresentam vantagens e desvantagens; outros métodos estão sendo testados e avaliados como alternativas para tornar as classificações mais precisas (CURRAN et al 2000).

Além dos métodos de classificação, métodos de realce de imagem podem evidenciar determinadas feições paisagísticas de interesse. Segundo CURRAN et al. (2000), índices de 
vegetação, muitas vezes, foram usados com sucesso em estudos epidemiológicos apresentando-se como variáveis que podem estar associadas principalmente aos vetores dos agentes etiológicos das doenças por eles transmitidos. $O$ índice mais difundido é o NDVI (Normalized Difference Vegetation Index) que está baseado no fato de que na faixa de radiação eletromagnética do vermelho, a clorofila e outros pigmentos absorvem grande parte da energia eletromagnética, havendo portanto uma baixa reflectância nesta região; já na região do infravermelho próximo, a reflectância da vegetação é alta em função da energia refletida pela estrutura foliar (EASTMAN 1999). O NDVI mede a diferença entre reflectância (ou melhor, o número digital que a representa) no infravermelho próximo e no vermelho, ponderado pela soma das reflectâncias nestas duas regiões, ou seja:

$$
\text { NDVI }=(N I R-R) /(N I R+R) \text { onde NIR corresponde à banda (faixa do }
$$
espectro eletromagnético) do infravermelho próximo e $R$ à banda do vermelho.

Assim, pode-se interpretar o NDVI como uma estimativa indireta da massa foliar presente em determinada área.

\subsubsection{Sistemas de Informações Geográficas (SIG)}

Os sistemas de informações geográficas são ambientes de computação que compreendem uma série de programas e rotinas interligados capazes de adquirir, armazenar manipular, analisar e produzir dados espacialmente referenciados. Através destes sistemas os dados podem ser georreferenciados, isto é associados a um mesmo sistema de referência e representados em duas formas: raster e vetor. Os sistemas raster armazenam e representam as informações na forma de uma matriz de linhas e colunas formando células (ou pixels) contendo a informação digital correspondente àquela porção do espaço. Já os sistemas vetoriais representam as informações através de pontos formados por um sistema de coordenadas, que unidos podem formar linhas e poligonos. A representação raster é utilizada para representar imagens (as imagens de sensoriamento remoto orbital são representadas nesta forma) e espaços contínuos, facilitando avaliações e operações matemáticas que envolvem 
múltiplos planos de informação, como mapas de cobertura vegetal, relevo e superfícies representando distâncias de rios. As representações vetoriais são normalmente utilizadas para representar rios, estradas, limites entre áreas, pontos de amostragem e locais de ocorrência de casos de uma doença. Imagens de representação vetorial tendem a ser utilizadas em associação com bancos de dados, pois armazenam apenas os contornos das feições tornando a visualização mais rápida e o armazenamento mais fácil (EASTMAN 1999). O sistema de banco de dados de um SIG pode armazenar as informações tabulares produzidas através das análises de mapas temáticos ou obtidas de dados de campo. A partir das informações armazenadas, pode-se realizar uma série de operações através dos programas integrados em um SIG: consultas para reclassificação de mapas (por exemplo: reclassificação de uma superfície de altitude contínua em classes de altitude), superposição de mapas (overlay) através de operações aritméticas, sumários tabulares ou estatísticos; operações algébricas entre mapas; operadores de contexto, usados para criar áreas de vizinhança a partir de uma classe em um mapa, ou calcular áreas em um mapa; operadores de distância, para medidas de distância relativa; e análise de dados espaciais, para visualizar, explorar e modelar (EASTMAN 1999).

Diante do exposto, partimos da hipótese de que através do uso de sensoriamento remoto orbital e técnicas de cartografia ambiental, modelo numérico de terreno e GPS, combinados e analisados em ambiente de Sistema de Informações Geográficas (SIG), seria possível identificar fatores ambientais associados a transmissão da LTA. Estes fatores talvez possam contribuir para a elucidação de questões que vem sendo levantadas através de estudos tradicionais sobre a ecologia desta doença e também servirão de novos parâmetros para futuras pesquisas que ajudem a esclarecer questões sobre a transmissão até hoje não elucidadas. 


\section{OBJETIVOS}

\subsection{Objetivo Geral}

Identificação de fatores ambientais associados à ocorrência de Leishmaniose Tegumentar Americana (LTA) no municipio de Itapira, SP, através da aplicação de sensoriamento remoto orbital, cartografia ambiental e Sistema de Informação Geográfica, que possam ser parâmetros ambientais para os estudos ecológicos dos ciclos de transmissão desta doença.

\subsection{Objetivos Especificos}

- Identificação dos locais de provável transmissão dos casos humanos de LTA e descrição da vegetação presente na área peridomiciliar.

- Verificação da influência do relevo na distribuição dos locais de provável transmissão, e distribuição dos fragmentos de matas.

- Identificação e caracterização dos fragmentos de matas, presentes nas proximidades dos locais de provável transmissão do parasita aos casos de LTA, em relação a tamanho, distância das residências, índice de vegetação e relevo.

- Verificação qualitativa da distribuição das espécies de flebotomíneos presentes. 


\section{MATERIAIS E MÉTODOS}

\subsection{Area de estudo}

O presente estudo foi realizado no município de Itapira (Figura 1), um dos municipios de maior incidência de LTA no Vale do Rio Mogi Guaçu, situado na região de Campinas (Regional 5 da SUCEN). Esta região está delimitada a leste e norte pela vertente da Serra da

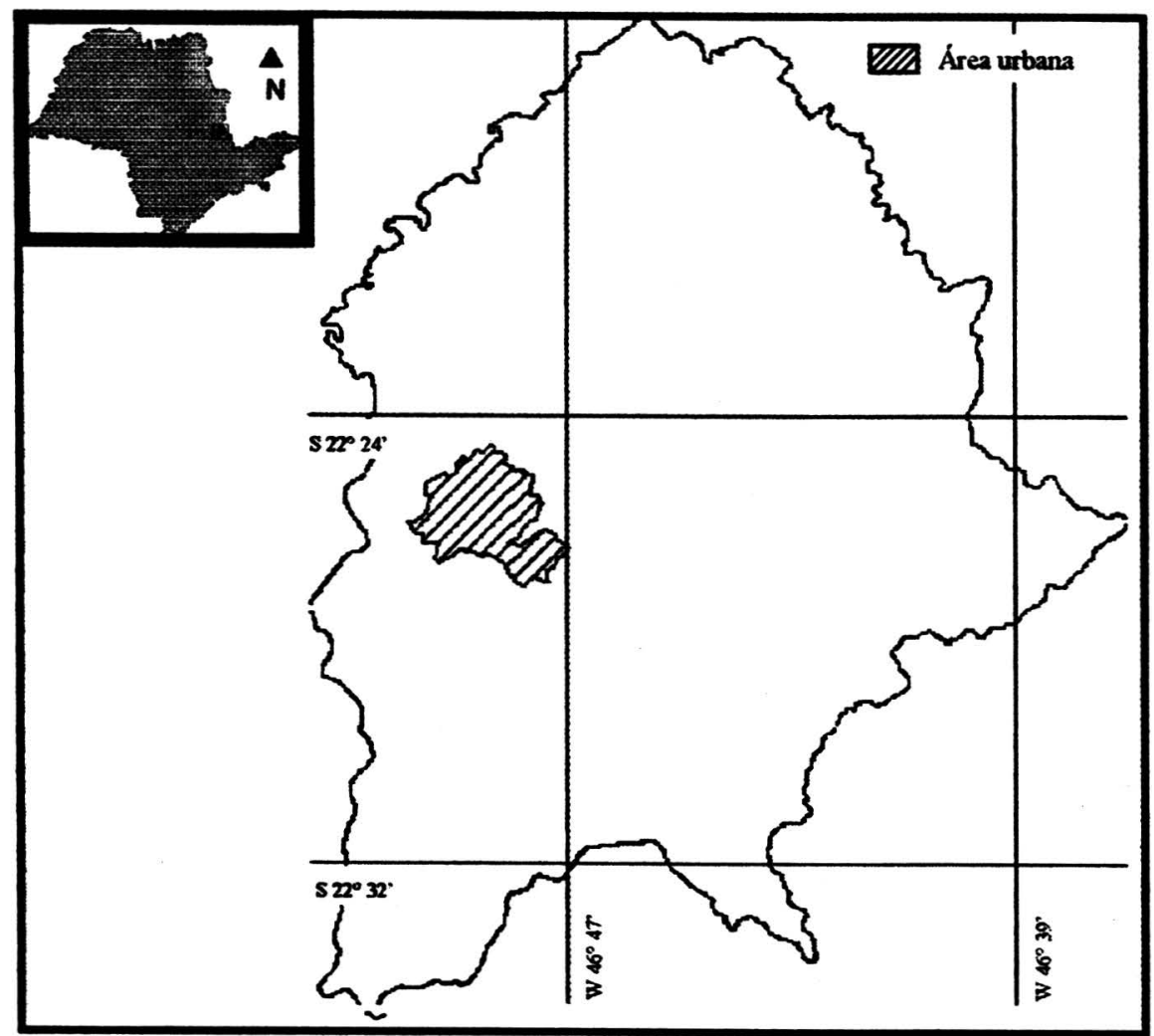

Figura 1: Limites da área de estudo, municipio de Itapira. SP. Fonte: Fundação IBGE.1972

Mantiqueira, ao sul por prolongamentos desta mesma Serra, sendo abrangida em grande parte pelas bacias dos Rios Pardo e Mogi Guaçu. A região de Campinas está incluída na Região de Coordenação de Saúde do Estado que teve o maior aumento relativo de casos de leishmaniose 
tegumentar americana no Estado de São Paulo nos últimos anos, segundo levantamento realizado por TOLEZANO (1994).

A ocupação das terras na região nordeste de São Paulo já estava em curso desde o século passado. Na década 1920 a principal cultura, o café, encontrava-se implantada em todos os seus municípios. Além do café, a Diretoria Regional Agrícola de Campinas (DIRA) tinha participação expressiva em outros seis produtos, como algodão, cana de açúcar e milho. A área cultivada representava $20 \%$ do total de terras nessa época. O processo de ocupação seguiu acelerado durante todas as décadas seguintes, havendo, entretanto, uma perda relativa de importância da cultura cafeeira em relação a culturas como cana de açúcar, milho, laranja, soja, algodão e amendoim. Em termos tecnológicos a DIRA de Campinas manteve a liderança da modernização agrícola no Estado, juntamente com a DIRA de Ribeirão Preto. Em 1981 o processo de ocupação estava praticamente concluído, com cerca de $70 \%$ da área da região ocupada por culturas ou pecuária (TARTAGLIA e OLIVEIRA 1988). Sua paisagem atual reflete a grande transformação a que a vegetação natural foi submetida: existem poucos remanescentes de floresta secundária e de cerrado e raros fragmentos de mata primária, como foi mostrado no inventário florestal do Estado de São Paulo apresentado em KRONKA et al. 1993.

\subsection{Levantamento dos casos de LTA}

Inicialmente os casos autóctones de Leishmaniose Tegumentar Americana ocorridos na região do Vale do Rio Mogi Guaçu entre 1992 e 1998 foram identificados através das Fichas de Investigação Epidemiológica da Secretaria da Saúde. Analisando as fichas dos municípios com maior incidência, para selecionar um que viesse a ser o objeto do nosso estudo, verificamos que em muitos casos as informações eram imprecisas em relação ao local de possível transmissão do parasita, permitindo apenas inferir que o caso havia ocorrido naquele município, em um lugar impreciso onde a pessoa havia desenvolvido alguma atividade de lazer, como pescar, passar o dia nas margens de um rio e assim por diante. Procuramos selecionar 
um município cujas fichas epidemiológicas tivessem informação suficiente para permitir identificar com a maior precisão possível o local onde a transmissão pudesse ter ocorrido. $\mathrm{O}$ município escolhido foi Itapira, pois a maioria dos casos registrados ocorreu ou no local de moradia ou em localidades rurais freqüentadas regularmente, em função do trabalho ou lazer, como chácaras ou sítios onde estas pessoas trabalhavam ou passavam o fim de semana.

De posse destas informações, foram realizadas visitas aos locais de moradia e ou locais freqüentados pelas pessoas que haviam desenvolvido a doença. Uma vez localizadas, foram feitas entrevistas para confirmação das informações constantes das fichas de investigação epidemiológica, assim como para a definição da possibilidade de autoctonia da transmissão. Assim, através de entrevistas abertas, procurou-se levantar questões como hábito de pesca ou caça, freqüência noturna às áreas de matas e viagens realizadas às áreas endêmicas. Aqueles casos que não puderam ser localizados e confirmados por entrevista com a própria pessoa ou responsável pela propriedade foram descartados deste trabalho, juntamente com aqueles que não se enquadravam nos critérios de autoctonia.

As coordenadas geográficas das residências dos casos selecionados foram obtidas através de um aparelho GPS. O conjunto de pontos obtido foi transferido para arquivo digital na forma vetorial e posteriormente transformado para a forma raster. A partir desta imagem, utilizando-se o módulo BUFFER, criou-se uma nova ímagem em que a cada pixel representando a residência foram adicionados os pixeis adjacentes a ele até um raio de $200 \mathrm{~m}$. A cada um destes conjuntos deu-se o nome de local de provável transmissão (LPT). Quando os raios de $200 \mathrm{~m}$ de duas ou mais residências se superpunham, o conjunto foi considerado como um único LPT. O LPT ficou então definido como a área contida em um raio de $200 \mathrm{~m}$ em torno da casa onde a pessoa que havia sido portadora de LTA residia ou freqüentava. Este raio foi definido principalmente em função do comportamento de dispersão do vetor. Utilizou-se o módulo GROUP do Idrisi32 para agrupar e identificar cada um dos LPTs. Este módulo atribui um novo identificador a cada conjunto isolado de pixeis, que são numerados segundo sua distribuição espacial na seguinte ordem: de norte para sul e de oeste para leste. 


\subsection{Estimativa da distribuição da população rural}

Infelizmente não houve possibilidade de estimar a distribuição da população rural atualizada para os anos de estudo. Entretanto para verificar como as áreas do município foram ocupadas, tendo em vista aspectos do relevo do município, utilizamos informações contidas nas cartas do IBGE, na escala 1:50.000, de 1972 (FUNDAÇÃO IBGE, 1972). Os pontos representando as edificações rurais foram digitalizados através do programa Tosta 2.12. Este arquivo vetorial foi transferido para o Idrisi32 e por processo de transformação de formato de representação, foi realizada uma cópia deste arquivo no formato raster.

\subsection{Distribuição das espécies vetoras}

Os dados referentes às espécies de flebotomíneos que ocorrem no município procedem de duas fontes: 1) Boletins de Captura de flebotomíneos da SUCEN (ficha que relata as atividades de coleta para verificação de autoctonia de casos de LTA); e 2) coletas adicionais em locais de possivel transmissão que se localizavam em regiões do município muito distantes daquelas para a qual se tinha informação da presença de uma espécie potencialmente vetora . Estas coletas foram feitas com armadilha de Shannon, instalada no peridomicílio na mata mais próxima. Também foram coletados espécimes nas paredes das próprias casas. Este levantamento teve apenas caráter qualitativo, não pretendendo avaliar densidade ou mesmo composição da fauna de flebotomíneos, pois um dos nossos objetivos neste trabalho é justamente o levantamento de parâmetros ambientais que orientem as coletas para feições paisagísticas que mostrem alguma associação com locais de possível transmissão de LTA.

\subsection{Levantamento da Vegetą̧ão}

O levantamento da vegetação foi realizado através da interpretação e classificação de imagens digitais obtidas pelo satélite Landsat-7 em 06/08/1999 e correspondem a órbita e ponto 219/076. Esta imagem foi fornecida com níveis básicos de correção radiométrica e geométrica, associada a um sistema de projeção cartográfica que permite precisão bem 
aproximada àquelas obtidas com base em pontos de controle cartográficos. Este produto é composto de um conjunto de nove imagens obtidas pelos sensores nos seguintes comprimentos de onda: banda $1(0,45-0,52 \mu \mathrm{m})$, banda $2(0,53-0,61 \mu \mathrm{m})$, banda $3(0,63-$ $0,69 \mu \mathrm{m})$, banda $4(0,78-0,90 \mu \mathrm{m})$, banda $5(1,55-1,75 \mu \mathrm{m})$, banda 6.1 e $6.2(10,4-12,5 \mu \mathrm{m})$, banda $7(2,09-2,35 \mu \mathrm{m})$, e banda 8 pancromática $(0,52-0,92 \mu \mathrm{m})$. As bandas do visível e infravermelho (bandas 1 a 5 e banda 7) têm resolução espacial de 30m; as bandas 6.1 e 6.2 do infravermelho termal têm resolução de $60 \mathrm{~m}$ e a banda 8 pancromática tem resolução de $15 \mathrm{~m}$.

O primeiro objetivo desta análise foi fazer o levantamento dos fragmentos de mata presentes na região de estudo, com ênfase naquela situada nas proximidades dos locais de provável transmissão de LTA. O recurso utilizado para realizar este levantamento foi a interpretação de imagens e classificação das imagens de sensoriamento remoto orbital. Para efeito de classificação, adotamos o conceito de mata em um sentido genérico, significando uma vegetação arbórea não plantada pelo homem, podendo ser de crescimento primário ou secundário. $\mathrm{O}$ aspecto geral deste tipo de vegetação era semelhante aquele visto nas fotos do anexo 2. O programa usado para o processamento, interpretação e análise das imagens foi o Idrisi32 (Clarks Lab, The Idrisi Project, Clark University, Worcester, MA, USA).

O primeiro passo para iniciar o processo de classificação foi a escolha do melhor conjunto de bandas para realizar a composição colorida. As informações espectrais dos diferentes alvos terrestres contidas em cada uma das bandas são em parte repetidas, ou seja, nem toda informação apresentada por uma banda é informação nova que já não está contida em outra banda. Para verificar quais as bandas que contém a maior parte da informação sobre um certo alvo, pode-se fazer uma análise de componentes principais. Normalmente os dois ou três primeiros componentes resultantes da análise retém mais de $95 \%$ de toda informação. Desse modo as bandas que apresentam maior correlação com esses dois ou três primeiros componentes são aquelas mais úteis para uma análise em termos quantitativos. Realizamos uma análise de componentes principais não padronizada através do módulo PCA do Idrisi32, utilizando as bandas $1,2,3,4,5$ e 7 . Verificamos primeiramente que os três primeiros 
componentes retinham 98,46 da informação e que banda 2 apresentava um grau de correlação de 0,98 com o componente 1 , a banda 4 uma correlação de 0,76 com o componente 2 e a banda 5 uma correlação de 0,25 com o componente 3 , sendo estas as mais altas correlações com os respectivos componentes. A banda 3 apresentava também um alto grau de correlação com o componente $1(0,97)$ sendo portanto muito próximo daquele apresentado pela banda 2 Sendo assim, optou-se por usar a banda 3 , pois a composição 3, 4, 5 é a mais utilizada neste tipo de trabalho e julgou-se que a utilização da composição tradicional não causaria perda significativa de informação para as análises baseadas nesta composição.

Todas as bandas da imagem foram primeiramente georreferenciadas, segundo a projeção Universal Transversa de Mercator UTM, Datum Córrego Alegre, através de pontos de referência obtidos em campo ou através do mapa temático das estradas e rios. A hidrografia e as estradas do municipio foram transpostas para a forma digital a partir das mesmas cartas topográficas do IBGE já citadas, utilizando o programa Tosca 2.12. Os arquivos vetoriais resultantes foram importados para programa Idrisi32.

Como primeiro passo para a identificação da vegetação, foi elaborada uma composição em falsa cor da banda 3 (faixa do vermelho), banda 4 (faixa de infravermelho próximo) e banda 5 (faixa do infravermelho médio). A esta composição adicionou-se uma imagem vetorial das estradas do município, digitalizadas a partir das cartas do IBGE (já citadas). Esta composição, foi impressa em uma escala 1:50.000, servindo de base para a orientação dos trabalhos de campo, o que permitiu uma primeira identificação visual de algumas matas residuais, bem como de outras vegetações (plantações, reflorestamentos com eucaliptos, pastagens, etc.). Serviu ainda para orientar a localização dos casos de LTA e para a obtenção de coordenadas geográficas dos pontos referenciais para matas, casas e pontos de referência (como cruzamentos de rodovias, pontes sobre grandes rios) para o georreferenciamento da imagem. Foram também obtidos, pontos referencias para outros tipos de vegetação como eucalipto, bosques de árvores frutiferas e vegetação natural em regeneração. Através da análise visual da imagem e do conhecimento de campo ficou claro que as matas e algumas plantações 
de eucalipto pareciam se confundir. Havia interesse em distinguir estes dois tipos de vegetação, pois tratam-se de biótopos que julgamos bastante diferentes para a manutenção das populações envolvidas no ciclo de transmissão da LTA.

Para identificar as matas e distinguí-las das plantações de eucalipto assim como de outros tipos de vegetação, de corpos de água, de áreas urbanas e de áreas de solo nu, foi realizada uma classificação supervisionada. Primeiramente foram identificados e digitalizados através da composição colorida das bandas 3, 4 e 5 os locais de treinamento para cada classe de vegetação, ou seja, os vários conjuntos de pixel distintos daqueles do seu entorno e que correspondiam às classes de interesse, identificadas através das visitas feitas no campo e da análise visual da composição colorida. A partir destes locais de treinamento foram desenvolvidas assinaturas baseadas nas Bandas 1 a 5 e banda 7, através do módulo MAKESIG do Idrisi32. Estas assinaturas foram então usadas como padrão pelo módulo BAYCLASS do Idrisi32 que fornece como resultado da análise não uma classificação definitiva mas a probabilidade de que um determinado pixel pertença a uma das classes. A seguir foi utilizado o módulo MAXBAY para realizar a classificação final.

A partir desta classificação, foram extraídos aqueles conjuntos que representaram a classe de interesse, dando origem a um mapa temático representando matas. Através do módulo AREA, foi calculada a área de cobertura de cada conjunto individualizado de matas e com auxílio do banco de dados foram eliminados aqueles cuja área era inferior a $0,50 \mathrm{ha}$, pois unidades muito pequenas em uma imagem sofrem interferência das reflectâncias de áreas vizinhas dificultando sua separação. De posse do mapa temático resultante desta classificação, realizaram-se novos trabalhos de campo para verificar sua adequação à realidade terrestre. Este trabalho foi feito somente nas matas relacionadas espacialmente aos casos de LTA até aproximadamente $500 \mathrm{~m}$ das casas onde suspeitava-se que ocorreu a transmissão do parasita. A classificação apresentou-se adequada para as matas relacionadas aos casos como resultado final da classificação supervisionada e das correções feitas após as observações em campo. 
Portanto, não se pretendeu validar esta classificação para todo o município de estudo. Para que uma classificação desta abrangência tenha validade, deve ser testada a partir de uma grande quantidade de áreas de amostragem, o que demandaria um tempo muito grande, fugindo das possibilidades concretas deste trabalho. Entretanto, em virtude do resultado da classificação para os locais observados ter sido válido, julgamos que esta classificação poderia ser utilizada para se ter uma idéia da distribuição das matas por todo o município, apesar das restrições já feitas. Optamos por utilizar esta classificação em lugar do índice de vegetação descrito a seguir, pois verificamos que este índice apresentava resultados semelhantes tanto para os fragmentos de mata como para os talhões de eucalipto que pudemos analisar.

Como vários objetivos deste trabalho estavam centrados na verificação da influência das matas residuais na transmissão do parasito da LTA ao homem, principalmente no ambiente domiciliar, havia a necessidade de adotar um raio máximo de distância entre os fragmentos de matas e as residências onde possivelmente ocorrera a transmissão. Em função das considerações teóricas, adotamos esta distância como sendo de $600 \mathrm{~m}$. As distâncias mínimas, entre a borda de cada mata até o centro dos LPTs, foram medidas utilizando-se uma imagem das matas (individualizadas e numeradas de 1 a $\mathrm{n}$ ) e de um mapa representando as distâncias do centro do LPT até qualquer local da imagem, através do módulo DISTANCE. As matas que distavam até $600 \mathrm{~m}$ de um dado LPT foram seleciónadas através de um banco de dados e foi gerada uma imagem representando aquelas que designamos como matas associadas aos LPTs. Foi medida também a distância das matas em relação aos rios usando procedimento semelhante ao já descrito.

O segundo objetivo da interprestação de imagens era verificar e quantificar a presença de vegetação arbóreo/arbustiva, nativa ou plantada, nos locais de provável transmissão, tendo em vista o papel que esta vegetação poderia representar para as populações de flebotomíneos e reservatórios. Sua distinção como uma classe a ser objeto da classificação supervisionada apresentou-se problemática em função de sua heterogeneidade. Assim utilizou-se o índice de vegetação conhecido como NDVI. Esta imagem foi reclassificada para representar 3 classes de 
vegetação: baixa (NDVI maior que zero até 0,10 ), média (NDVI entre 0,10 a 0,35 ) e alta (NDVI acima de 0,35 - que era o resultado da média do NDVI para as matas identificadas como tais menos um desvio padrão amostral). Posteriormente as vegetações localizadas no raio de $200 \mathrm{~m}$ dos domicílios e classificadas como alta e média foram identificadas e descritas, como por exemplo os pomares, a vegetação arbustiva em regeneração, bambuzais e as próprias matas.

\subsection{Altitude e Declividade}

Os mapas temáticos de altitude e declividade foram obtidos a partir de um modelo numérico de terreno (MNT). Para a construção deste modelo, primeiramente foram digitalizadas as isolinhas, representando as curvas de nível de 20 em $20 \mathrm{~m}$ constantes das cartas do IBGE na escala 1:50.000 (já citadas). A digitalização e edição (correções necessárias em função de erros de digitalização) dos dados vetoriais foram feitas através do programa Tosca 2.12. No programa Idrisi32 for Windows, estes dados vetoriais foram transformados em uma imagem raster. Através do módulo INTERCON foi feita uma interpolação linear entre as isolinhas, para produzir a superficie contínua representando as altitudes do terreno, ou seja, o MNT. Este modelo foi reclassificado para formar o mapa hipsométrico composto das seguintes classes de altitude: inferior a $700 \mathrm{~m}$ acima do nível do mar (a.n.m.), entre 701 e $800 \mathrm{~m}$ e acima de $801 \mathrm{~m}$.

O MNT foi utilizado para gerar um mapa inclinográfico do terreno através do módulo SURFACE que calcula a inclinação de uma dada célula baseado nos valores de altitude das células vizinhas e na resolução da imagem (tamanho do pixel). Esta imagem de declividade foi reclassificada para gerar este mapa inclinográfico, com as seguintes classes: planas (com declividade até 5 graus), com declividade entre 5 e 10 graus, entre 10 e 20 graus e acima de 20 graus. Através do módulo CROSSTAB os mapas hipsométrico e inclinográfico foram combinados fornecendo o mapa das classes de altitude/declividade que mostra a localização das combinações possiveis das categorias dos mapas originais. 
O cálculo de cobertura de matas por classe de altitude declividade foi obtido através da aplicação do módulo AREA sobre o mapa resultante da multiplicação do mapa de matas pelo de classes de altitude/declividade. As classes de altitude/declividade em que se encontravam as edificações rurais existentes nas cartas do IBGE (já citadas), as residências dos LPTs e as classes máximas dos LPTs foram calculadas usando-se o módulo EXTRACT. Através deste módulo pode-se identificar os valores contidos no mapa de altitude/declividade relativos à posição ocupada pelos pontos de interesse indicados naqueles mapas que os representam.

\subsection{Classificą̧ão das matas segundo sua relação com a hidrografia}

Havia o interesse em verificar qual a porção de matas que se encontrava nas áreas planas ao lado dos rios e teoricamente sujeitas ao efeitos de sua inundação, ou pelo menos que sofressem alguma influência devido ao contato com os mesmos.Os critérios estabelecidos para a classificação das matas foram os seguintes: localização em áreas planas e proximidade dos rios. A partir do arquivo vetorial da hidrografia foi gerada uma imagem no formato raster, a partir da qual gerou-se um mapa de distâncias dos rios, através do módulo DISTANCE. O mapa das áreas planas, ou seja, aquelas com inclinação igual a zero graus, foi obtido por reclassificação do MNT. Utilizando-se o processo OVERLAY evidenciou-se a interseção entre o mapa das áreas planas com o mapa das matas associadas aos LPTs, sendo assim gerado o mapa das matas associadas localizadas nas áreas planas. Os fragmentos assim obtidos que distavam menos de um metro dos rios foram considerados como localizando-se em áreas na várzea dos rios, gerando assim dois novos mapas de matas localizadas no plano: uma associada e outra não associada aos rios. Estes mapas foram então integrados aqueles de matas localizadas em terreno inclinado. Foram então calculadas as superficies destas três classes temáticas. O resultado final foi um mapa temático em que as matas associadas aos LPTs foram classificadas da seguinte maneira: aquelas cuja área em várzea superava $30 \%$ da área total foram chamadas de matas ciliares, aquelas cuja área na várzea era inferior a 30\% foram chamadas matas mistas e aquelas que não ocupavam várzea foram classificadas como matas de encosta. 


\section{RESULTADOS}

O presente estudo abrangeu 37 casos de LTA notificados em Itapira entre 1992 e 1998, conforme relação apresentada no anexo 1. Do total de casos examinados alguns não puderam ser localizados devido a imprecisões nas informações do local de provável transmissão, seja por não ter sido confirmada a moradia ou porque a localidade, sítio ou fazenda, não mais existia. Dois casos foram descartados, por não haver como determinar a autoctonia em relação ao municipio, pois os pacientes haviam permanecido em outras áreas endêmicas por ocasião do aparecimento dos primeiros sintomas de LTA. Um caso foi descartado por não ser possível determinar o LPT, pois tanto nos locais de trabalho e moradia como em outros onde a pessoa ia pescar à noite, havia condições de transmissão. De acordo com informações colhidas nas entrevistas, dentre os casos analisados, nenhum tinha por hábito freqüentar áreas cobertas por matas residuais em horário noturno na ocasião em que contrairam a doença. Assim, foram incluídos neste estudo 26 casos autóctones do município de Itapira distribuídos por 20 LPT, um dos quais situava-se em área urbana, onde não havia comprovação da presença de vetor, mas foi mantido como autóctone pelas evidências colhidas através de entrevista.

Esses casos distribuiram-se entre as faixas etárias de 10 anos ou mais, com o maior número ocorrendo na faixa de 40 a 59 anos. Nas faixas superiores a 19 anos a ocorrência foi maior no sexo masculino. Ressalta-se que nenhum caso foi constatado em individuos com idade inferior a 10 anos (Figura 2).

Em relação à atividade profissional, exerciam atividades diretamente ligadas a agropecuária 12 pessoas do sexo masculino e duas do feminino, sendo que mais 6 do sexo feminino exerciam atividades domésticas, na época da doença (Figura 3). Apenas em um caso a atividade profissional poderia relacionar-se ao contato homem-retor em área de mata: mesmo assim o contato pode ter ocorrido em área domiciliar, quando o homem exercia a função de vigia noturno da casa-sede da fazenda, distante menos de trinta metros de uma grande mata. 
Figura 2: Distribuição dos casos autóctones investigados de LTA, segundo sexo e faixa etária, Itapira, SP, 1992 a 1998.

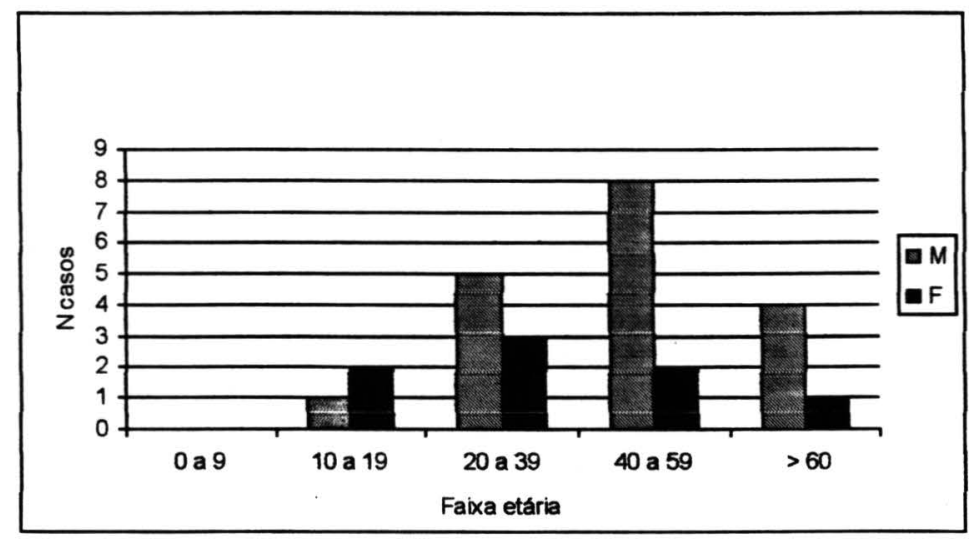

Figura 3: Distribuição dos casos autóctones investigados de LTA , segundo ocupação, Itapira, SP, 1992 a 1998

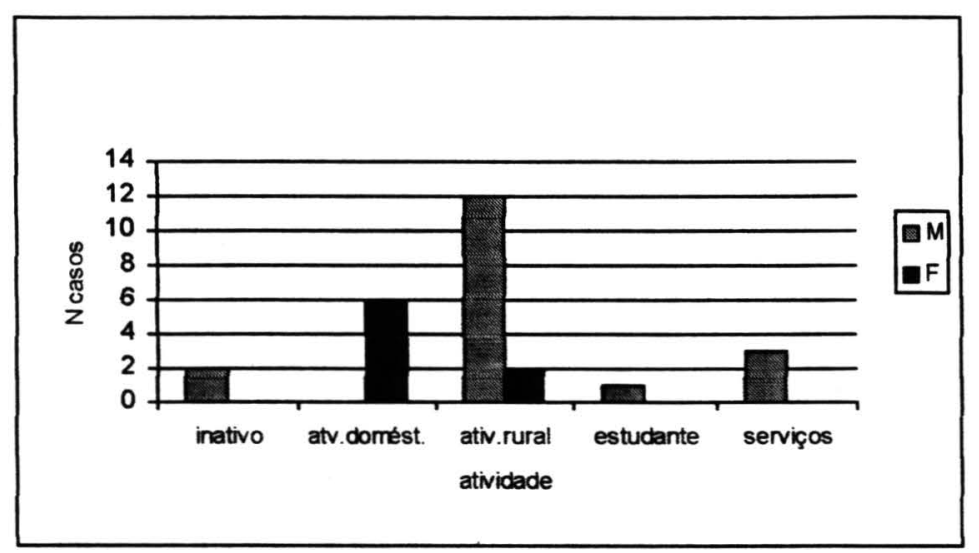

Figura 4: Distribuição dos casos autóctones investigados de LTA, segundo tempo de permanência no LTP, Itapira, SP, 1992 a 1998

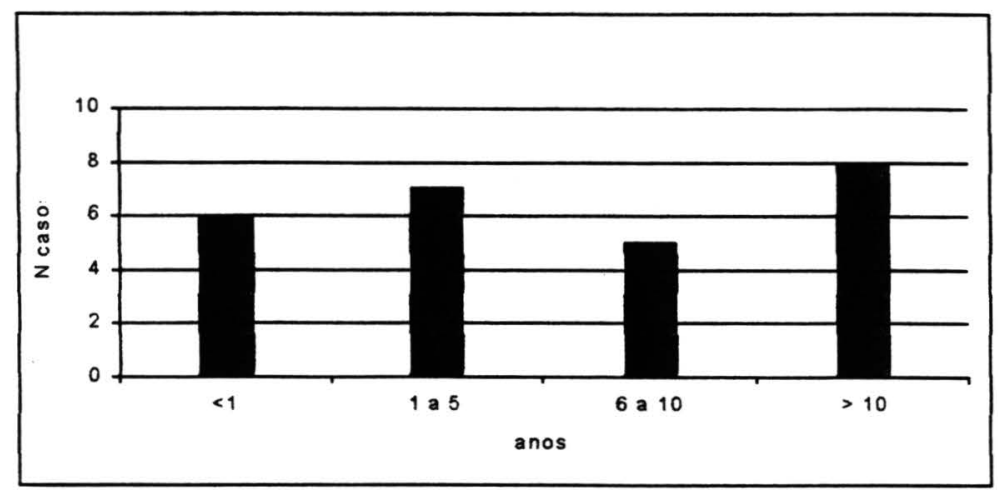


Dentre os casos analisados verificou-se que o tempo de permanência no LPT variou de menos de um ano a 37 anos. Em seis casos este tempo foi igual ou menor que um ano, em outros seis estava entre um e cinco anos e em 14 casos acima de 5 anos (Figura 4).

$\mathrm{Na}$ Figura 5 está representada a vegetação classificada como mata no município discriminada daquelas identificadas como associadas aos LPTs. $\mathrm{Na}$ tabela 1 verifica-se a descrição comparativa destas matas através de alguns parâmetros. Cerca de $8 \%$ do território do municipio era coberto por vegetação identificada como matas, distribuidos por 939 fragmentos maiores que 0,54ha, abrangendo uma área de aproximadamente 5.400ha. Embora o número de

Tabela 1: Descriçåo das matas em geral e matas associadas aos Locais de Provável Transmissão de LTA, identificadas no Município de Itapira, 1999.

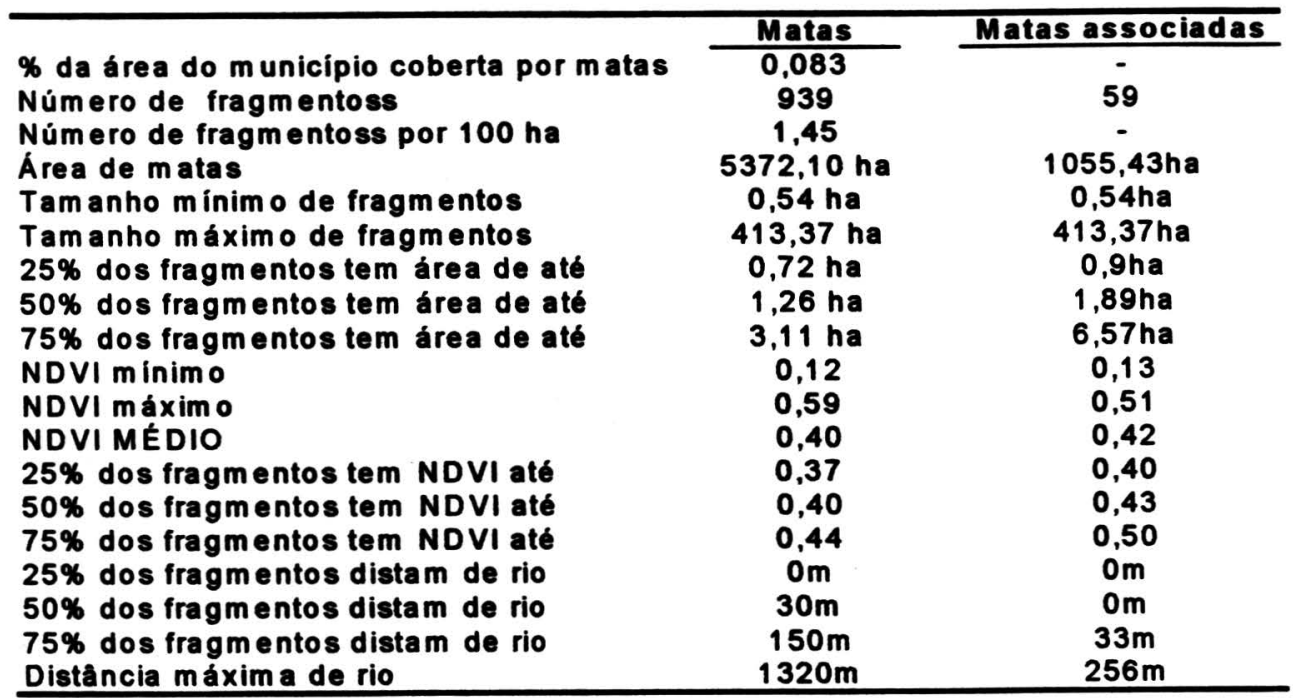

fragmentos de mata associados aos LPTs fosse de apenas 59, estes recobriam uma área total de cerca de 1.000ha. Destaca-se que os fragmentos de mata presentes eram, em geral de tamanho reduzido: no município como um todo, $75 \%$ tinham área de até 3 ha e entre aqueles associados aos LPTs, 75\% tinham área de até 6,5ha; os índices de vegetação (NDVI) eram comparáveis nos dois tipos de fragmentos; as distâncias entre os rios e as matas em geral eram pequenas, e estas distâncias eram ainda menores em relação as matas associadas aos LPTs.

A análise da distribuição das áreas cobertas por matas segundo classes de altitude e de declividade, mostrou uma associação positiva entre as duas variáveis, razão pela qual estas 


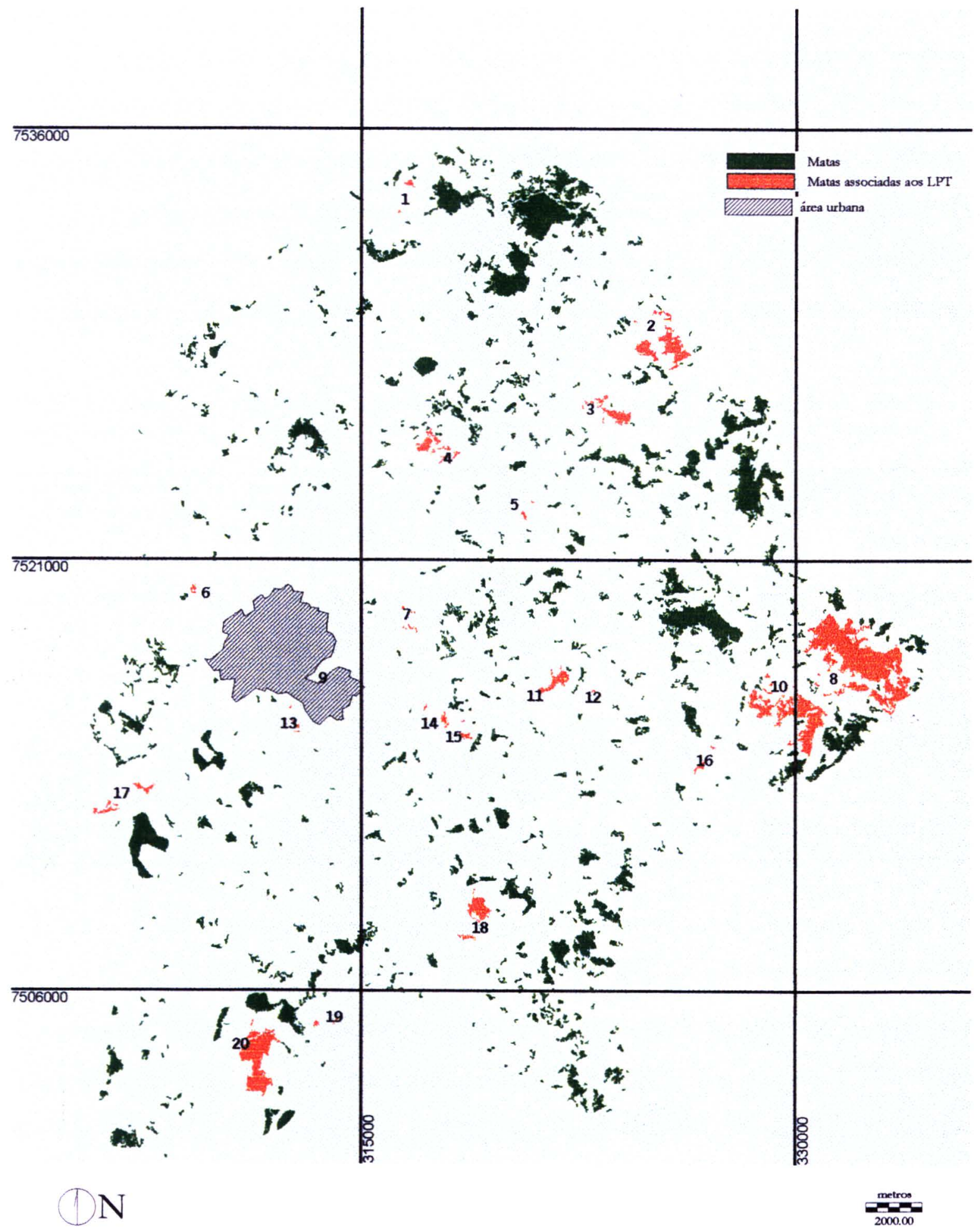

Figura 5: Distribuição das matas associadas aos LPTs (1 a 20) e das matas presentes em outros locais do municipio de Itapira, SP, identificadas através de classificação de imagens TM Landsat-7. 
foram tratadas em conjunto, formando classes de altitude/declividade, para o estudo da distribuição dos LPTs e matas em relação à topografia.

A Figura 6 apresenta o relevo do município em classes de altitude/declividade, mostrando também a localização dos LPTs. Nota-se que a maioria destes locais de transmissão parece situar-se em áreas de vales de rios nas proximidades de áreas de relevo mais acidentado.

A tabela 2 mostra a distribuição das matas em geral e matas associadas aos LPTs, comparativamente à distribuição das terras do município por classes de altitude/declividade. A área do município de Itapira compreende, em sua maioria, áreas de altitude inferior a $801 \mathrm{~m}$ e

Tabela 2: Área de cobertura de matas do município e matas associadas aos Locais de Provável Transmissão de LTA em relação as classes de altitude/declividade no município de Itapira, SP.

\begin{tabular}{|c|c|c|c|c|c|c|c|c|}
\hline \multirow{2}{*}{$\begin{array}{l}\text { classes de altitude(m)/ } \\
\text { declividade(graus) }\end{array}$} & \multicolumn{2}{|c|}{ classes(A) } & \multicolumn{3}{|c|}{ matas(B) } & \multicolumn{3}{|c|}{ matas assoc. (C) } \\
\hline & área (ha) & $\%$ & área (ha) & $\%$ & $\overline{B / A}$ & área (ha) & $\%$ & $\overline{C / A}$ \\
\hline até $700 / 0 \vdash 5$ & 17847.09 & $27.50 \%$ & 479.25 & $8.92 \%$ & 0.027 & 57.60 & $5.46 \%$ & 0.003 \\
\hline 701 a $800 / 0 \vdash 5$ & 8164.71 & $12.58 \%$ & 594.81 & $11.07 \%$ & 0.073 & 128.43 & $12.17 \%$ & 0.016 \\
\hline 801 ou mais $/ 0 \vdash 5$ & 937.35 & $1.44 \%$ & 85.86 & $1.60 \%$ & 0.092 & 13.77 & $1.30 \%$ & 0.015 \\
\hline até $700 / 5 \vdash 10$ & 9843.12 & $15.17 \%$ & 474.03 & $8.82 \%$ & 0.048 & 57.96 & $5.49 \%$ & 0.006 \\
\hline 701 a $800 / 5 \vdash 10$ & 9528.12 & $14.68 \%$ & & $14.03 \%$ & 0.079 & 111.78 & $10.59 \%$ & 0.012 \\
\hline 801 ou mais $/ 5 \vdash 10$ & 2733.84 & $4.21 \%$ & 308.34 & $5.74 \%$ & 0.113 & 77.40 & $7.33 \%$ & 0.028 \\
\hline até $700 / 10 \vdash 20$ & 2283.75 & $3.52 \%$ & 279.45 & $5.20 \%$ & 0.122 & 37.53 & $3.56 \%$ & 0.016 \\
\hline 701 a $800 / 10 \vdash 20$ & 6082.56 & $9.37 \%$ & 722.43 & $13.45 \%$ & 0.119 & 80.28 & $7.61 \%$ & 0.013 \\
\hline 801 ou mais / $10 \vdash 20$ & 5514.39 & $8.50 \%$ & 1071.63 & $19.95 \%$ & 0.194 & 325.80 & $30.87 \%$ & 0.059 \\
\hline até 700 / 20 ou mais & 86.67 & & 18.09 & $0.34 \%$ & 0.209 & 0.27 & $0.03 \%$ & 0.003 \\
\hline 701 a 800 / 20 ou mais & 305.01 & $0.47 \%$ & 68.58 & $1.28 \%$ & 0.225 & 6.66 & $0.63 \%$ & 0.022 \\
\hline 801 ou mais / 20 ou mais & 1561.50 & $2.41 \%$ & 515.70 & $9.60 \%$ & 0.330 & 157.95 & $14.97 \%$ & 0.101 \\
\hline Total & 64888.11 & $100.00 \%$ & 5372.10 & $100.00 \%$ & 0.083 & 1055.43 & $100.00 \%$ & 0.016 \\
\hline
\end{tabular}

planas ou de baixa declividade (5 a 10 graus), embora existam áreas de transição para uma topografia mais acidentada localizadas nas proximidades da Serra da Mantiqueira, cuja altitude é superior a $801 \mathrm{~m}$ e a declividade chega a ser superior a 20 graus. Verificou-se maior ocorrência de matas, em termos absolutos, em áreas cuja altitude é superior a $701 \mathrm{~m}$ e com declividade entre 10 e 20 graus (cerca de 33\%), seguida de áreas com altitude de 701 a $800 \mathrm{~m}$ e declividade entre 5 e 10 graus e outra com altitude de 701 a $800 \mathrm{~m}$ e declividade entre 0 e 5 graus. A maior concentração de matas associadas aos LPTs deu-se nas classes de $81 \mathrm{~m}$ ou mais e declividade superior a 10 graus (45\%). Em termos relativos pode-se observar que as terras 


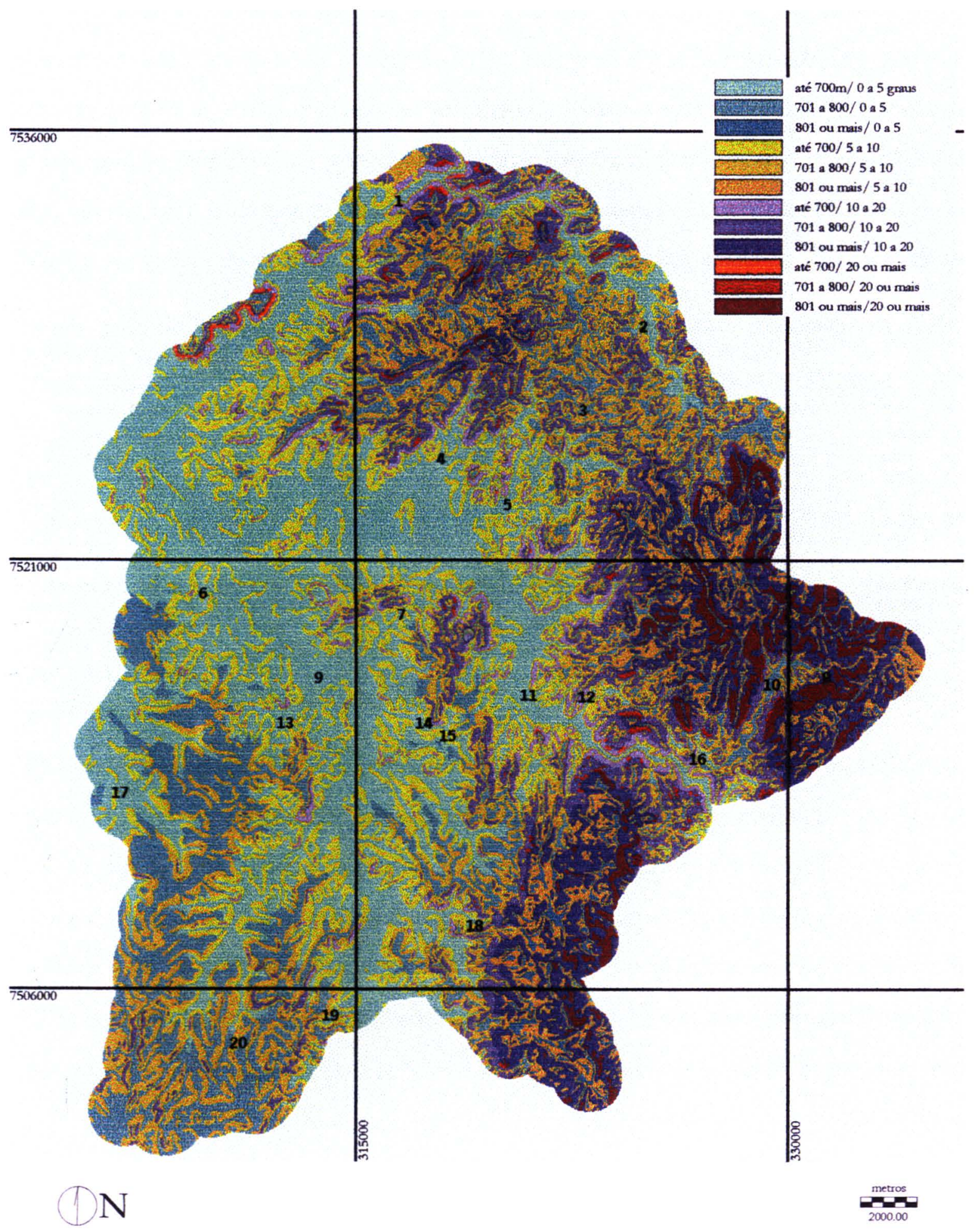

Figura 6: Distribuição dos LPTs em relação às classes de relevo no município de Itapira, SP. 
mais altas e de maior declividade possuiam proporcionalmente maior área coberta por matas.

A distribuição dos LPTs e das áreas de colonização rural, estimada pela localização das edificações existentes em 1972, em relação à distribuição de terras do municipio por classes de altitude/declividade, estão apresentadas na tabela 3. Pode-se observar que a distribuição da colonização no município era inversamente proporcional às classes de altitude/declividade, ou seja, quanto maior a altitude e a declividade, menor era o número de edificações. As áreas até $700 \mathrm{~m}$ e até 5 graus de declividade abrigavam $44 \%$ das edificações rurais em 1972 e $55 \%$ dos

Tabela 3: Locais de provável transmissăo de LTA, edificaçőes rurais existentes em 1972 e distribuiçăo das terras do municipio, por classes de altitude/declividade, Itapira, SP.

\begin{tabular}{|c|c|c|c|c|c|c|c|c|c|c|c|c|}
\hline \multirow{2}{*}{\multicolumn{2}{|c|}{$\begin{array}{l}\text { classe altilude(m) } \\
\text { dectividade(graus) }\end{array}$}} & \multicolumn{2}{|c|}{ clesses } & \multicolumn{3}{|c|}{ cases rurais en 1972} & \multicolumn{3}{|c|}{ nes residencias do LPT } & \multicolumn{3}{|c|}{ classe mbxima do LPT } \\
\hline & & area (ha) & \% da sirea & \multicolumn{3}{|c|}{ ncmero \% do total densid. } & \multicolumn{3}{|c|}{ nimero \% do total densid. } & \multicolumn{2}{|c|}{ nimero \% do total } & densid. \\
\hline ate $700 \mathrm{I}$ & Or & 17847.00 & 27.50\% & 1081 & $44.41 \%$ & 6.06 & 11 & $55.00 \%$ & 0.08 & 1 & $5.00 \%$ & 0.01 \\
\hline 701 a 8001 & $\mathbf{O}_{\vdash}$ & 8164.71 & $1250 \%$ & 273 & $11.22 \%$ & 3.34 & 3 & $15.00 \%$ & 0.04 & 0 & $0.00 \%$ & $0 . \infty 0$ \\
\hline 801 ou mais 1 & $0 \vdash$ & 937.35 & $1.44 \%$ & 80 & $3.20 \%$ & 853 & 0 & $0.00 \%$ & 0.00 & 0 & $0.00 \%$ & 0.00 \\
\hline atb $700 \mathrm{l}$ & $5 \vdash 10$ & 9843.12 & $15.17 \%$ & 427 & $1754 \%$ & 434 & 5 & $25.00 \%$ & 0.05 & 7 & $3500 \%$ & 0.07 \\
\hline $\mathrm{TOH}$ a $800 \mathrm{l}$ & $5 \vdash 10$ & 9528.12 & $14.6 \% \%$ & 285 & $11.71 \%$ & 299 & 0 & $0.00 \%$ & 0.00 & 6 & $30.00 \%$ & 0.06 \\
\hline 801 ou mais 1 & $5 \vdash 10$ & 273584 & $4.21 \%$ & 111 & $4.56 \%$ & 4.06 & 0 & $0.00 \%$ & 0.00 & 0 & $0.00 \%$ & 0.00 \\
\hline ate 7001 & $10 \vdash 20$ & 2283.75 & $3.52 \%$ & 32 & $1.31 \%$ & 1.40 & 0 & $0.00 \%$ & 0.00 & 5 & $25.00 \%$ & 0.22 \\
\hline $701 \times 8001$ & $10 \vdash 20$ & 6082.56 & $9.37 \%$ & 72 & $2.98 \%$ & 1.18 & 0 & $0.00 \%$ & 0.00 & 0 & $0.00 \%$ & 0.00 \\
\hline 801 ou mais I & $10 \vdash 20$ & 5514.39 & $8.50 \%$ & 68 & $2.79 \%$ & 1.23 & 1 & $5.00 \%$ & 0.02 & 0 & $0.00 \%$ & 0.00 \\
\hline$a t b 700 / 2$ & 20 ou mais & 86.67 & $0.13 \%$ & 0 & $0.00 \%$ & 0.00 & 0 & $0.00 \%$ & 0.00 & 0 & $0.00 \%$ & 0.00 \\
\hline $701 \times 800 / 2$ & 20 ou mais & 305.01 & $0.47 \%$ & 1 & $0.04 \%$ & 0.33 & 0 & $0.00 \%$ & 0.00 & 0 & $0.00 \%$ & 0.00 \\
\hline 801 ou mais 12 & 20 oume's & 1581.5 & $2.41 \%$ & 4 & Q.16\% & 026 & 0 & $0.00 \%$ & 0.00 & 1 & $5.00 \%$ & 0.06 \\
\hline Total & & 64898.11 & $100.00 \%$ & 2434 & $100.00 \%$ & 3.75 & 20 & $100.00 \%$ & 0.03 & 20 & $100.00 \%$ & 0.03 \\
\hline
\end{tabular}

LPTs, enquanto apenas $27 \%$ das terras do municipio situam-se nesta classe. As áreas de menor declividade foram aquelas preferidas para o estabelecimento das edificações rurais, fato evidenciado pela distribuição da densidade de moradias por classe de altitude/declividade. Por sua vez, a grande maioria dos LPTs $(80 \%)$ situava-se em altitudes de até $700 \mathrm{~m}$ e de declividade inferior a 10 graus. Porém considerando-se as altitude e declividades máximas existente no LPT, estes localizavam-se próximos a áreas mais íngremes. Esta configuração concorda com o que pode ser visualizado na Figura 6, ou seja, os LPTs situam-se nos vales dos cursos de água.

As relações de distância entre os LPTs e suas matas associadas e a quantificação das mesmas em número de fragmentos e área de cobertura por classe de distância, podem ser observadas na tabela 4. A distância minima entre um LPT e a mata mais próxima variou de um mínimo de $30 \mathrm{~m}$ até um máximo de $433 \mathrm{~m}$, sendo a mediana $201 \mathrm{~m}$. A quantidade de fragmentos 
Tabela 4: Distância mínima entre os fragmentos de matas e os LPT ; área das matas associadas aos LPT, em ha, e número de fragmentos $(n)$, segundo classes de raio de distância(m). Itapira, SP.

\begin{tabular}{|c|c|c|c|c|c|c|c|}
\hline \multirow{2}{*}{ Local } & \multirow{2}{*}{$\begin{array}{c}\text { Dist.minima } \\
(\mathrm{m})\end{array}$} & \multicolumn{6}{|c|}{ Classes de distância } \\
\hline & & $\leq 200$ & $201-300$ & $301-400$ & $401-500$ & $501-600$ & Total \\
\hline 1 & 433 & & & & $5.76(2)$ & & $5.76(2)$ \\
\hline 2 & 391 & & & $1.44(1)$ & $64.89(2)$ & $27(2)$ & $93.33(5)$ \\
\hline 3 & 228 & & $8.73(4)$ & $27.99(1)$ & & $0.81(1)$ & $37.53(6)$ \\
\hline 4 & 67 & $4.68(2)$ & 3.42 (1) & & $1.35(1)$ & $23.22(1)$ & $32.67(5)$ \\
\hline 5 & 258 & & $2.52(1)$ & & & $0.54(2)$ & $3.06(2)$ \\
\hline 6 & 361 & & & $3.6(1)$ & & & $3.6(1)$ \\
\hline 7 & 127 & $1.8(2)$ & & $1.35(1)$ & $0.72(1)$ & $0.9(1)$ & $4.77(5)$ \\
\hline 8 & 309 & & & $434.88(4)$ & $1.89(1)$ & $1.53(2)$ & $438.3(7)$ \\
\hline 10 & 218 & & $0.9(1)$ & 40.77 ( 2) & $1.8(1)$ & $126.18(1)$ & $169.65(5)$ \\
\hline 11 & 108 & $30.69(1)$ & & & & & $30.69(1)$ \\
\hline 12 & 182 & $0.99(1)$ & & & & & $0.99(1)$ \\
\hline 13 & 150 & $2.34(1)$ & & $0.72(1)$ & & $0.63(1)$ & $3.69(3)$ \\
\hline 14 & 424 & & & & $8.37(2)$ & & $8.37(2)$ \\
\hline 15 & 201 & & $6.12(1)$ & & & $0.54(1)$ & 6.66 ( 2) \\
\hline 16 & 30 & $4.68(1)$ & & & $0.99(1)$ & & 5.67 ( 2) \\
\hline 17 & 379 & & & $0.99(1)$ & $1.89(1)$ & $17.01(2)$ & 19.89 ( 4 ) \\
\hline 18 & 42 & $40.05(1)$ & & & & $5.04(1)$ & $45.09(2)$ \\
\hline 19 & 85 & $1.62(1)$ & & & & $2.34(1)$ & 3.96 ( 2 ) \\
\hline 20 & 30 & $140.58(1)$ & & & $1.17(1)$ & & $141.75(2)$ \\
\hline Total & & $227.43(11)$ & $21.69(8)$ & $511.74(12)$ & $88.83(13)$ & $205.74(15)$ & $1055.43(59)$ \\
\hline
\end{tabular}

Tabela 5: Área de cobertura das matas associadas aos LPT, em ha, e número de fragmentos $(n)$, segundo sua relação com a hidrografia e relevo, Itapira, SP.

\begin{tabular}{|c|c|c|c|c|}
\hline \multirow[t]{2}{*}{ LPT } & ciliar & \multicolumn{2}{|l|}{ mista } & encosta \\
\hline & & & a várzea & \\
\hline 1 & & & & $5.76(2)$ \\
\hline 2 & $1.44(1)$ & $59.22(1)$ & 10.00 & 32.67 ( 3 ) \\
\hline 3 & $6.48(1)$ & $27.99(1)$ & 17.01 & $3.06(4)$ \\
\hline 4 & $4.68(2)$ & $3.42(1)$ & 3.51 & $24.57(2)$ \\
\hline 5 & & $2.52(1)$ & 0.09 & $0.54(1)$ \\
\hline 6 & & & & $3.6(1)$ \\
\hline 7 & $0.72(1)$ & & & $4.05(4)$ \\
\hline 8 & & & & $438.3(7)$ \\
\hline 10 & & $38.7(1)$ & 3.69 & $130.95(4)$ \\
\hline 11 & & $30.69(1)$ & 3.33 & \\
\hline 12 & & & & $0.99(1)$ \\
\hline 13 & & & & $3.69(3)$ \\
\hline 14 & & $6.84(1)$ & 0.45 & $1.53(1)$ \\
\hline 15 & & $6.12(1)$ & 1.62 & $0.54(1)$ \\
\hline 16 & & $4.68(1)$ & 0.54 & $0.99(1)$ \\
\hline 17 & & $8.64(1)$ & 1.08 & $11.25(3)$ \\
\hline 18 & & $5.04(1)$ & 1.71 & $40.05(1)$ \\
\hline 19 & $1.62(1)$ & $2.34(1)$ & 1.53 & \\
\hline 20 & & $140.58(1)$ & 15.75 & $1.17(1)$ \\
\hline Total & $14.94(6)$ & $336.78(13)$ & 60.31 & $703.71(40)$ \\
\hline
\end{tabular}


presentes nas proximidades dos casos variou de uma unidade até um máximo de sete. Nota-se também que a quantidade de mata presente nas proximidades de um LPT variou de cerca de 1ha (situado a cerca de $220 \mathrm{~m}$ do LPT 12) até um máximo de 438 ha (representado pela área total de 7 fragmentos localizados junto ao LPT 8). Em 45\% dos LPTs havia uma quantidade de mata superior a 19 ha e nos $55 \%$ restantes, esta quantidade variava de 1 ha até um máximo de 8,4 ha.

As matas associadas aos LPTs, classificadas segundo sua relação com a hidrografia podem ser vistas na Figura 7. Pode ser verificado, que poucas matas associadas aos LPTs estavam localizadas próximo aos dois principais rios existentes no município, o rio Mogi Guaçu e o rio do Peixe. Na tabela 5 verifica-se que havia predominância de matas não associadas a rios. A quantidade de matas ciliares era reduzida, seja em número seja em área coberta e estavam presentes em poucos LPTs, entretanto se consideramos as matas mistas, a quantidade de LPT que tinham matas relacionadas a rios aumenta. Em cinco locais havia somente matas de encosta.

Os dados relativos à vegetação existente na área peridomiciliar dos LPTs discriminada através do indice de vegetação (NDVI) estão apresentados na tabela 6. Apresentamos no quadro 1 a descrição das vegetações correspondentes às classes de NDVI, alto e médio. A vegetação correspondente à classe de NDVI baixo correspondia, em geral, a pastagens ou a arbustos esparsos. A classe de vegetação de NDVI médio recobria parte significativa da área peridomiciliar, independentemente da localização das matas em relação ao raio de $200 \mathrm{~m}$ do domicílio. Encontravam-se associadas a esta classe de NDVI na maioria dos casos, vegetação arbustiva nativa em processo de regeneração ou degradação e, em menor freqüência, bosques de árvores frutíferas ou ornamentais, bambuzais e eucalipto em regeneração. No caso de vegetação de NDVI alto, a proporção de área coberta nos peridomicílios com matas no raio de $200 \mathrm{~m}$ foi maior, no entanto, estava associada a outros tipos de vegetação como plantações de café, em dois casos, e eucalipto misturado à mata, em um dos locais. 


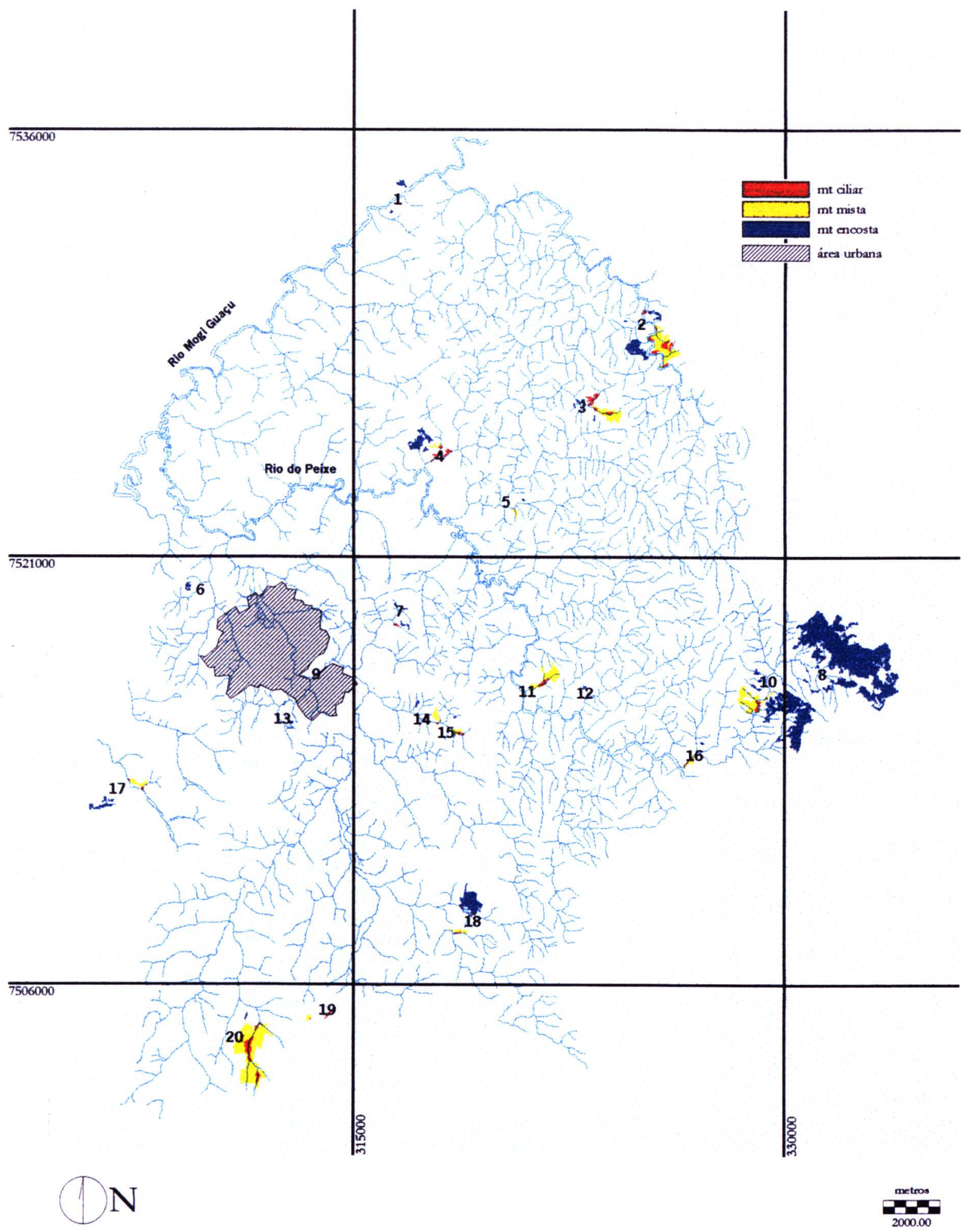

Figura 7: Distribuição das matas associadas aos LPTs classificadas segundo sua relação com a hidrografia, no município de Itapira, SP, 1999. 
Tabela 6: Classes de índice de vegetação (NDVI) por LPT agrupado por níveis de distância da mata mais próxima, Itapira, 1999.

\begin{tabular}{|c|c|c|c|c|c|c|c|c|c|}
\hline \multirow{4}{*}{$\begin{array}{l}\text { Distância da mata } \\
\text { até } 200 \mathrm{~m}\end{array}$} & \multirow[b]{3}{*}{ LPT } & \multicolumn{8}{|c|}{ Classe de NDVI } \\
\hline & & \multicolumn{2}{|c|}{ baixo } & \multicolumn{2}{|c|}{ médio } & \multicolumn{2}{|c|}{ alto } & \multicolumn{2}{|c|}{ sem vegetaçâo } \\
\hline & & área (ha) & $\%$ & área (ha) & $\%$ & área (ha) & $\%$ & área (ha) & $\%$ \\
\hline & 4 & 1.89 & 14.09 & 4.32 & 32.21 & 2.97 & 22.15 & 4.23 & 31.54 \\
\hline & 7 & 2.16 & 16.11 & 4.32 & 32.21 & 2.25 & 16.78 & 4.68 & 34.90 \\
\hline & 11 & 2.52 & 18.79 & 2.79 & 20.81 & 2.07 & 15.44 & 6.03 & 44.97 \\
\hline & 12 & 4.05 & 30.20 & 5.31 & 39.60 & 0.45 & 3.36 & 3.60 & 26.85 \\
\hline & 13 & 1.71 & 12.75 & 2.61 & 19.46 & 2.88 & 21.48 & 18.63 & 72.13 \\
\hline & 16 & 2.61 & 19.46 & 4.95 & 36.91 & 2.43 & 18.12 & 3.42 & 25.50 \\
\hline & 18 & 2.07 & 15.44 & 4.59 & 34.23 & 2.97 & 22.15 & 3.78 & 28.19 \\
\hline & 19 & 2.88 & 21.48 & 5.67 & 42.28 & 2.07 & 15.44 & 2.79 & 20.81 \\
\hline & 20 & 1.31 & 9.77 & 2.52 & 18.79 & 5.76 & 42.95 & 3.82 & 28.49 \\
\hline \multicolumn{2}{|l|}{ Mediana } & 2.16 & 16.11 & 4.32 & 32.21 & 2.43 & 18.12 & 3.82 & 28.49 \\
\hline \multirow[t]{11}{*}{ mais de $200 \mathrm{~m}$} & 1 & 2.52 & 18.79 & 2.97 & 22.15 & 1.80 & 13.42 & 6.12 & 45.64 \\
\hline & 2 & 0.63 & 4.70 & 1.26 & 9.40 & 0.18 & 1.34 & 11.34 & 84.56 \\
\hline & 3 & 2.70 & 20.13 & 4.77 & 35.57 & 3.06 & 22.82 & 2.88 & 21.48 \\
\hline & 5 & 2.97 & 11.50 & 6.03 & 23.34 & 0.90 & 3.48 & 3.51 & 26.17 \\
\hline & 6 & 1.53 & $11.41^{\circ}$ & 1.35 & 10.07 & 0.09 & 0.67 & 10.44 & 77.85 \\
\hline & 8 & 3.42 & 25.50 & 5.67 & 42.28 & 2.07 & 15.44 & 2.25 & 16.78 \\
\hline & 9 & 1.80 & 13.42 & 0.54 & 4.03 & 0.00 & 0.00 & 11.07 & 82.55 \\
\hline & 10 & 3.87 & 28.86 & 6.66 & 49.66 & 0.45 & 3.36 & 2.43 & 18.12 \\
\hline & 14 & 1.98 & 14.77 & 2.70 & 20.13 & 0.18 & 1.34 & 8.55 & 63.76 \\
\hline & 15 & 2.43 & 18.12 & 4.23 & 31.54 & 0.72 & 5.37 & 6.03 & 44.97 \\
\hline & 17 & 3.96 & 29.53 & 3.87 & 28.86 & 1.26 & 9.40 & 4.32 & 32.21 \\
\hline Mediana & & 2.52 & 18.12 & 3.87 & 23.34 & 0.72 & 3.48 & 6.03 & 44.97 \\
\hline
\end{tabular}

Quadro 1: Descrição das classes de vegetação média e alta (NDVI), presentes no peridomicílio dos locais de provável transmissão de LTA, Itapira, SP.

\begin{tabular}{|c|c|c|}
\hline \multicolumn{3}{|c|}{ Classes de vegetaçã̃o } \\
\hline Local & média & alta \\
\hline 1 & Mata nativa degradada ou em regeneração & Mata nativa em regeneração \\
\hline 2 & Mata degradada ou em regeneração na mangem de rio & $f$ \\
\hline 3 & Mata nativa degradada ou em regeneraçäo & Café na maior parte, mata nativa em regeneração \\
\hline 4 & Bosque, veget. degradada ou em regenenação, pomar & Mata \\
\hline 5 & Mata nativa degradada ou em regeneração, eucalipto, bambuzal & \\
\hline 6 & Bambuzal, pomar de lacanja & \\
\hline 7 & Mata nativa degradada ou em regeneração, bosque de mangueiras & \\
\hline 8 & Mata nativa degradada ou em regeneração & Mata nativa em regeneração \\
\hline 9 & Vegetação arbórea degradada na margem de rio & \\
\hline 10 & Mata nativa degradada ou em regeneração & Mata nativa em regeneração \\
\hline 11 & Mata degradada ou em regeneração na margem de rio & Mata \\
\hline 12 & Mata nativa degradada ou em regeneração & Mata \\
\hline 13 & Mata nativa degradada ou em regeneração & Eucalipto \\
\hline 14 & Mata nativa degradada ou em regeneração, bosque de árvores frutíferas & \\
\hline 15 & Mata nativa degradada ou em regeneraçāo, bosque de árvores frutireras & Mata \\
\hline 16 & Bosque de frutiferas e árvores omamentais & Mata \\
\hline 17 & Mata nativa degradada ou em regeneração & Mata em regeneraçâo e mata ciliar em regeneração \\
\hline 18 & Mata nativa degradada ou em regeneraçäo & Mata \\
\hline
\end{tabular}


As figuras 8a e 8b mostram a vegetação de NDVI médio distribuída por LPT, no raio de até $600 \mathrm{~m}$ das residências e as matas associadas. Através destas figuras é possivel notar que na maioria dos LPTs as vegetações que apresentavam NDVI médio estavam dispostas de modo a formar corredores de vegetação entre as matas e o domicílio. Chamam a atenção o LPT de número 9, situado em área urbana, sem mata nas proximidades e com pouca vegetação de NDVI médio, assim como também o LPT 13 pela sua proximidade com a área urbana.

O resultado das coletas de flebotomíneos realizadas em 12 dos 20 LPTs, conforme apresentado na tabela 7 , mostra que todas as cinco espécies suspeitas de serem transmissoras

Tabela 7: Espécies de flebotomíneos coletadas em 12 LPT, 1992 a 1998, Itapira, SP

\begin{tabular}{|c|c|c|c|c|c|c|c|c|c|c|c|c|c|}
\hline \multirow{3}{*}{$\begin{array}{l}\text { espécie } \\
\text { L. borgmeieri }\end{array}$} & \multicolumn{12}{|c|}{ Local de Provável Transmissâo } & \multirow[b]{2}{*}{ Total } \\
\hline & 1 & 2 & 4 & 5 & 6 & 11 & 12 & 13 & 16 & 17 & 19 & 20 & \\
\hline & & & & & 1 & & & & & & & & 1 \\
\hline L. firmatoi & & & 4 & & & 1 & & & & & 1 & & 6 \\
\hline L. fischeri & & & 2 & & & & & & & & 1 & 8 & 11 \\
\hline L. intermedia & 4 & 27 & 35 & 16 & 1 & 6 & 1 & 7 & & 8 & 1 & & 106 \\
\hline L. migonei & & & 3 & & & & & & & & 2 & 4 & 9 \\
\hline L. monticola & & & & & & 1 & & & & & & 1 & 2 \\
\hline L. pessoai & & & 1 & & & & & & & 6 & & & 7 \\
\hline L. sallesi & & & 1 & & & & & & & & & & 1 \\
\hline L. whitmani & & & 8 & 6 & 6 & 8 & 9 & & 14 & 2 & 12 & 7 & 72 \\
\hline Total & 4 & 27 & 54 & 22 & 8 & 16 & 10 & 7 & 14 & 16 & 17 & 20 & 215 \\
\hline
\end{tabular}

Tabela 8: Coletas de flebotomíneos realizadas em 12 dos LPT, Itapira, 1992 a 1998.

\begin{tabular}{|c|c|c|c|c|c|c|c|}
\hline \multirow{2}{*}{$\begin{array}{l}\text { Diatânela da mata } \\
\text { atte } 200 \mathrm{~m}\end{array}$} & \multirow[b]{2}{*}{ esplele } & \multicolumn{2}{|c|}{ Colotas em área domicllitar } & \multicolumn{2}{|c|}{ Coletas em área de mata } & \multicolumn{2}{|c|}{ mata mals próxima (ha) } \\
\hline & & N colotas & Nespbeimes & N colotas & N espielmes & mener & malor \\
\hline & L. frmatoi & 2 & 2 & 1 & 4 & 1.62 & 30.69 \\
\hline & L. fischeri & 1 & 1 & 2 & 10 & 1.62 & 140.58 \\
\hline & L. intermedis & 5 & 45 & 1 & 5 & 0.99 & 30.69 \\
\hline & L. migonei & 3 & 6 & 2 & 3 & 1.62 & 140.58 \\
\hline & L. monticole & 2 & 2 & & & 30.69 & 140.58 \\
\hline & L. pessoai & & & 1 & 1 & 1.80 & 1.80 \\
\hline & L. sallosi & & & 1 & 1 & 1.80 & 1.80 \\
\hline & L. whameni & 5 & 49 & 2 & 9 & 0.99 & 140.58 \\
\hline \multicolumn{8}{|l|}{ mais de $200 \mathrm{~m}$} \\
\hline & L. borgmeieri & 1 & 1 & & & 3.60 & 3.60 \\
\hline & L. intermedia & 5 & 33 & 1 & 23 & 0.81 & 3.60 \\
\hline & L. pessoai & 1 & 6 & & & 0.99 & 0.99 \\
\hline & L. whitmani & 3 & 14 & & & 0.99 & 3.60 \\
\hline Total de coletas & & 12 & & 3 & & & \\
\hline
\end{tabular}



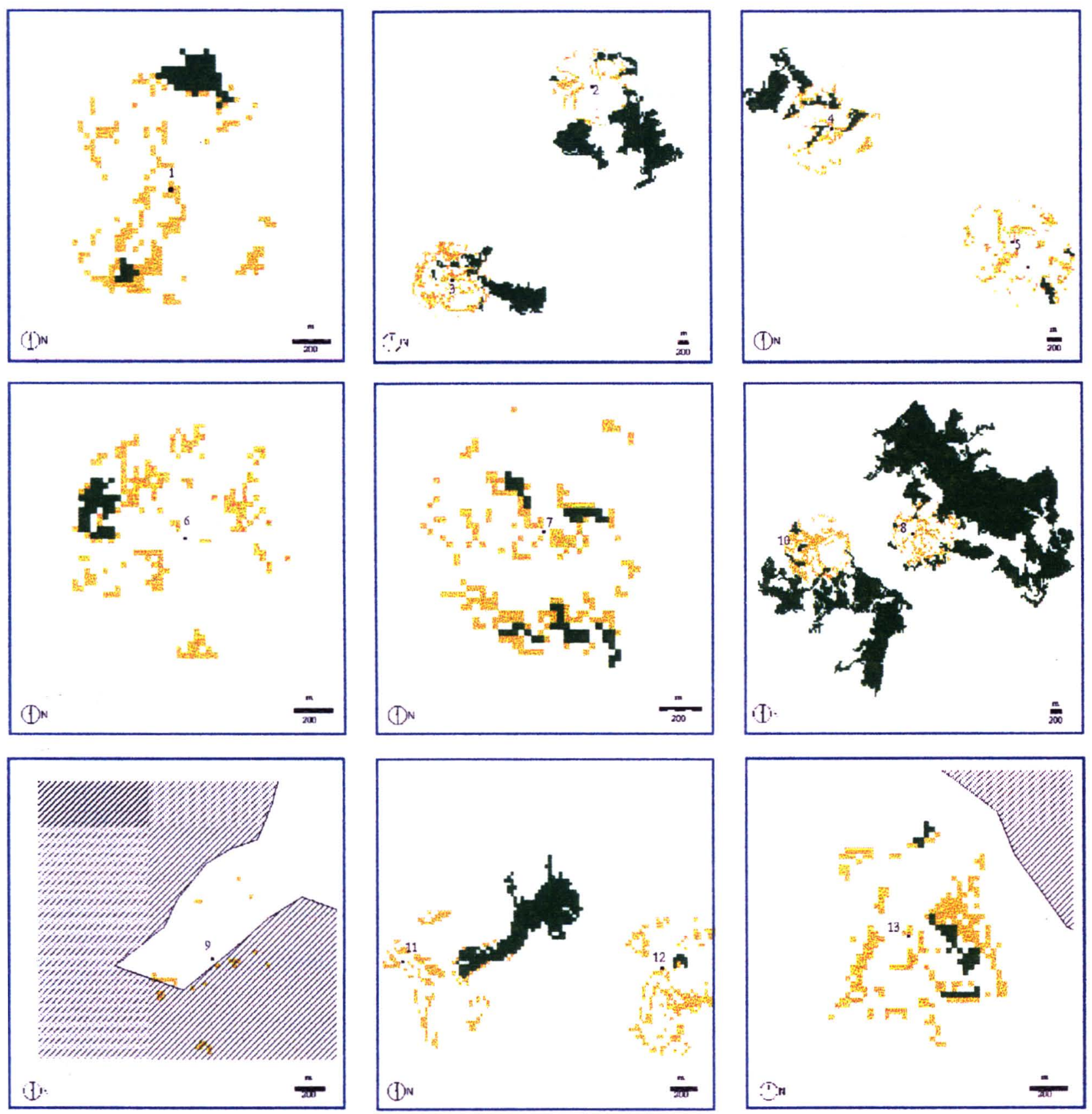

Matas associadas

Vegetação de NDVI médio

Área urbana

Figura 8a: Vegetação de NDVI médio presente em um raio de $600 \mathrm{~m}$ do domicílio e as matas associadas aos LPTs 1 a 13, Itapira, 1999. 

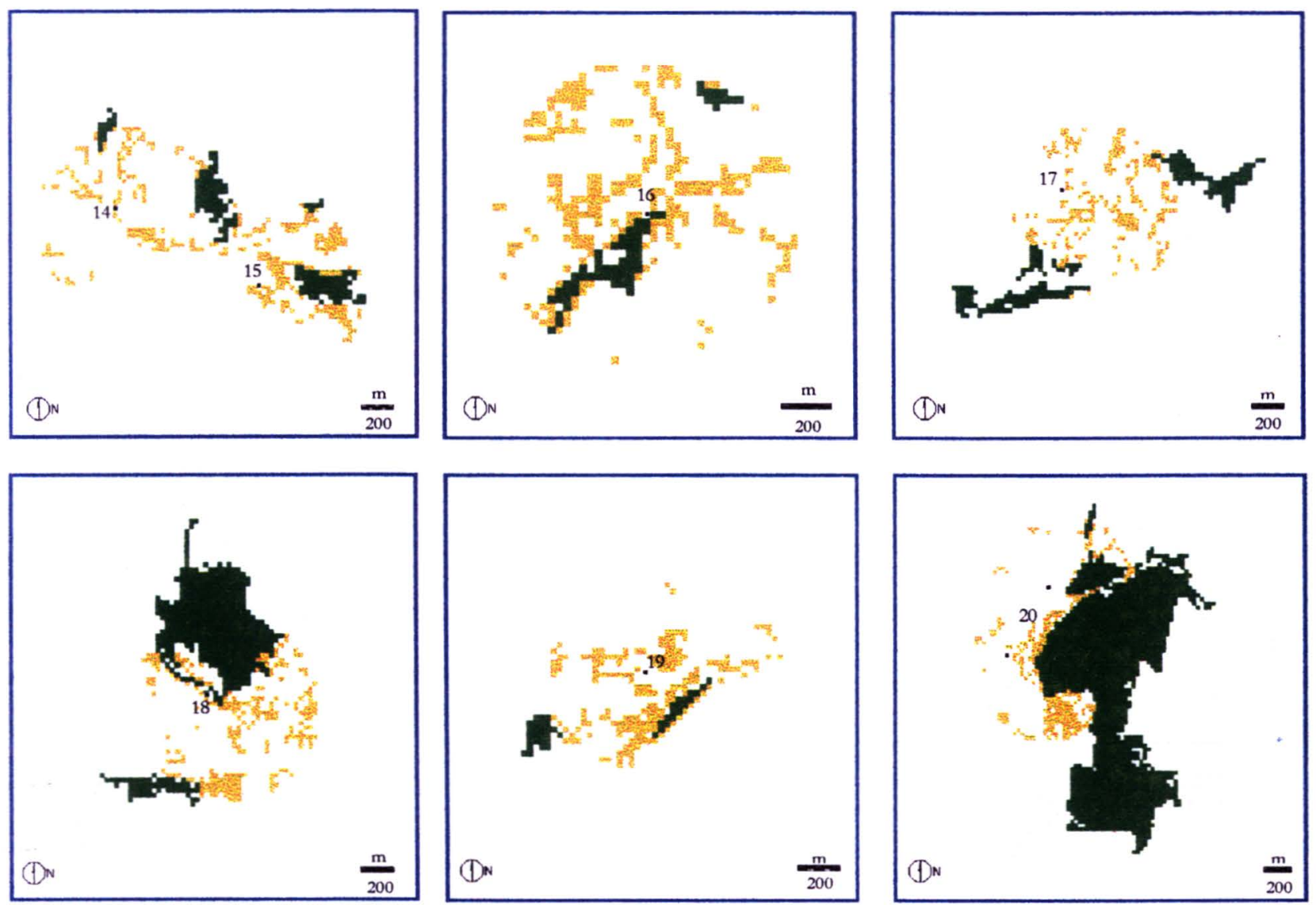

Matas associadas

Vegetação de NDVI médio

Figura 8b: Vegetação de NDVI médio presente em um raio de $600 \mathrm{~m}$ do domicílio e as matas associadas aos LPTs 14 a 20, Itapira, 1999 
da LTA no Estado de São Paulo estavam presentes. Destaca-se, que as espécies $L$ intermedia e L whitmani estavam presentes em maior numero de locais e em maiores quantidades. Em alguns locais registrou-se a presença de $L$ intermedia e a ausência de $L$ whitmani, enquanto em outros, esta última espécie foi registrada na ausência de $L$ intermédia.

As figuras 9 e 10 mostram a distribuição de $L$ intermédia e $L$ wbitmani respectivamente em relação às matas associadas classificadas conforme sua relação com a hidrografia em relação às classes de relevo.

$\mathrm{Na}$ tabela 8 verificamos as diferenças entre as espécies presentes em coletas esporádicas realizadas em doze dos LPTs, em função da distância relativa entre as matas e a residência. Nos locais em que as matas estavam localizadas num raio de $200 \mathrm{~m}$ da residência, a riqueza de espécies era maior. $\mathrm{O}$ número de locais em que $L$ intermedia e $L$ whitmani foram coletadas, não apresentou diferenças significativas entre os dois grupos. 


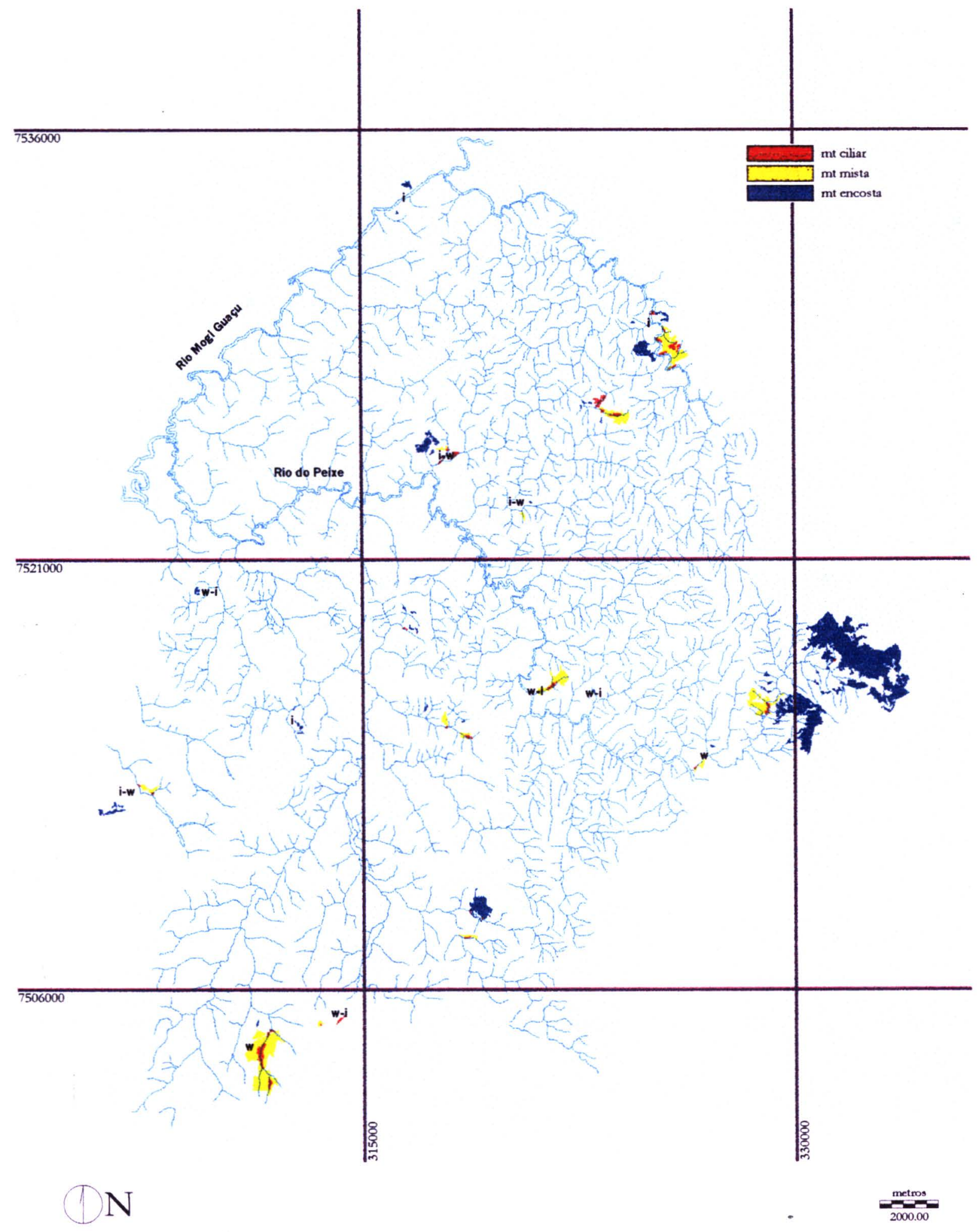

Figura 9: Distribuição de L. intermedia ( i ) e L. whitmani ( w ) por LP'T, segundo dados de coletas realizadas entre 1992 e 1998 em Itapira, SP, em relação às matas associadas aos LP'Ts classificadas segundo sua relação com hidrografia. 


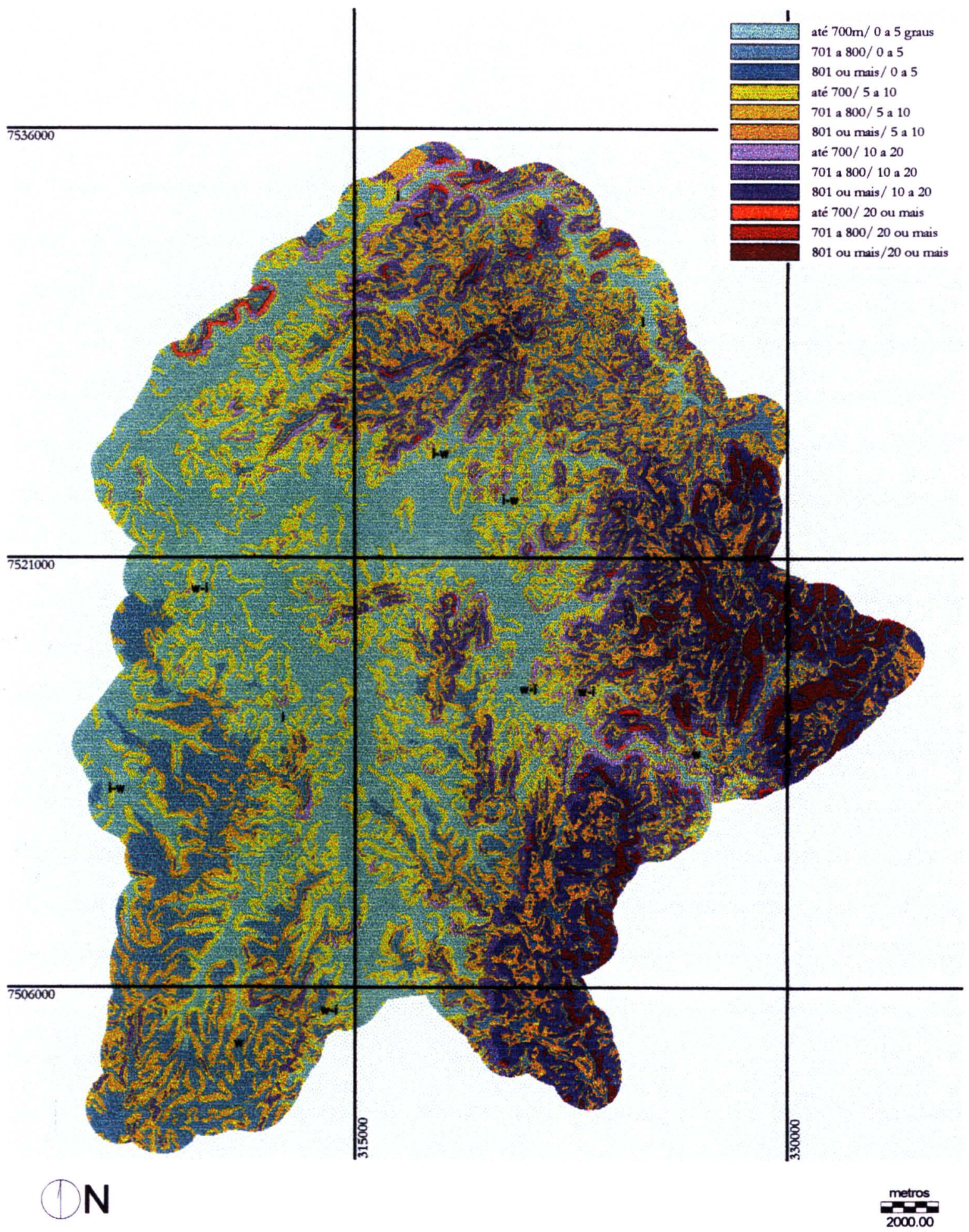

Figura 10: Distribuição de L intermedia ( i ) e L. whitmani ( w ) por LPT, segundo dados de coletas realizadas entre 1992 e 1998 em Itapira, SP, em relação ao relevo. 


\section{DISCUSSÃO}

Há consenso entre os pesquisadores que nas áreas agrícolas do interior do Estado do São Paulo, assim como no Nordeste, Sudeste e Sul do Brasil, a transmissão ao homem do agente da leishmaniose tegumentar americana (provavelmente $L$ (V.) braziliensis) ocorra no ambiente domiciliar (GRIMALDI et al. 1989).

No município de Itapira, uma primeira caracterização dos casos notificados entre 1992 e 1998, apontando ausência de casos em crianças, maior freqüência em indivíduos do sexo masculino e a grande maioria dos casos representada por indivíduos ligados à atividade rural, levaria a supor que a transmissão da LTA no município fosse extradomiciliar, ao contrário do que está descrito para outros locais do Vale do Rio Mogi Guaçu (MASCARINI et al. 1994) e outras áreas do Estado de São Paulo (KATZ 1997). Entretanto, as entrevistas mostraram que a grande maioria dos casos não relatava atividades noturnas em áreas de matas residuais que justificassem o contato com vetores da LTA nestes ambientes. Em apenas um caso a atividade profissional pode ser responsabilizada pelo contato homemvetor em área próxima de mata. Na mesma localidade rural, distante cerca de $100 \mathrm{~m}$ do local de provável transmissão desta ocorrência, encontramos em uma mesma casa dois casos de LTA com suspeita de transmissão domiciliar. Assim, o fato de encontrarmos uma proporção grande de casos em trabalhadores rurais não implica que estes estejam expostos ao contato com o vetor em áreas de matas, pois a atividade rural em si não é um indicador de transmissão extradomiciliar.

Pelo acima exposto, pode-se assumir que a transmissão do parasito aos casos estudados, exceto um, tem grande possibilidade de ter ocorrido em área domiciliar.

A metodologia empregada neste trabalho permitiu fazer uma descrição pormenorizada de alguns fatores ambientais que poderiam dar suporte a esta forma de transmissão. Alguns destes fatores já foram estudados seja em escala local, em focos 
individualizados, seja em escala mais ampla, através de metodologias tradicionais. Outros são descritos ou mensurados pela primeira vez fornecendo novos parâmetros de análise que podem contribuir para o esclarecimento de questões relativas à ecoepidemiologia da LTA.

A identificação dos fragmentos de matas residuais permitiu verificar que o percentual de cobertura do município (de cerca de $8,3 \%$ ) era comparável ao valor calculado para a Região Administrativa de Campinas, aproximadamente 7,7\% em 1992 (valor calculado a partir dos dados de KRONKA et al. (1993), considerando-se as categorias de mata e capoeiras).

Algumas observações chamam a atenção sobre a importância das matas residuais na transmissão da leishmaniose tegumentar no município em questão: 1) a área total de matas dos 59 fragmentos representa cerca de $20 \%$ da cobertura total de matas do município, podendo significar que os LPTs estariam associados a grandes fragmentos; 2) entretanto o tamanho mínimo do fragmento ou mesmo a menor quantidade total de matas presente em um LPTs (tabelas 1 e 5) que parecem condicionar a ocorrência de casos foram relativamente pequenos (cerca de 1ha); 3) a presença constante de matas junto aos locais de provável transmissão pode significar que esta é uma condição necessária para a transmissão.

O significado do tamanho das matas para a transmissão de LTA é desconhecido, tanto em relação aos possíveis reservatórios da Leishmania $(V$.$) braziliensis como em relação às$ populações de espécies de flebotomíneos envolvidas no ciclo zoonótico. Entretanto, como as matas nativas eram o ambiente primitivo onde a zoonose se mantinha, pode-se supor que um ambiente em melhor estado de conservação, representaria melhores condições para a manutenção das populações de flebotomineos e reservatórios. Por outro lado, é importante notar que a vegetação arbórea presente na região de estudo parece ser, em sua maioria, de crescimento secundário, fruto da exploração das terras para fins agrícolas com o conseqüente desmatamento da vegetação nativa, que já havia se iniciado em fins do século XIX. Portanto, pode-se supor que: se o ciclo zoonótico da leishmaniose persiste nesta região, os elementos participantes de sua cadeia já passaram por processo de adaptação a este ambiente alterado.

Os processos de fragmentação podem "afetar negativamente a biodiversidade original 
das florestas, no nível de genes, de espécies e de associações entre espécies" (ZUIDEMA et al., 1996). Segundo estes autores, o tamanho do fragmento tem sido o mais estudado dentre os vários fatores que podem afetar a biodiversidade. As áreas abertas contíguas aos fragmentos florestais propiciam temperaturas do ar mais altas, maior grau de insolação, maior velocidade do vento e menor umidade do ar e do solo nas áreas marginais das matas, quando comparadas com as vigentes no seu interior. Ainda segundo os autores, os efeitos de borda podem penetrar de 50 a $250 \mathrm{~m}$ a partir da margem das matas. Em pequenos fragmentos a proporção da área afetada por este efeito de borda em relação a área interna é significativa, reduzindo a área favorável a espécies cujo habitat é o interior das de matas, enquanto poderiam favorecer espécies que se adaptam bem a áreas marginais. Estes mesmos pesquisadores citam ainda trabalhos que mostram que em um fragmento de 1 ha, o efeito marginal prevalece e nenhuma área é mantida nas condições microclimáticas originais. Em se tratando de fauna, o efeito do tamanho do fragmento sobre determinada população depende também do tamanho da área de vida da espécie em questão e da sua capacidade de se deslocar de um fragmento para outro, ou seja do isolamento relativo dos fragmentos para estas espécies. Em relação a esse fator os autores citados encontraram poucos trabalhos na literatura levantada e comentam que isto provavelmente deve-se à dificuldade e complexidade em definir o que é isolamento para uma determinada espécie.

Em relação à área de vida das espécies de roedores prováveis de exercerem a função de reservatórios da leishmaniose tegumentar em áreas do Estado de São Paulo, ALHO, PEREIRA e PAULA (1986) encontraram valores de 0,22ha para Oryzomys capito e de 0,4ha para Akodon cursor em área de mata ciliar na região dos cerrados do Brasil Central. Portanto, os fragmentos de matas encontrados os locais de provável transmissão de LTA poderiam ter dimensões com capacidade de abrigar populações destes roedores. Entretanto em face da inexistência de dados sobre reservatórios, não só na região de estudo como em toda a região de distribuição de leishmaniose tegumentar no sudeste do Brasil, seria necessário que as pesquisas fossem voltadas não somente para a tentativa de isolamento de $L(V$.) braziliensis dos 
reservatórios, mas também para a aspectos de sua ecologia, tais como, habitats, área de vida e tamanho das populações.

Acredita-se que a riqueza de espécies de flebotomíneos também seja maior em matas maiores e mais preservadas. Estas condições podem ser favoráveis às populações de determinadas espécies. Entre elas pode-se citar o principal vetor nas áreas de alta endemicidade da primeira metade do século no Estado de São Paulo, $L$ whitmani espécie que estava associada à transmissão nas áreas de matas primitivas do oeste do Estado. Esta espécie muito provavelmente mantém um papel na transmissão dessa endemia em algumas áreas do Estado de São Paulo e pode estar associada aos remanescentes de matas mais preservadas (GOMES et al. 1989, TOLEZANO 1994). Por outro lado admite-se que $L$ intermedia tenha se adaptado aos ambientes alterados pelo homem ou mesmo sido favorecida pela degradação das matas, fato corroborado pela sua ampla distribuição em ambientes domiciliares (FORATTINI et al. 1976, GOMES et al. 1980, 1982, 1992).

Outro fator que foi possível medir através deste estudo, e que tem importância fundamental para a compreensão da ecoepidemiologia da LTA é a distância existente entre os fragmentos de matas e os LPTs. Admitindo-se a transmissão domiciliar aos casos humanos da LTA, a distância existente entre a mata e o domicílio passa a ser um fator condicionante tanto das formas de contato entre o ciclo silvestre e as áreas domiciliares quanto da possibilidade de existência de um ciclo domiciliar propriamente dito. Esta distância pode determinar se a Leishmania circulante no ambiente de matas tem maior probabilidade de chegar ao domicílio humano através do flebotomíneo infectado ou de um reservatório silvestre. Dependendo da distância, pode-se pensar mesmo na impossibilidade do contato entre os dois ambientes, o que favoreceria a hipótese de que um ciclo domiciliar esteja instalado. No município de Itapira, os resultados mostram que a distância máxima entre um LPTs e a mata mais próxima permitem supor um grau variado de interação entre o ciclo silvestre da LTA e a transmissão do parasito no nível domiciliar. Para efeito de análise podemos dividir os LPTs, basicamente em dois grupos: o primeiro, formado por $45 \%$ dos 
locais, possuía matas dentro de um raio de $200 \mathrm{~m}$ a partir do domicílio e o outro cujas matas mais próximas situavam-se além deste limite até cerca de $430 \mathrm{~m}$.

O primeiro grupo de casos, situa-se dentro do raio de dispersão, a partir dos criadouros, onde se espera encontrar a maior concentração das populações de flebotomíneos neotropicais. Portanto nestes locais, o contato do homem com o ciclo silvestre poderia ocorrer diretamente através de populações de flebotomíneos.

No caso da distância que separa os dois ambientes superar os $200 \mathrm{~m}$, pode-se admitir que estas condições sejam desfavoráveis para que os flebotomíneos participantes do ciclo silvestre atingissem o domicílio em densidade suficiente para ter capacidade de transmissão do parasito. Em nenhum dos dois casos pode-se descartar a possibilidade de intercâmbio entre elementos das populações domiciliadas e silvestres de flebotomíneos, ou mesmo que estas sejam essenciais para a manutenção das primeiras. Também as espécies de roedores até agora encontradas naturalmente infectadas por $L(V$.) braziliensis, ou espécie assemelhada (TOLEZANO 1994) no Estado de São Paulo, podem habitar tanto áreas de matas ou áreas mais abertas, onde a vegetação é mais degradada, podendo aproximar-se do ambiente domiciliar.

Embora em alguns focos de LTA no Brasil, tenha sido constatado a presença de cães e outros animais infectados por Leishmania, não é possível afirmar que quaisquer destes animais atuem como verdadeiro reservatório em áreas domiciliares (REITHINGEN e DAVIES 1999). Assim, o mais plausível é que a Leishmania chegue até as áreas domiciliares através de reservatórios silvestres que possam eventualmente freqüentar o peridomicílio, servindo de fonte de infecção para populações de espécies de flebotomíneos domiciliadas. Esta hipótese foi levantada por GOMES et al. (1990), complementando que, no Vale do Ribeira, a transmissão domiciliar ficaria por conta de $L$ intermedia.

Pode-se questionar se as populações de flebotomíneos necessitam de alguma condição especial em relação a vegetação arbustiva, nas áreas peridomiciliares, para o seu estabelecimento e manutenção. 
Como ficou caracterizado no presente estudo, nas áreas peridomiciliares dos LPTs, existia considerável porcentagem de área coberta ora por capoeiras, matas degradadas ou vegetação arbórea em regeneração, ora por pomares e bosques, além da presença de matas em cerca de $45 \%$ dos LPTS. Seria necessário verificar em que medida a cobertura vegetal consiste em condição para a existência de populações de flebotomíneos em densidade suficiente para ter potencial de transmissão do parasito ao homem, assim como o significado de alguns tipos de vegetação cultivada para estas populações. CAMPBELL-LENDRUM et al. (1999) mostraram que a abundância da $L$ whitmani, no Nordeste do Brasil, poderia estar associada aos remanescentes florestais e plantações de banana. Afirmam que mapas de vegetação baseados em imagens de satélite são ferramentas com alto potencial para acompanhar o efeito de mudanças de uso da terra sobre a abundância de flebotomíneos e na epidemiologia da doença e também, para produzir mapas de risco de transmissão da leishmaniose. Na Colômbia, árvores nativas deixadas para sombreamento em plantações de café têm um importante papel como local de abrigo de flebotomíneos transmissores de Leishmaniose Tegumentar (ALEXANDER 1987).

Os resultados encontrados no município de Itapira mostraram que as relações de distância entre os focos domésticos e silvestres e as condições ecológicas existentes, embora favoreçam a hipótese da transmissão no nível do domicilio, não propiciam um isolamento entre os dois ambientes e reforça a hipótese da não existência de um verdadeiro ciclo domiciliar - ou seja, que se mantenha de forma independente do silvestre.

As possibilidades de análise integrada oferecidas por um SIG permitiram verificar a influência do relevo na distribuição das matas, dos locais de provável transmissão de casos e da tendência de ocupação das áreas rurais pela população. Verificando a distribuição dos LPTs em relação a este parâmetro, nota-se que, embora a maioria das residências se localizasse em classes de baixa altitude e pouca declividade, acompanhando a distribuição das edificações rurais em 1972, sua área peridomiciliar abrangia em geral classes de altitude/declividade maiores. Embora a maior presença de matas estivesse associada às classes de maior 
declividade e nestas classes, às áreas de maior altitude, a classificação das matas em relação à hidrografia mostrou uma quantidade apreciável de matas associadas aos LPTs localizada em áreas de várzea dos rios. A localização topográfica dos LPTs em relação às classes de altitude/declividade parece confirmar o que pode ser observado no mapa de relevo: os LPTs parecem acompanhar os vales dos rios, mas estão em geral próximo às encostas. Esta localização expõe estes locais ao contato tanto das matas localizadas em áreas mais elevadas, como daquelas associadas aos rios.

No Estado de São Paulo, pouco se sabe a respeito da influência da altitude na distribuição das espécies transmissoras da leishmaniose tegumentar. A distribuição dos vetores associados à transmissão da LTA em função do relevo e outras variáveis ambientais no Estado de São Paulo foi registrada recentemente por alguns pesquisadores mostrando que $L$ whitmani e $L$ pessoai estão ausentes na Planície Costeira e presentes em todas as regiões do planalto, juntamente com $L$ intermedia, $L$ fischeri e $L$ migonei (GOMES et al. 1995; NEVES 1999). Outro caso de distribuição de espécies de flebotomíneo que poderia estar relacionado à altitude faz parte da discussão sobre a diferenciação entre $L$ intermedia e $L$ neivax: a primeira estaria restrita às áreas baixas das regiões litorâneas enquanto a segunda ocuparia as áreas de planalto (MARCONDES et al. 1998). Os resultados relativos à distribuição dos municípios com presença das principais espécies pelas grandes províncias geomorfológicas apontou que o número de municípios onde a $L$ wbitmani e de $L$ intermedia tem sido registrada, é bastante baixa (cerca de $10 \%$ ) na região topográfica do Planalto Ocidental (cujas altitudes médias situam-se na faixa de 400 a $500 \mathrm{~m}$ ) enquanto no Planalto Atlântico, (com altitudes médias situadas na casa dos $800 \mathrm{~m}$ ) esta porcentagem de municípios chega a 50\% (NEVES 1999). Deve-se ressaltar que era justamente em áreas do Planalto Ocidental que até meados do século XX L whitmani era encontrada em altas densidades nas matas primitivas então existentes, sendo responsabilizada pela alta taxa de transmissão em áreas de matas naquela região (PESSOA E BARRETO 1948). Entretanto, as metodologias e as escalas empregadas pelos trabalhos até agora realizados permitiram que as análises 
apontassem as questões mais gerais, não possibilitando esclarecer aspectos que dependessem de uma localização mais precisa das ocorrências das espécies em relação ao relevo ou outras variáveis ambientais. Em uma escala mais ampla, dada a magnitude das diferenças envolvidas, não é somente o fator altitude que está em jogo mas todo um sistema ecológico que envolve tipo de clima, solo e vegetação bastante diferentes. Em uma escala menor, por exemplo no nível de um município, as diferenças de topografia podem ser pronunciadas o bastante para implicar diferenças nos fatores ambientais determinantes da composição de espécies de flebotomíneos ou da densidade de suas populações. O trabalho de GALATI et al (1996), no Mato Grosso do Sul, conduzido em uma escala local, mostrou que a densidade populacional e a distribuição de $L$ whitmani, assim como a composição da fauna flebotomínea, era diferente em função da vegetação que ocorria em diferentes localizações topográficas. SCORZA e ORTIZ (1960) estudaram a distribuição de outras espécies de flebotomíneos, em outros paises da América do Sul, em um gradiente de altitude em relação ao nível do mar que variava de 550 a cerca de $1100 \mathrm{~m}$. Os resultados encontrados indicavam que a presença de determinadas espécies estava relacionada com a vegetação e a altitude: um grupo vivendo entre 1075 e 860 metros em mata sempre úmida com pequenas variações climáticas; outro grupo vivendo em mata decídua de altitude entre 650 e $500 \mathrm{~m}$ e um grupo mais eclético. Estes autores verificaram que os flebotomineos se reproduziam em ambiente mais estável, como tocas de animais, em que a temperatura variou com regularidade em um gradiente de $0,7^{\circ} \mathrm{C}$ a cada $100 \mathrm{~m}$ de altitude. Também na Venezuela, AÑEZ et al. 1988 realizaram estudo semelhante, abrangendo pisos altitudinais mais extremos e encontraram espécies mais ecléticas e outras mais restritas quanto a sua distribuição em relação à altitude. Em Itapira, as diferenças de classes de altitude são de outra ordem e como no caso citado anteriormente no Mato Grosso do Sul, poderiam ter outras implicações na distribuição da fauna flebotomínea.

A escala de trabalho e os instrumentos utilizados em nosso trabalho mostraram-se adequados para o tratamento desta questão e permitirão que pesquisas entomológicas quantitativas possam ser direcionadas em função da localização topográfica precisa da moradia 
dos casos de LTA, assim como dos fragmentos de mata. Infelizmente, não foi possível ir a campo após levantamento dos fatores ambientais, mas podemos avaliar a possível influência da topografia na distribuição das espécies de modo indireto, utilizando dados de pesquisas entomológicas já realizadas, através da comparação com outros municípios da região. Em Espirito Santo do Pinhal os dados de levantamentos realizados (SUCEN, dados internos não publicados), mostram que a $L$ whitmani estava presente em todos os locais relacionados aos casos de LTA ocorridos no município, sendo que mesmo nos poucos locais em que também L intermedia estava presente, a primeira espécie ocorreu em um número muito superior ao desta. Utilizando um modelo digital de terreno (Cristina Aparício - dados não publicados) desenvolvido para Espírito Santo do Pinhal, verificamos que mais de 60\% deste município situa-se acima de 800 metros de altitude, sendo portanto muito diferente de Itapira onde encontramos a maioria das terras localizadas a uma altitude abaixo de $700 \mathrm{~m}$ de altitude. Novamente pode-se ressaltar a possível influência da altitude e declividade na maior presença de matas e assim L whitmani poderia estar associada à maior quantidade de matas, ou a matas mais preservadas. Esta é uma hipótese a ser testada.

A presença de matas associadas aos cursos de água, ciliares ou mistas, não mostrou ser uma constante nos LPTs. Também não pode ser verificada no presente trabalho sua relação com a presença de determinada espécie de flebotomíneo. Entretanto, a literatura consultada forneceu alguns exemplos da importância da relação das matas com a hidrografia para as espécies de flebotomíneos e roedores possivelmente envolvidos no ciclo da LTA. Em relação aos flebotomíneos WARD et al. (1973) levantaram a hipótese de que para Lutzomyia flaviscutellata seja regulada principalmente pelo grau de saturação do solo, que por sua vez depende da natureza do solo e das condições topográficas. GOMES et al. (1989), realizando pesquisas em matas localizada nas margens do Rio Mogi Guaçu e sujeita a enchentes periódicas, encontraram uma população numerosa de $L$ intermedia, nestas matas, sugerindo o autor que as matas residuais situadas às margens de grandes rios favorecem esta espécie na região. GALATI et al. (1996), em Mato Grosso do Sul, encontraram diferenças na composição 
da fauna flebotominea assim como na abundância de $L$ whitmani entre matas localizadas em encostas de morros e matas de galeria.

A dependência que tem os mamíferos de água necessária para sua sobrevivência pode significar que sua área de vida deva incluir locais que tenham proximidade de fontes de água. Como vimos anteriormente, determinadas espécies de roedores podem estar associadas a matas de galeria, pelo menos em determinadas regiões. LAINSON e SHAW (1968), estudando a leishmaniose em roedores afirmam que as áreas degradadas de matas de várzea pareciam favorecer o aumento da população de roedores, fato já notado por outros autores de América Central, onde tal fato poderia estar favorecendo o aumento da ocorrência da zoonose entre estes roedores. Oryzomys capito e Akodon cursor, são preferencialmente encontrados em matas de galeria em regiões de cerrado no Brasil Central (FONSECA e KIERULFF 1989; GENTILE e CERQUEIRA 1995; ALHO, PEREIRA e PAULA 1986; MARES e ERNST 1995) embora também tenham sido encontrados no cerrado. Em Minas Gerais, Oryzomys capito foi encontrado em áreas de matas úmidas que variavam em grau de degradação desde um nível médio de perturbação até a mata primária (STALLINGS 1989). Já Akodon cursor foi capturado tanto em áreas de campos úmidos com gramíneas e arbustos como em mata secundária (FONSECA e KIERULFF 1989; STALLINGS 1989).

Pode-se supor que populações de espécies de mamíferos que tenham uma maior dependência da água possam localizar-se nas matas de várzea estando assim mais sujeitas ao contato com espécies de flebotomineos que também tenham preferência por ambientes mais úmidos. Estes fatos poderiam ter relação com a capacidade de determinados ambientes serem mais propícios à manutenção do ciclo zoonótico da leishmaniose tegumentar.

Uma análise da influência dos parâmetros ambientais sobre a distribuição das espécies de flebotomineos, principalmente das espécies consideradas como potenciais vetores da LTA, somente seria possível através de pesquisas quantitativas. Os dados aqui apresentados são de natureza qualitativa e foram obtidos principalmente nas áreas domiciliares dos LPTs. Estes possibilitam apenas algumas constatações gerais. Os locais onde L whitmani ocorreu isolada de 
L intermedia ou predominando sobre esta espécie, parecem situar-se ou em áreas mais a leste, próximas às nascentes do rio do Peixe, que apresentam relevo mais acidentado, ou áreas localizadas mais ao sul do municipio. Enquanto isso $L$ intermedia ocorreu isoladamente ou predominando sobre $L$ whitmani em alguns locais ao norte próximo aos rios Mogi Guaçu e do Peixe. $\mathrm{O}$ fato de haver indícios de que ambas as espécies podem dividir o papel de vetor em um mesmo município confirma a necessidade de estudos mais aprofundados, para os quais a metodologia de geoprocessamento e sensoriamento remoto tem participação preponderante. Itapira, em termos de vetores da LTA pode ter uma posição intermediária em relação ao Vale do Rio Mogi Guaçu. Nesta região as áreas mais planas situadas a partir do município de Mogi Guaçu em direção à foz do referido rio predominam locais de transmissão onde $L$ intermedia surge como a principal espécie associada à transmissão (SUCEN, dados internos); de outro lado no município de Espírito Santo do Pinhal L whitmani, como já assinalado, parece ser o principal vetor. Quais variáveis direta ou indiretamente estão influenciando esta distribuição ainda é uma questão em aberto.

Até agora os estudos em áreas endêmicas da LTA no sudeste do Brasil estiveram voltados principalmente para o conhecimento de alguns aspectos da capacidade vetorial dos flebotomineos, a identificação de reservatórios naturais e o esclarecimento do papel de animais domésticos no ciclo de transmissão (sintetizados por TOLEZANO 1994). Os trabalhos que levantaram questões ambientais ligadas ao ciclo de transmissão foram realizados ou em escala local, o que dificultava a comparação com outras áreas (GOMES et al.1989), ou então, as unidades de análise eram muito amplas permitindo apenas a observação de aspectos macrogeográficos de clima, vegetação e topografia possivelmente relacionados com a distribuição das principais espécies vetoras e casos de LTA no Estado de São Paulo (GOMES et al 1995; NEVES 1999).

Existe a necessidade do uso de instrumentos que permitam integrar informações ecológicas (como relevo, hidrografia e vegetação) relacionadas à distribuição da população humana, dos vetores e reservatórios envolvidos na transmissão da LTA. 
No presente trabalho, a aplicação de técnicas de sensoriamento remoto, cartografia e sistema de informação geográfica mostraram-se adequadas para levantar, mensurar e relacionar um maior número de variáveis ambientais, as quais podem formecer novos parâmetros para estudos analíticos que auxiliarão no esclarecimento de aspectos fundamentais dos ciclos de transmissão da LTA.

Parte destes estudos analíticos poderiam ser implementados através do aumento do número de casos examinados ou estudos de prevalência, o que demandaria uma ampliação da área de estudo no primeiro caso, ou a realização de inquérito sorológico na população, no segundo. Estes últimos envolveriam a seguinte questão ética: investigar para tomar medidas efetivas de proteção da população ou para aumentar o conhecimento sobre o assunto? Quando este conhecimento poderia reverter em medidas concretas que protegessem a população? $\mathrm{Na}$ ausência de respostas claras sobre estas questões, mesmo contando com recursos suficientes, seria preferível utilizar outros métodos que não expusesse a população a práticas que não trouxessem beneficios concretos à sua saúde.

O uso deste método em outras áreas mais amplas demanda tempo e recursos, mas é possível. Certamente algumas técnicas adicionais a esta metodologia serão necessárias. Ficou claro que há necessidade do uso de uma ferramenta que permita identificar as edificações rurais existentes. Também, dependendo da necessidade de maior precisão na classificação da vegetação, por exemplo, teríamos de realizar estudos que permitissem avaliar esta precisão. Estes aspectos entretanto não tiram o caráter geral desta metodologia descritiva para o estudo da LTA. 


\section{CONCLUSÕES}

Os resultados deste trabalho demonstram principalmente o grande potencial representado pelo emprego de sensoriamento remoto orbital e SIG para a identificação e análise integrada de fatores ambientais associados a transmissão de LTA em áreas rurais. Resguardados os limites da escala de trabalho, do número de casos examinados, na disponibilidade de dados, do conhecimento prévio de parâmetros importantes sobre as populações de vetores e reservatórios envolvidos no ciclo da LTA e a extensão da área que foi possível observar, podem ser feitas considerações indicativas da importância de alguns fatores para a epidemiologia da doença.

- A presença de matas residuais nas proximidades dos locais de provável transmissão do parasito aos casos humanos foi uma constante no município, indicando que esta pode ser uma condição necessária para transmissão domiciliar em áreas de matriz agrícola com presença de remanescentes de matas.

- A área mínima de mata associada ao local de provável transmissão foi de cerca de 1 ha. Embora na maioria destes locais existisse uma área total de matas acima de 3 ha.

- As relações de distâncias entre os fragmentos de mata e os locais de provável transmissão são tais que permitem a interação entre o ciclo silvestre $\mathrm{e}$ as áreas domiciliares. Estas condições não favorecem a hipótese da existência de um verdadeiro ciclo domiciliar de transmissão na área de estudo.

- Foi constatada nas áreas peridomiciliares e entre estas e as matas residuais, a presença de vegetação arbórea de natureza variada com potencial de abrigar fauna flebotomínea e de reservatórios. É possivel que esta vegetação possa estabelecer conexão ambiental, do ponto de vista dos reservatórios, entre as matas e os locais de transmissão."

- As condições de relevo mais acidentado e altitudes relativas maiores parecem contribuir para a maior presença de matas residuais no municipio. 
- No município de Itapira o papel de vetor da Leishmania pode estar sendo desempenhado pelas espécies $L$ intermedia e $L$ wbitmani em diferentes locais.

- No município estudado, os grandes rios não parecem abrigar em suas margens porcentagem importante das matas associadas aos locais de possível transmissão de LTA, contrastando com o que se descreve sobre as características de parte do Vale do Rio Mogi Guaçu.

- Há necessidade de ampliar a área de estudo para permitir o emprego da metodologia de forma analítica às questões aqui discutidas, além de elucidar a questão de uma possível divisão desta região em duas áreas com algumas características distintas que podem influenciar a distribuição de espécies vetoras: a do Vale do Rio Mogi Guaçu propriamente dito e a área de suas nascentes, situadas na Serra da Mantiqueira.

A metodologia aqui empregada fornece ferramenta alternativa na busca de variáveis ecológicas para o estudo das populações envolvidas nos ciclos de transmissão da LTA, além de ser um passo inicial para o estabelecimento de parâmetros para a construção de modelos preditivos sobre ambientes de risco 


\section{REFERÊNCIAS BIBLIOGRÁFICAS}

Aguiar GM, Vilela ML, Ferreira VA e Santos TG. Ecologia dos flebótomos em um recente foco ativo de leishmaniose tegumentar no Norte do Estado do Paraná (Diptera, Psychodidae, Phlebotominae). Memórias do Instituto Oswaldo Cruz 1989; 84 (IV): 7-8.

Alexander JB. Dispersal of Phlebotominae sand flies (Diptera: Psychodidae) in a Colombian coffee plantation. Journal of Medical Entomology 1987; 24 (5): 552- 558.

Alho CJR, Pereira LA e Paula AC. Patterns of habitat utilization by small mammal populations in cerrado biome of central Brazil. Mammalia 1986; 50 (4): 447- 460.

Añez N, Cazorla D, Nieves E, Chataing B, Castro M e Yarbuh AL. Epidemilogia de la leishmaniasis tegumentaria en Merida, Venezuela. I. Diversidad y dispersión de especies de flebotominas en tres pisos altitudinales y su posible role en la transmission de la enfermedad. Memórias do Instituto Oswaldo Cruz 1988; 83 (4): 455- 463.

Azevedo ACR e Rangel EF A study of sandfly species (Diptera: Psychodidae: Phlebotominae) in a focus of cutaneous leishmaniasis in the Municipality of Baturité, Ceará, Brazil. Memórias do Instituto Oswaldo Cruz 1991; 86 (4): 405-410.

Barreto MP. Observações sobre a biologia , em condições naturais, dos flebótomos do Estado de São Paulo (Diptera, Psychodidae). São Paulo, 1943. [Tese de livre docência, da cadeira de parasitologia, da Faculdade de Medicina da Universidade de São Paulo]

Barreto AC, Cuba CC, Vexenat JA, Rosa AC, Marsden PD e Magalhães AV. Características epidemiológicas da leishmaniose tegumentar americana em uma região endêmica do estado da Bahia. II Leishmaniose canina. Revista da Sociedade Brasileira de Medicina Tropical 1984; 17: 59-65.

Beck LR, Rodriguez, MH, Dister SW, Rodriguez ER, Ulloa A, Meza RA et al. Remote sensing as a landscape epidemiologic tool to identify villages at high risk for malaria transmission. 
American Journal of Tropical Medicine and Hygiene 1994; 51 (3): 271 - 280.

Campbell-Lendrum D, Bakker B, Brandão-Filho S and Davies CR. Radar-derived vegetation maps and domestic animal numbers as predictors of Lutzomyia wbitmani abundance and cutaneous leishmaniasis risk in NE Brazil. In: International Symposium on Phlebotomine Sandflies; August 23-27; Montpellier (FR). Montpellier; 1999, p 54.

Casanova C. A Soil Emergence Trap for Collections of Phlebotomine Sand Flies. Memórias do Instituto Oswaldo Cruz 2001; 96 (2): 273-275.

Chaniotis BN, Correa MA, Tesh RB e Johnson KM. Horizontal and vertical movements of phlebotomine sandflies in a Panamanian rain forest. Journal of Medical Entomology $1974 ; 11$ (3): 369- 375.

Cross ER, Newcomb WW and Tuker CJ. Use of weather data and remote sensing to predict the geographic and seasonal distribution of Pblebotomus papatasi in southwest Asia. American Journal of Tropical Medicine and Hygiene 1996; 54 (5): 530-536.

Curran PJ, Atkinson PM, Foody GM e Milton EJ. Linking remote sensing, land cover and disease. Advances in Parasitology 2000; 47: 37-77.

Dedet JP. Leishmania et leishmanioses du continent américain. Annales de L'Institut Pasteur 1993; 34 (1): 3-25.

Dister SW, Fish D, Bros SM, Frank DH., e Wood, BL. Landscape characterization of peridomestic risk for Lyme disease using satellite imagery. American Journal of Tropical Medicine and Hygiene 1997; 57 (6): 687- 692.

Eastman JR. Idrisi 32 - Guide to GIS and image processing 1999; V. 2, Clarks Labs Clark University, Worcester, MA, USA.

Elnaiem DA, Connor SJ, Thomson MC, Hassan MM, Hassan HK, Aboud MA e Ashford RW. Environmental determinants of the distribution of Phlebotomus orientalis in Sudan. Annals of Tropical Medicine e Parasitology 1998; 92 (8): 877-887.

Falqueto A, Sessa PA, Varejão JBM, Barros GC, Momen H e Grimaldi Jr G. Leishmaniasis due 
to Leishmania braziliensis in Espírito Santo State, Brazil. Further evidence on the role of dogs as a reservoir of infection for humans. Memória do Instituto Oswaldo Cruz 1991; 86 (4): 499-500.

Falqueto AF, Coura JR, Barros GC, Grimaldi $F^{\circ}$ G, Sessa PA, Carias VRD, Jesus AC e Alencar JTA. Participação do cão no ciclo de transmissão da leishmaniose tegumentar no município de Viana, Estado do Espírito Santo, Brasil. Memórias do Instituto Oswaldo Cruz 1986; 81 (2): 155- 163.

Fonseca GAB e Kierulff MC. Biology and natural history of Brazilian Atlantic forest small mammals. Bulletin Florida State Museum 1989; 34 (3): 99- 152.

Forattini OP. Nota sobre criadouros naturais de flebótomos em dependências peridomiciliares no Estado de São Paulo. Arquivos da Faculdade de Higiene de São Paulo 1953; 7: 157168.

Forattini OP. Algumas observações sobre biologia de flebótomos (Diptera, Psychodidae), em região da bacia do rio Paraná (Brasil). Arquivos da Faculdade de Higiene de São Paulo 1954; 8: 15-136.

Forattini OP. Novas observações sobre biologia de flebótomos em condições naturais (Diptera, Psychodidae). Arquivos da Faculdade de Higiene de São Paulo 1960; 25: 209215.

Forattini OP. Entomologia Médica. São Paulo: Edgard Blucher/Editora da Universidade de São Paulo; 1973. v.4.

Forattini OP, Pattoli DBG, Rabello EX e Ferreira OA. Infecções naturais de mamíferos silvestres em área endêmica de leishmaniose tegumentar no Estado de São Paulo, Brasil. Revista de Saúde Pública 1972; 6: 255-261.

Forattini OP, Pattoli DBG, Rabello EX e Ferreira OA. Nota sobre infeção natural de Oryzomys capito laticeps em foco enzoótico de leishmaniose tegumentar no Estado de São Paulo, Brasil. Revista de Saúde Pública 1973; 7: 181-184. 
Forattini OP, Rabello EX, Serra OP, Cotrim MD, Galati EAB, e Barata JMS. Observações sobre a transmissão da leishmaniose tegumentar no Estado de São Paulo, Brasil. Revista de Saúde Pública 1976; 10: 31-43.

Fundação IBGE. Carta do Brasil -1: 50.000, $1^{\text {a }}$ edição, Rio de Janeiro, 1972 (folhas: Amparo, Socorro, Mogi Guaçu e Águas de Lindóia).

Galati EAB, Nunes VLB, Dorval MEC, Oshiro ET, Cristaldo G, Espindola MA, Rocha HC e Garcia WB. Estudo dos flebotomíneos (Diptera, Psychodidae), em área de leishmaniose tegumentar, no Estado de Mato Grosso do Sul, Brasil. Revista Saúde Pública 1996; 30 (2): 115-128.

Gentile R e Cerqueira R. Movement patterns of five species of small mammals in a Brazilian restinga. Journal of Tropical Ecology 1995; 11: 671- 677.

Glass GE, Morgan JM, Johnson DT Noy Pm, Israel E e Schwartz BS. Infectious disease epidemiology and GIS: a case study of Lyme disease. GeoInfo Systems 1992; 2: 65- 69.

Goetz SJ, Prince SD e Small J. Advances in satellite remote sensing of environmental variables for epidemiological applications. Advances in Parasitology 2000; 47: 289-307.

Gomes AC. Perfil epidemiológico da leishmaniose tegumentar no Brasil. Anais Brasileiros de Dermatologia 1992; 67 (2): 55-60.

Gomes A C. Sand Fly Vectorial Ecology in the State of São Paulo. Memórias do Instituto Oswaldo Cruz, 1994; 89 (3): 457-460.

Gomes AC, Barata JMS, Rocha e Silva EO e Galati EAB. Aspectos ecológicos da leishmaniose tegumentar americana: 6- Fauna flebotomínea antropofilica de matas residuais situadas na região centro-nordeste do Estado de São Paulo. Revista do Instituto de Medicina Tropical 1989; 31 (1): 32- 39.

Gomes AC, Coutinho SG, Paim, GV, Oliveira SMO, Galati EAB, Nunes MP, Capinzaiki X, Uamamoto YI e Rotter P. Aspectos ecológicos da leishmaniose tegumentar americana. 8. Avaliação da atividade enzoótica de Leishmania (Viannia) brąiliensis, em ambiente florestal e 
peridomiciliar, região do Vale do Ribeira, Estado de São Paulo, Brasil. Revista do Instituto de Medicina Tropical, São Paulo 1990; 32 (2): 105- 115

Gomes AC e Galati EAB. Aspectos ecológicos da leishmaniose tegumentar americana: 5Estratificação da atividade espacial e estacional de Phlebotominae (Diptera: Psychodidae) em áreas de cultura agrícola da região do Vale de Ribeira, Estado de São Paulo, Brasil. Memórias do Instituto Oswaldo Cruz, 1987; 82: 467-472.

Gomes AC, Galati EAB, Casanova C, Domingos MF, Marques GRAM e Neves VLFC. Analysis of the geographical distribution of leishmaniasis vectors in the state of São Paulo, Brazil. Boletin de la Dirección de Malariología y Saneamiento Ambiental 1995; 35 (Supl. 1): 143- 146.

Gomes AC, Rabello EX, Santos JLF e Galatti EAB. Aspectos ecológicos da leishmaniose tegumentar americana: 1- Estudo experimental da freqüência de flebotomíneos a ecótopos artificiais com referência especial a Psychodopygus intermedius . Revista de Saúde Pública 1980; 14: 540- 56.

Gomes AC, Rabello EX, Santos JLF e Galatti EAB. Aspectos ecológicos da leishmaniose tegumentar americana. 2. Ecótopo artificial como abrigo de Psychodopygus intermedius e observações sobre alimentação e reprodução sob influência de fatores físicos naturais. Revista de Saúde Pública 1982; 16: 149-159.

Gomes AC, Rabello EX, Santos JLF e Galatti EAB. Aspectos ecológicos da leishmaniose tegumentar americana:3- Observações naturais sobre o ritmo diário da atividade de Psychodopygus intermedius em ambiente florestal e extraflorestal. Revista de Saúde Pública 1983; 17: 23- 30 .

Gomes AC, Santos JLF, e Galati EAB. Ecological aspects of American cutaneous leishmaniasis. 4. Observations on the endophilic behavior of the sandfly and the nectorial role of Psychodopygus intermedius in the Ribeira Valley region of the S. Paulo State, Brazil. Revista de Saúde Pública 1986; 20 (4): 280- 7. 
Gomes AC, Yamamoto YI, Capinzaiki AN, Amaral NMM e Guimarães AJG. Aspectos ecológicos da leishmaniose tegumentar americana. 9. Prevalência/incidência da infecção humana nos município de Pedro de Toledo e Miracatu, São Paulo, Brasil. Revista do Instituto de Medicina Tropical de São Paulo 1992; 34 (2): 149-158.

Grimaldi GJR, Tesh RB e Mcmahon-Pratt D. A review of the geographic distribution and epidemiology of leishmaniasis in the New World. American Journal of Tropical Medicine and Hygiene 1989; 4 (6): 687-725.

Hendrickx G, Napala A, Rogers D, Bastiansen P e Slingenbergh J. Can remotely sensed meteorological data significantly contribute to reduce costs of tsetse surveys?. Memórias do Instituto Oswaldo Cruz 1999; 94 (2): 273 - 276.

Hugh-Jones M. Introductory remarks on the application of remote sensing and geographic information systems to epidemiology and disease control. Preventive Veterinary Medicine 1991; 11: 159- 161.

INPE. Spring 3.3 - Tutorial. Instituto Nacional de Pesquisas Espaciais, São José dos Campos, 1998. Disponível em <URL:http://www.dpi.inpe.br/spring [fev.2000]

Katz, G. Epidemiologia da Leishmaniose Tegumentar Americana no Estado de São Paulo, período de 1986 a 1995. São Paulo, 1997 (Tese de mestrado apresentada à Faculdade de Medicina da Universidade de São Paulo).

Killick-Kendrick $\mathrm{R}$ Phlebotominae vectors of the leishmaniasis: a review. Medical and Veterinary Entomology, 1990; 4: 1- 24.

Killick-Kendrick R e Ward RD. Ecology of Lesibmania. Parasitilogy 1981; 82: 143- 152.

Kitron U. Landscape ecology and epidemiology of vector-borne diseases: tools for spatial analysis. Jornal of Medical Entomology, 1998; 35 (4): 435- 445.

Kloos H, Gazzinelli A e Zuyle PV. Micro geographical patterns of schistosomiasis and water contact behavior; examples from Africa and Brazil. Memórias do Instituto Oswaldo Cruz 1998; 93 (Suppl. I): 37- 50. 
Kronka et al. Inventário Florestal do Estado de São Paulo. São Paulo, Secretaria Do Meio Ambiente, Instituto Florestal, 1993.

Lacerda MM. The Brazilian leishmaniasis control program. Memórias do Instituto Oswaldo Cruz 1994; 89 (3):489-95.

Lainson R e Shaw JJ. Evolution, classification and geographical distribution. In: Peters W. e Killick-Kendrick R. The leishmaniasis in biology and medicine, Academic Press, London, 1987.

Lainson $\mathrm{R}$ e Shaw JJ. Leishmaniasis in Brazil: I. Observations on enzootic rodent leishmaniasis - incrimination of Lutzomyia flaviscutellata (Mangabeira) as the vector in the lower Amazonian basin. Transactions of the Royal Society of Tropical Medicine and Hygiene 1968; 62 (3): 385- 395.

Lainson R, Shaw JJ, Silveira FT, Souza AAA, Braga L R, e Ishikawa E M Y. The dermal leishmaniasis of Brazil, with special reference to the eco-epidemiology of the disease in Amazonia. Memórias do Instituto Oswaldo Cruz 1994; 89 (3): 435-43.

Leopoldo e Silva R, Corrêa FMA, Comes AC e Yoshida ELA. Investigação epidemiológica sobre leishmaniose tegumentar americana no município de Conchas- Estado de São Paulo, Brasil. Revista de Ciências Biomédicas 1984; 5: 49-55.

Lillesand, TM Kiefer, e Ralph W. Remote sensing and image interpretation. 3rd ed., John Wiley e Sons, New York , 1994.

Linthicum KJ, Bailey CL, Davies FG e Tucker CJ Detection of Rift Valley fever viral activity in Kenya by satellite remote sensing imagery. Science 1987; 235: 1656 - 1659.

Marcondes CB, Lozovei AL e Vilela JH. Distribuição geográfica de flebotomíneos do complexo Lutzomyia intermedia (Lutz \& Neiva, 1912) (Diptera, Psychodidae). Revista da Sociedade Brasileira de Medicina Tropical 1998; 31 (1): 51 - 58.

Mares MA e Ernest KA. Population and community ecology of small mammals in a gallery forest of Central Brazil. Journal of Mammalogy 1995; 76 (3): 750- 768. 
Mascarini LM, Casanova C, Cipoli EAR e Mayo RC. Caracterização do perfil epidemiológico da leishmaniose tegumentar americana (LTA) na bacia do rio Mogi Guaçu, Estado de São Paulo. In: Congresso Brasileiro de Parasitologia- XIV, Goiânia, 1995, Revista de Patologia Tropical 1994; 23 (2): 336.

Mbarki L, Ben Salah A, Chlif S, Chahed MK, Balma A, Chemam N, Garraoui A and BenIsmail R. Monitoring zoonotic cutaneous leishmaniasis with GIS. Copyright International Development Research Center. 1996. Available from <URL: http//www.idrc.ca/books/ focus $/ 766 /$ mbarki.html.

Mayo RC, Casanova C, Mascarini LM, Pignati MG, Rangel O, Galati, EAB, Wanderley DMV e Corrêa FMA. Flebotomíneos (Díptera, Psychodidae) de área de transmissão de leishmaniose tegumentar americana, no município de Itupeva, região sudeste do Estado de São Paulo, Brasil. Revista da Sociedade Brasileira de Medicina Tropical 1998; 31(4): 339-345.

Miranda C, Marques CCA e Massa JL. Sensoriamento remoto orbital como recurso para análise da ocorrência da leishmaniose tegumentar americana em localidade urbana da região Sudeste do Brasil Revista de Saúde Pública 1998; 32(5): 455-463.

Miranda C, Massa JL e Marques, CCA. Análise da ocorrência de leishmaniose tegumentar americana através de imagem obtida por sensoriamento remoto orbital em localidade urbana da região Sudeste do Brasil. Revista de Saúde Pública 1996; 30 (5): 433-437.

Morrison AC, Ferro C, Morales A, Tesh RB e Wilson ML. Dispersal of the sand fly Lutzomyia longipalpis (Diptera: Psychodidae) at an endemic focus of visceral leishmaniasis in Colombia. Journal of Medical Entomology 1993; 30 (2): 427- 435.

Neves VLFC. Características da transmissão da leishmaniose tegumentar americana no Estado de São Paulo, Brasil. São Paulo; 1999. [Dissertação de mestrado - Faculdade de Saúde Pública - USP].

Nicholson MC and Mather TN. Methods for evaluating Lyme disease risks using geographic 
information systems and geospacial analysis. Journal of Medical Entomology 1996; 33: 711- 720.

Oliveira- Neto MP, Pirmez C, Rangel E, Shubach A e Grimaldi Jr. G. An outbreak of American cutaneous leishmaniais (Leishmania braziliensis braziliensis) in a periurban area of Rio de Janeiro city, Brazil: clinical and epidemiological studies. Memórias do Instituto Oswaldo Cruz 1988; 83 (4): 427- 435.

Pessoa SB e Barreto, MP. Leishmaniose Tegumentar Americana. Rio de Janeiro, Ministério da Educação e Saúde, 1948.

Pignatti MG, Mayo RC, Alves MJCP, Souza SSAL, Macedo F, e Pereira RM. Leishmaniose tegumentar americana na Região Nordeste do Estado de São Paulo, Brasil. Revista da Sociedade Brasileira de Medicina Tropical 1995; 28 (3): 243-247.

Pirmez C, Coutinho SG, Marzochi MCA, Nunes MP e Grimaldi Jr G. Canine American cutaneous leishmaniasis: a clinical and immunological study in dogs naturally infected with Leisbmania braziliensis braziliensis in a endemic area of Rio de Janeiro, Brazil. The American Society of Tropical Medicine and Hygiene 1988; 38 (1): 52-58.

Rangel EF, Azevedo ACR, Andrade CA, Souza NA e Wermelinger ED. Studies on sandfly fauna (Diptera: Psychodidae) in a foci of cutaneous leishmaniasis in Mesquita Rio de Janeiro State Brazil. Memórias do Instituto Oswaldo Cruz 1990; 85 (1): 39-45.

Rangel EF, Souza NL, Wermelinger ED, Azevedo ACR, Barbosa AF e Andrade CA. Flebótomos de Vargem Grande, foco de leishmaniose tegumentar no Estado do Rio de Janeiro. Memórias do Instituto Oswaldo Cruz 1986; 81 (3): 347- 349.

Reithinger R e Davies CR. Is the domestic dog (Canis familiaris) a reservoir host of American cutaneous leishmaniasis? A critical review of the current evidence. The American Society of Tropical Medicine and Hygiene 1999; 61 (4): 530-541.

Rodrigues VLCC. Prevalência da leishmaniose tegumentar americana, a partir do teste de intradermo-reação especifica, em coes no município de Ilhabela, Estado de São 
Paulo, Brasil. São Paulo, 1999 [Dissertação de mestrado, Escola Paulista de Medicina, Universidade Federal de São Paulo]

Rocha e Silva EO, Capinzaiki AN, Kuratom ICA e Guedes ACM. A leishmaniose tegumentar americana no litoral sul do Estado de São Paulo. Revista brasileira de Malariologia e Doenças Tropicais 1980; 32: 9-25.

Shaw JJ e Lainson R. Leishmaniasis in Brazil: VI. Observations on the seasonal variations of Lutzomyia flaviscutellata in different types of forest and its relationship to enzootic rodent leishmaniasis (Leishmania mexicana amazonensis). Transactions of the Royal Society of Tropical Medicine and Hygiene 1972; 66 (5): 709-723.

Scorza JV e Ortiz I. On microclimatic conditions of the habitats of certain sandyfly species (Diptera, Psychodidae) from Venezuela. Tropenmedizinund Parasitologie 1960; 433440.

Stallings JR. Brazilian small mammal inventories. Bulletin Florida State Museum 1989; 34 (4): $159-193$.

Taniguchi H.H, Tolezano JE, Correa FMA, Moraes RHP, Veiga RMO, e Marassá AM. Epidemiologia da leishmaniose americana no Estado de São Paulo, Brasil. I- Composição da Fauna flebotomínica no município de São Roque, região de Sorocaba. Revista do Instituto Adolfo Lutz 1991; 51 (1/2): 23-30.

Tartaglia JC e Oliveira OL. Agricultura paulista e sua dinâmica regional. (In: SEADE, UNICAMP. A Interiorização do desenvolvimento econômico do Estado de São Paulo (1920 - 1980). Coleção Economia Paulista, v.1 n.2, SEADE, São Paulo, 1988.

Teodoro U La Salvia Filho V, Lima EM, Misuta NM, Verginassi TG e Ferreira MEMC. Leishmaniose tegumentar americana: flebotomíneos de área de transmissão no Norte do Paraná, Brasil. Revista de Saúde Pública 1991; 25 (2): 129-133.

Teodoro U e Kühl J B. Interação flebotomíneos, animais domésticos e dominância de Lutzomyia (Nyssomyia) intermedia (Lutz e Neiva, 1912) em área com alto grau de antropia, no 
Sul do Brasil. Revista de Saúde Pública, 311997 (5): 512- 506.

Tolezano JE Ecoepidemiological Aspects of American Cutaneous Leishmaniasis in the State of São Paulo Brazil. Memórias do Instituto Oswaldo Cruz, 1994; 89 (3): 427-434.

Tolezano JE., Macoris S.A.G. e Diniz J.M.P. Modificação na epidemiologia da leishmaniose tegumentar no Vale do Ribeira, Estado de São Paulo, Brasil. Revista do Instituto Adolfo Lutz 1980: 40 (1): 49-54.

Tolezano JE, Taniguchi HH, Araújo MFL, Bisugo MC, Cunha EA, Elias CR e Larosa R. Epidemiologia da leishmaniose tegumentar americana no Estado de São Paulo, Brasil. II. Utilização de antígeno particulado de Leishmania (Viannia) braz̧iliensis em inquérito canino em regiões endêmicas. Revista do Instituto Adolfo Lutz 1998; 57 (2): 65-71.

Vexenat JA, Barreto AC, Cuba CC e Marsden PD. Características epidemiológicas da leishmaniose tegumentar americana em uma região endêmica do Estado da Bahia. III. Fauna flebotomínica. Memórias do Instituto Oswaldo Cruz 1986; 81 (3): 293-301.

Vieira VP, Ferreira AL e Falqueto A. Pesquisa de criadouros de Flebotomíneos no ambiente peridomiciliar, em área endêmica de leishmaniose tegumentar (LT) no Estado do Espírito Santo. Revista da Sociedade Brasileira de Medicina Tropical 1999, 32 (Supl. I): 31-32, 1999 [Apresentado no XXXV Congresso da Sociedade Brasileira de Medicina Tropical; 28 fev. a 04 mar; Guarapari, ES]

Ward RD, Shaw JJ, Lainson R e Fraiha H Leishmaniasis in Brazil: VIII. Observations on the phlebotomine fauna of an area highly endemic for cutaneous leishmaniasis, in the Serra dos Carajas, Pará State. Transactions of the Royal Society of Tropical Medicine and Hygiene 1973; 67 (2): 174-183.

Wood BL, Washino RK, Beck LR, Hibbard K, Pitcairn C, Salute JS, Sebesta P e Legters L. Distinguishing high and low anopheline producing rice fields using remote sensing and GIS technologies. Preventive and Veterinary Medicine 1992; 11: 277- 288. 
Zuidema PA., Sayer JA e Dijkman NF Forest fragmentation and biodiversity: the case for intermediate-sized conservation areas. Environmental conservation 1996; 23 (4): 290-97. 


\section{ANEXO 1}

Relação de todos os casos, por data de primeiros sintomas, sexo, idade, tempo de permanência no LPT, condição de uso, localização da residência e ocupação, notificados no município de Itapira, SP, entre 1992 e 1997.

\begin{tabular}{|c|c|c|c|c|c|c|}
\hline Data.sint & Sexo & idade & $\begin{array}{c}\text { tempo } \\
\text { permanência }\end{array}$ & $\begin{array}{l}\text { condição } \\
\text { de uso }\end{array}$ & LPT & Atividade \\
\hline jan-94 & $F$ & 30 & 4 & frequentador & 1 & e. doméstica \\
\hline set-95 & M & 33 & $<1$ & morador & 2 & lavrador \\
\hline nov-96 & M & 16 & 4 & morador & 3 & estudante \\
\hline dez-91 & $M$ & 51 & 10 & morador & 4 & administrador da fazenda \\
\hline jul-93 & $M$ & 40 & 8 & morador & 5 & lavrador \\
\hline nov-94 & M & 29 & 16 & morador & 5 & lavrador \\
\hline mai-94 & $F$ & 42 & 4 & morador & 6 & e. doméstica \\
\hline mar-94 & M & 44 & 4 & morador & 6 & pedreiro \\
\hline jul-94 & M & 41 & 37 & morador & 7 & lavrador \\
\hline abr-94 & $F$ & 13 & 13 & morador & 7 & e. doméstica \\
\hline jun-92 & M & 67 & $>3$ & frequentador & 8 & carpinteiro \\
\hline$a b r-96$ & $F$ & 53 & 26 & morador & 9 & faxineira \\
\hline out-92 & M & 31 & $<1$ & morador & 10 & retireiro \\
\hline jul-98 & $F$ & 21 & $<1$ & morador & 11 & e. doméstica \\
\hline jan-95 & M & 40 & $<1$ & morador & 12 & lavrador \\
\hline out-94 & $F$ & 62 & 9 & frequentador & 13 & do $\mathrm{lar}$ \\
\hline jun-94 & $F$ & 20 & 20 & morador & 14 & e. doméstica \\
\hline nov-92 & M & 57 & 8 & morador & 15 & pedreiro \\
\hline mai-94 & M & 62 & 27 & morador & 16 & lavrador \\
\hline jun-93 & $M$ & 64 & 2 & morador & 17 & aposentado \\
\hline jan-95 & M & 58 & $<1$ & morador & 17 & almoxarife \\
\hline fev-94 & $F$ & 18 & $<1$ & morador & 18 & e. doméstica \\
\hline jun-92 & M & 25 & 5 & morador & 19 & lavrador \\
\hline out-93 & M & 77 & 16 & morador & 20 & jardineiro \\
\hline dez-93 & M & 37 & 17 & morador & 20 & desocupado \\
\hline mai-93 & M & 43 & 6 & morador & 20 & guarda da fazenda \\
\hline fev-92 & $\mathbf{M}$ & 41 & 6 & morador & $x$ & lavrador \\
\hline mar-97 & $F$ & 35 & & morador & * & comerciante \\
\hline nov-92 & M & 60 & & morador & * & comerciante \\
\hline jan-96 & $F$ & 18 & & morador & $*$ & operánia indstr. \\
\hline jul-92 & M & 46 & & morador & $x$ & comerciante \\
\hline mar-93 & M & 26 & & morador & $x$ & agricultor \\
\hline nov-96 & $F$ & 41 & & morador & $x$ & e. doméstica \\
\hline set-92 & $\mathrm{F}$ & 26 & & morador & $x$ & estudante \\
\hline nov-94 & $\mathbf{F}$ & 31 & & morador & $x$ & do lar \\
\hline mai-94 & $M$ & 24 & & morador & $x$ & agricultor \\
\hline jul-94 & M & 34 & & morador & $x$ & lavrador \\
\hline
\end{tabular}

$\mathrm{x}=$ caso não localizado * $=$ caso não autóctone 


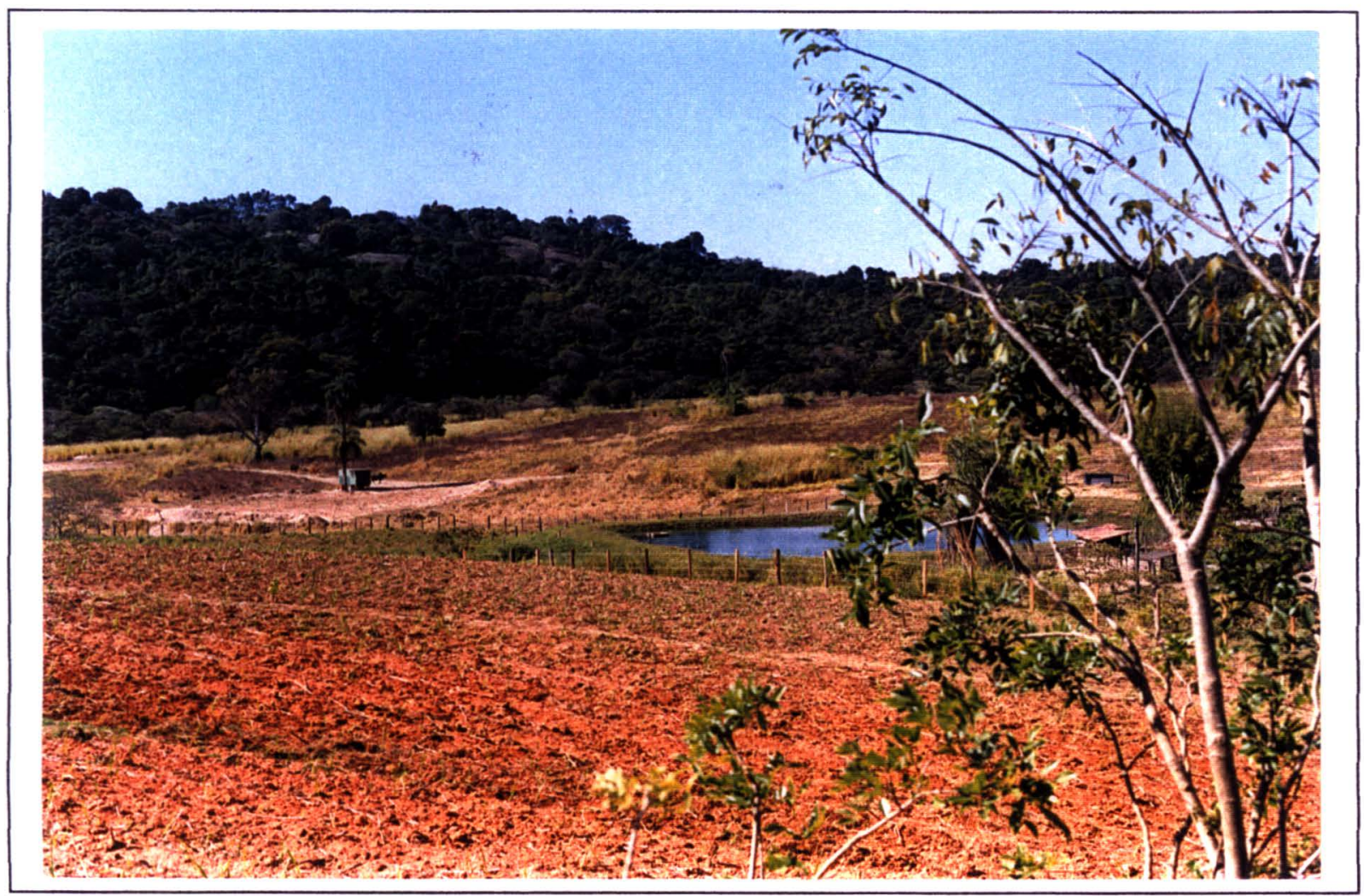

Figura A: Aspecto geral de mata no LPT 2, Itapira, SP. Fonte: Costa junho/2000

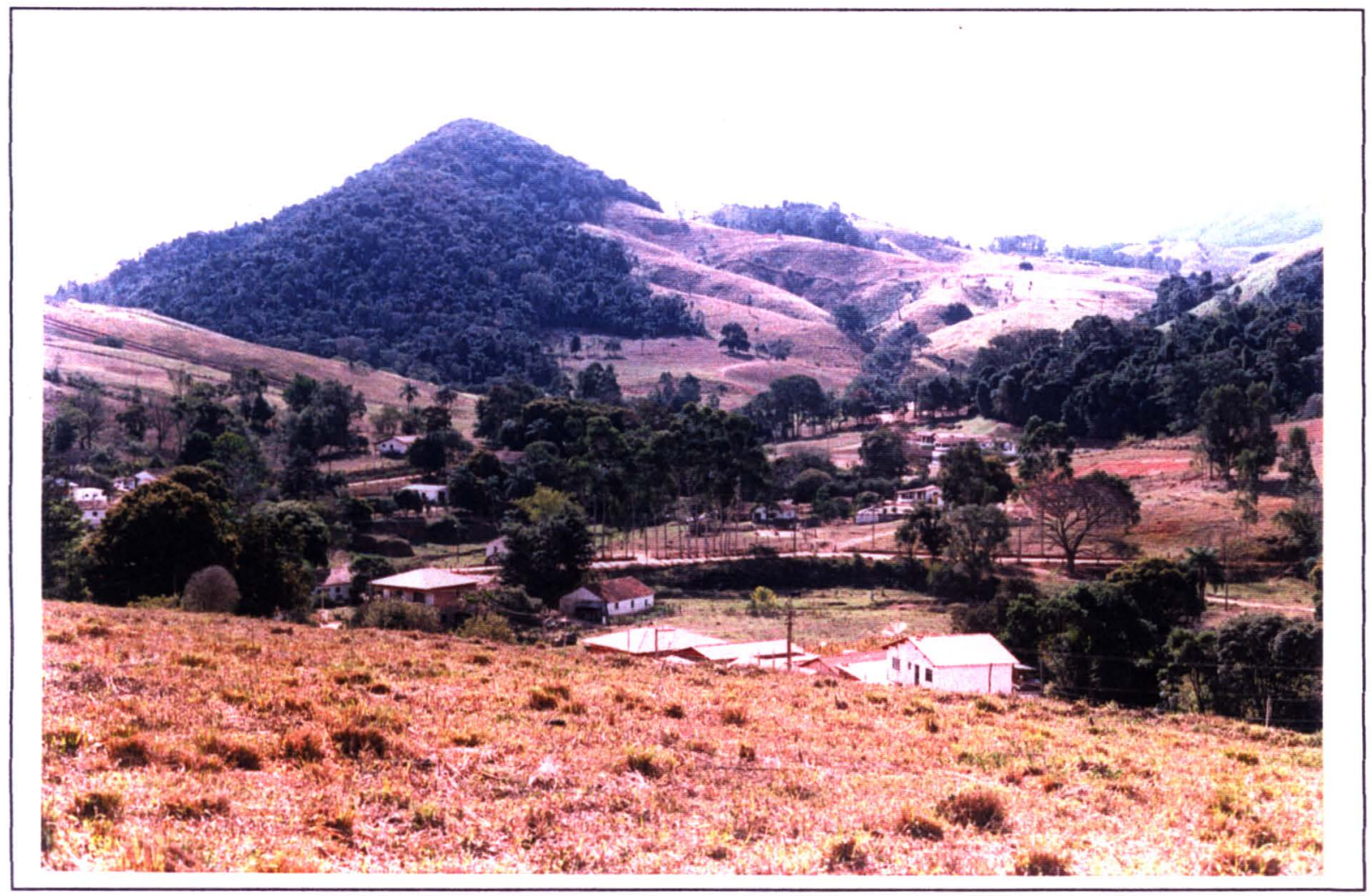

Figura B: Aspecto geral de mata no LPT 16, Itapira, SP. Fonte: Costa agosto/2000 


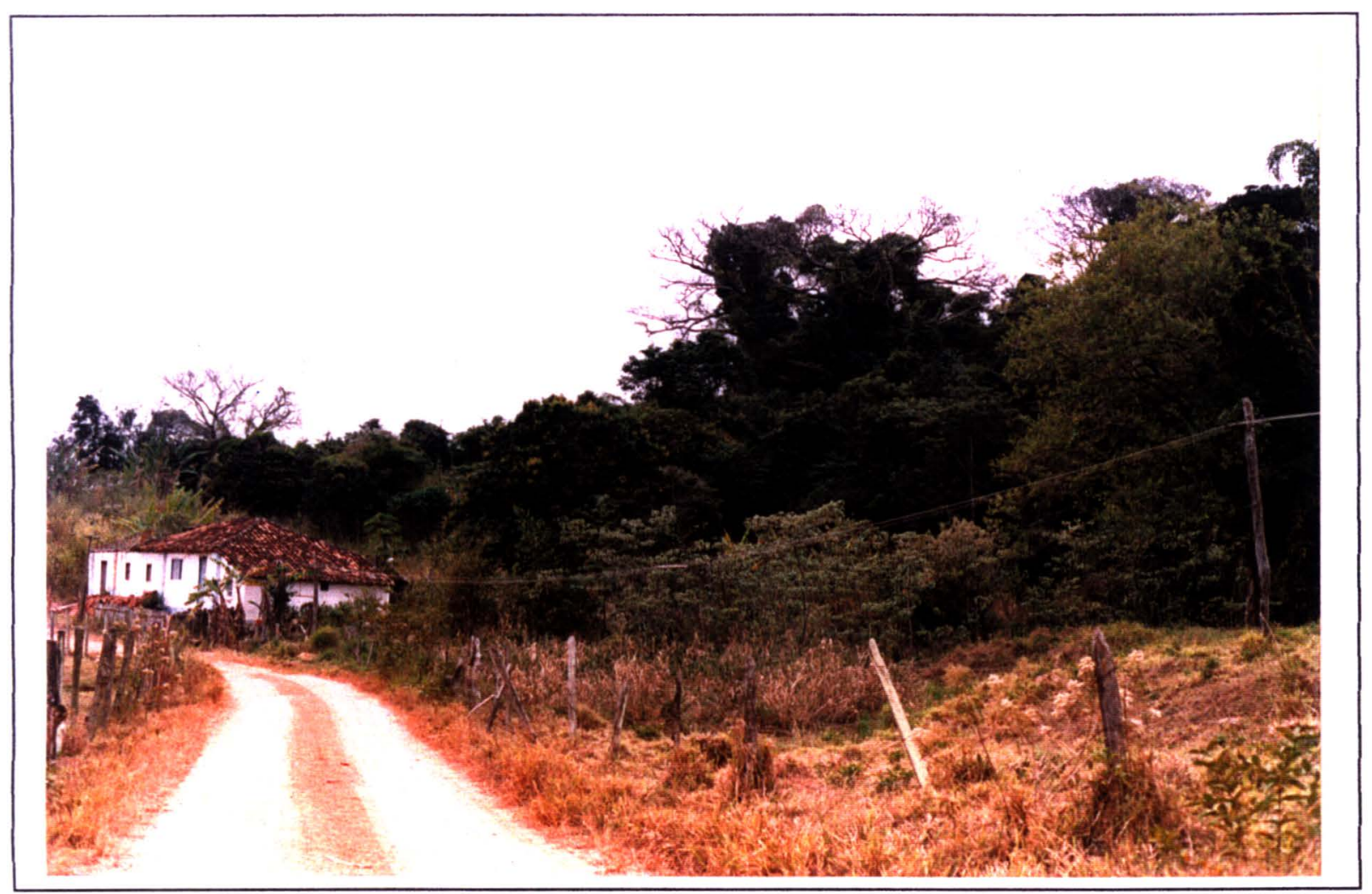

Figura C: Aspecto geral de mata no LPT 11, Itapira, SP. Fonte: Costa junho/2000

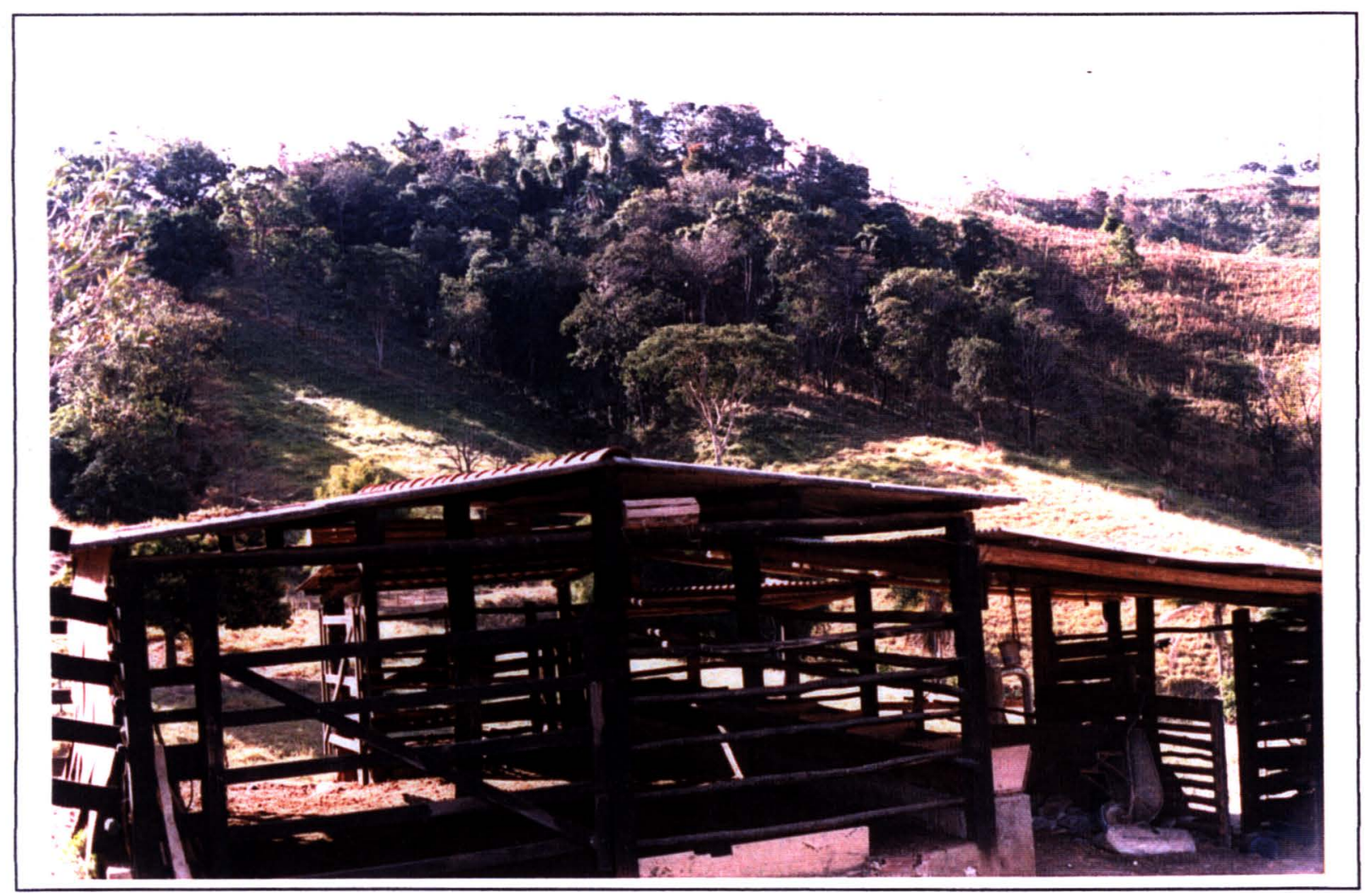

Figura D: Aspecto geral de mata no LPT 12, Itapira, SP. Fonte: Costa agosto/2000 